Aus dem anatomischen Institut in Götringen.

\title{
HISTORISCHE DARSTELLUNG ZUR DEUTUNG DES WESENS DER SILBERMETHODE AN NICHT FIXIERTEN OBJEKTEN UND EXPERIMENTELLE STUDIEN BEZÜGL. DER BEHANDLUNG NICHT FIXIERTER EPITHELIEN UND MARKHALTIGER NERVENFASERN MIT ARGENTUM NITRICUM.
}

\author{
VON \\ DR. MED. FRANZ STADTMÜLLER \\ ASSISTRET AM ANATOMISOHLN INGTITUT IN GÖTTINGEN. \\ HABILITATIONSSCHRIF'I.
}

Mit 1 Tafel (3). 



\section{Einleitung.}

Eine häufig geübte Methode zur Darstellung der Zellgrenzen bei Epithelien ist die Versilberung mit Argentum nitricum. Im Sommer 1918 bediente ich mich öfter dieser Technik und hatte hierbei das Bedürfnis, mich über verschiedene Fragen zu orientieren. Vor allem suchte ich nach einer bestimmten Angabe in der Literatur, die sich darüber ausspräche, was durch die Versilberung dargestellt wird beziehungsweise wo der entstehende Niederschlag zustande kommt. Ich fand nun bereits bei Einsicht nur weniger einschlägiger Arbeiten und der gebräuchlichsten histologischen und technischen Lehr- und Handbücher vielfache Unklarheiten. Die eingehendere Durchsicht der Literatur liess erkennen, dass diese und verwandte Fragen hereits vielfach der Gegenstand von Untersuchungen zahlreicher Forscher gewesen sind. Trotzdem blieb das Wesen der Versilberung nicht fixierter Gewehe in vieler Beziehung unerkannt, scheinbar vor allem weil die Mittel zur Prüfung der Vorgänge bei diesem Verfahren nur in begrenztem Masse Schlüsse gestatteten. Der Gegensatz der Meinungen wird bei der Literaturbesprechung auffallen.

In naher Beziehung zur Frage nach dem Wesen der Versilberung steht, wie besonders ein Aufsatz Merkels über das Epithel aus jüngerer Zeit (1908, Lit. 76) zeigt, die Frage nach der Art der Intercellularstruktur; dieser Frage ist ja grosse Be- 
deutung beizumessen. Jeh habe daher auch standig versucht, die bei den. in dieser Arheit geschilderten experimentèllen Studien gewonnenen Eindrücke heranzuziehen, um eine Vorstellung bezüglich der intercellulären Verbindungen zu gewinnen. Mit anderen Worten: ich suchte zu einem Urteil zu kommen, ob das Wesen dieser Silbermethoden gestatlet, sie als beweiskräftig für die Richtigkeit gewisser Anschauungen bezüglich der Intercellularstruktur anzusehen, wie es von vielen Forschern, besonders von den Anhängern der „Kittsubstanz"Hypothese, lisher trotz aller geltend gemachten Zweifel ge: schehen ist.

Ein Bedürfnis ähnlicher Art ist die Klärung der Frage, ob die Silberlinien mit den „Kittleisten" oder "Schlussleisten" identisch sind, so dass auch hierüber gesprochen werden soll.

Wenn ich auch zunächst Bedenken trug an alle diese Fragen, die heute noch nicht in allen Punkten als befriedigend beantwortet gelten können, aber bereils Gegenstand der Bearbeitung vieler sehr erfahrener Forscher waren, heranzugehen, so entschloss ich mich doch auf Anregung von Herm Geh. Med.-Rat Prof. Dr. Fr. Merkel ihre weitere Aufklärung nach Prüfung der Befunde ällterer Autoren durch eigene eingehende Untersuchungen anzustrehen. Ich beschränkte mich zunächst auf das Epithelgewebe und zog dann auch die markhaltigen Nervenfasern in den Kreis meiner Prüfungen. Von der Untersuchung der Verhältnisse bei den anderen Geweben habe ich zunächst, durch die Umstände der Zeit gezwungen, absehen müssen.

Meinem hochverehrten Lehrer, Herrn Geh. Med.-Rat Prof. Dr. Fr. Merkel, Direktor des hiesigen anatomischen Institutes, gestatte ich mir hier meinen ergebensten Dank auszusprechen für seine ersten und vielfachen weiteren Anregungen und sein stets bewiesenes Interesse an meiner Arbeit. Auch darf ich wohl hier Herrn Prof. Dr. M. Voit, Abteilungs- 
Historische Darstollang zur Deutung des Wesens der Silbermethode etc. 81

Vorsteher und I. Prosektor am hiesigen anatomischen Institut, für seine zahlreichen, guten Ratschläge und viele Gefälligkeiten aufrichtig danken.

\section{Ordnung des Stoffes.}

1. Literatur-Besprechung und geschichtliche Bemerkungen zur Deutung des Wesens der Versilberung am nicht fixierten Objekt.

IJ. Bemerkungen allgemeiner, Art zum Teil auf Grund eigener Untersuchungen, Aufstellung verschiedener der Klärung bedürftiger Punkte betreffend das Epithelgewebe.

III. Eigene Untersuchungen und Uberlegungen bezüglich dieser Punkte betreffend das Epithelgewebe.

IV. Entsprechende Untersuchungen und Uberlegungen an markhaltigen Nervenfasern bezüglich der „Ranvierschen Kreuze“.

V. Kurze Zusammenfassung der Ergebnisse.

\section{Literatur-Besprechung und geschichtliche Bemerkungen zur Deutung des Wesens der Versilberung am nicht fixierten Objekt.}

Bei der Literatur-Besprechung mögen nur diejenigen Äusserungen Erwahnung finden, welche die Deutung des Wesens der Versilberung am nicht fixierten Objekt betreffen oder welche in irgend einer Hinsicht $\mathbf{h} i$ storisches Interesse baben. Diejenigen Arbeiten, welche hauptsächlich nur die Verwendang dieser Methode zu irgendwelchen Zwecken und deren Resultat angeben oder nur technische Modifikationen erwahnen, obne sich in erwahnenswerter Weise uber die Wirkungsart der Silbersalzlösungen auszusprechen - und deren gibt es eine sehr grosse Zabl - sind nicht berícksichtigt. Infolge der Zerstreutheit der Äussernngen in den verschiedenartigsten Arbeiten ist es wohl möglich, dass irgendwelche Angaben unbeachtet geblieben sind, Wesentliches glaube ich jedoch nicht übersehen zu haben. Um zu 
einer Urteilsfahigkeit zu gelangen, war die Durchsicht aller auffindbaren Ábhandlungen nötig, welche sich uberhaupt mit der in Frage kommenden Methode befassen, einerlei bei welcher Gewebsart, obwohl meine eigenen Studien sich auf die Verhältaisse bei dem Epithelgewebe und den markhaltigen Nervenfasern beschränken; der damit verbundene Zeitaufwand bestimmt mich zur Veröffentlichung der Literatur-Besprechung in dieser moglicherweise weit erscheinenden Fassung in der Annahme, dass die Zusammenstellung in dieser Form vielleicht spateren Bearbeitern ahnlicher Themata willkommen sein wird. Die Besprechung erfolgt im wesentlichen in chronologischer Folge. Wo nicht in dem der Arbeit am Ende beigegebenen "Literaturverzeichnig" ausdrücklıch anderes vermerkt ist, ist in die angezogenen Originalarbeiten Einsicht genommen. In diesem "Literaturverzeichnis" sind auch diejenigen Quellen besonders kenntlich gemacht, welche eine weitere Orientierung bezüglich der Technik, der Leistangsfahigkeit und der Entwickelung des Verfahrens ermögliehen. Soweit es mir angängig orsehien, habe ich mich bei der Besprechung der einzelnen Arbeiten zur Kurze gezwungen, ich muss duher zur eingebenderen Unterrichtung die Einsicht der Originalabhandlungen selbst empfehlen. Dies gilt besonders fur die Arbeiten, welche die Versilberung des Bindegewebes and Muskelgewebes betreffen, sowie für alle Angahen bezüglich der 'Technik.

Die Versilberung nicht fixierter Objekte wird zu dem Zweige der Methodik der Gewebs- und Gewebselements-Differenzierung, zur sogenannten "Imprägnation mit Metallsalzen“" gerechnet, welcher bereits vor dem anderen Zweige, der "Tinktion“, den Beginn seiner Entwickelung datiert. Während nun die Tinktionsverfahren mit gelösten Farbstoffen vor allem in dem fünften und siebenten Dezennium des vorigen Jahrhunderts ihre zahlreichen Fortschritte zu verzeichnen hatten, so wurde alles Wesentliche der Imprägnalionsmethoden und somit auch der hier zu berücksichtigen Versilberungstechnik in den sechziger Jahren gefunden und publiziert. Ihre aushauenden Modifikationen stammen aus den folgenden Jahrzehnten. Ebenso erstrecken sich die Äusserungen bezüglich der Beurteilung ihres Wesens, die Konlroversen über einige sie helreffenden Fragen bis in unser Jahrhundert. Ihre Anfänge aber fallen schon mit der Einführung des neuen Prinzips der „Metallimprägnation“ in die histologische Technik zusammen und sind somit bereits für einen Zeitpunkt vor dreiviertel Jahrhundert (1844) zu verzeichnen. 
Es war C. Krause (Lit. 66) im Jahre 1844, der als erster bei der Durchforschung der Epidermis eine Silbermethode und damit zuerst eine „Metallimprägnation" angewandt hat (auch nach Angabe seines Sohnes W. Kra use in seinem Handbuch der menschlichen Anatomie, Lit. 68, - „die Zellgrenzen schwarz zu färben" - ${ }^{1}$ ). Er legt Stückchen dicker Epidermis in Silbernitratlösung und setzt sie dann dem Lichte aus. Nach Abtragen der sich dabei braunschwarz färbenden freien Flächen fertigt er von den unverändert hell erscheinenden tieferen Epidermisschichten Schnitte. Diese schwärzen sich im Licht, sie zeigen bei mikroskopischer Untersuchung gànz unverändertes Epithelgewebe, nur sieht man ,an der Aussenseite der grösseren Zellen, besonders da, wo sie zusammenstossen, sehr dunkle. Körnchen . . .; ohne Zweifel Chlorsilber und reduciertes Silber".

Nach C. Krause erzeugen Flinzer (bei Coccius, 1854, Lit. 33) nach einer die Anwendung des Höllensteins als therapeutisches Mittel bei Augenkrankheiten betreffenden Dissertation und $\mathrm{H}$ is $(1856$, Lit. 49) nach einer Publikation über die genauere. Untersuchung der Wirkung des Silbersalzes auf die gesunde und kranke Cornea durch Ätzung derselben Niederschläge in ihr.

Die Silberbehandlung aber erst $\mathrm{zu}$ einer anatomischen "Methode" gemacht zu haben, ist das Verdienst v. Recklinghausens (1860, Lit. 87). Dies geschah, wie er später (1868, Lit. 90) ausdrücklich betont, dadurch, „dass er einerseits äusserst schwache Silberlösungen angewandt habe, andererseits nicht in situ die tierischen Teile behandelt oder wenigstens das Epithel vorher entfernt habe". Er erhielt Bilder, die ihn zur Empfehlung des Silbers als einer Methode zur Sichtbarmachung der Grenzlinien von Epithelzellen veranlasste.

1) L. Landois erwähnt auffallenderweise in einem Aufsatz uber die Geschichte der Metallimpragnation (Lit. 72) nicht den Anteil C. Krauses an der Entwickelung dieser Methode. 
In seiner ersten diesbezüglichen Notiz über ,eine Methode, mikroskopische hohle und solide Gebilde von einander zu unterscheiden" aus dem Jahre 1860 (Lit. 87) sagt v. Recklinghausen: „Legt man frische oder besser noch getrocknete thierische Theile in schwache Lösungen von Höllenstein, bringt sie dann in eine dünne Kochsalzlösung und setzt sie hierauf der Einwirkung des Lichtes aus, so erhält man einen feinen, dichten, schwarzen Silberniederschlag in denjenigen Theilen, welcho wesentlich wässerige Lösungen enthalten, wohingegen solidere Substanzen (Intercellularsubstanzen) nur zerstreutere Körner oder eine diffuse Färbung zeigen, ja fast unverändert bleiben können."

Dieser ersten Notiz v. Recklinghausens folgt. eine kurze Mitteilung von $\mathrm{H}$ is (1.861, Lit. 50). Er kann nach seinen Resultaten an Hornhäuten in der Regel eine extra- und eine intracelluläre Ablagerung der Silberkörnchen und in gewissen Fällen eine solche „unmittelbar an der Zellwand“ unterscheiden, die erste nach Behandlung frischer Objekte mit konzentrierten Solutionen, die zweite bei Anwendung diluierter Lösungen. $\mathrm{H}$ is macht gleichzeitig darauf aufmerksam, dass bereits Coccius 1854 nach Flinzers Dissertation (Lit. 33) diese zu unterscheidenden Wirkungsarten im wesentlichen erkannt habe.

Im Jahre 1862 gibt v. Recklingha usen (Iit. 88) dann in einer weiteren. Arheil die bekannten und anfänglich viel umstrittenen beutungen der bei der Silberbehandlung entstehenden Zeichnungen. Er kommt auf seine früheren Untersuchungen (1860, Lit. 87) zurück mit den. Worten: „Ich hatte nämlich gefunden, dass ein $k$ örn i ge $r$ schwarzer Niederschlag von Silber sich in dem flüssigen, an fällbarem Material reichen Inhalt von Kanälchen bildete, während festere Grundsubstanzen entweder farblos blieben oder eine so feine Vertheilung des Präcipitates darłoten, dass bei den üblichen Vergrösserungen 
nur eine $\mathrm{F} \ddot{a} \mathrm{rbung}$ resultierte." Er bespricht eingehend die. Resultate der Silberapplikation auf die verschiedenen Gewebe:

Bei den Epithelien unterscheidet er für gewöhnlich zwei Wirkungsarten: Erstens die nach geringerer Einwirkung entstehende Markierung der Grenzlinien, bei der der Niederschlag nicht etwa in den Zellmembranen, sondern zwischen den einzelnen Zellen, ,wahrscheinlich innerhalb einer Kittsubstanz" auftritt. Diese Auffassung begründet er mit der Feststellung, dass einerseits die beiden Ränder einer solchen fast schwarz gefärbten, zuweilen hier und da unterbrochenen silberlinie äusserst scharf sind, andererseits sich die Niederschlïge bei geschichteten Epithelien durch die einzelnen Schichten fortsetzen, oft ohne dass die darin befindlichen Zellen irgend eine Färbung angenommen haben, wie überhaupt die Zellen selbst bei schwacher Wirkung ganz farblos, ihre Kerne besonders nach Applikation von Karminlösung noch erkennbar bleiben. Zweitens führt er die nach intensiverer Einwirkung resultierende Färbung der Zellen an, welche vom Rande derselben nach dem Centrum abnimmt, anfangs den Kern noch als farblosen Fleck erkennen lässt, später aber auch diesen überzieht und unkenntlich macht. Selten tritt noch eine dritte Wirkungsart auf: stärkere Färbung des Kerns als des Zelleninhaltes. Immer wird die Abgrenzung des Kernes undeullicher, als sie ohne silberapplikation besonders nach Essigsäurezusatz zu sein pflegt.

Beim Bindegewebe lassen sich nach r. Recklingha us on sehr versehiedene Arten der Silberwirkung selbst bei Anwendung schwacher Lösungen hervorrufen. Die wichtigsten von diesen entsprechen den von Flinzer-Coccins und His (1854, Lit. 33 und 1861, Lit. 50) crwähnten und erscheinen $\mathrm{ihm}$ allein methodisch verwertbar (intra- und extracelluläre Ablagerung des Niederschlags). Beim Kn orpel lassen sich ganz ähnliche Resultate erzielen, auch hier ist der schärfste Gegensatz zwischen Grundsubstanz und Knorpelhöhlen herbeizu- 
führen. Bei der Behandlung feuchten $\mathrm{Knoch}$ en s mit Silberlösung kommt v. Recklinghausen zu keinem erwähnenswerten Ergebnis.

Quergestreifte Muskelfasern färben sich nach den spärlichen Erfahrungen des Autors entweder nur diffus oder lassen einen kömigen Niederschlag auftreten, ohne eine besondere Differenzierung im Innern zu demonstrieren. Glatte Muskelfasern zeigen bei schwacher Einwirkung ebenso wie die Epithelien die Grenzlinien, ,auch hier wahrscheinlich durch einen Niederschlag innerhalb. der Kittsubstanz", bei starker Wirkung resultiert eine Färbung der einzelnen Elemente.

Die Nervenfasern selbst nehmen nach v. Reckling$\mathrm{h}$ a u s e n schwer eine Färbung durch Silber an, in den feinsten Stämmchen tritt eine ähnliche feine Streifung durch den Niederschlag zwischen den Primitivröhren hervor, wie bei den glatten Muskelfasern.

Allgemein sagt v. Recklinghausen dann noch: „Was nun die Applikation der Silberlösung selbst betrifft, so muss ich gleich hier bemerken, dass ich trotz vieler Versuche leider nicht imstande war, scharfe Normen aufzufinden, um mit Sicherheit diese oder jene Wirkungsart zu producieren. Ich kann gegenwärtig nur empfehlen, möglichst schwache Lösungen (1 Theil Silbersalz auf 400-800 Theile Wasser) anzuwenden, ferner die einzutauchenden Substanzen entweder vom ganz frischen oder höchstens 24 Stunden alten Leichnam zu entnehmen. Wichtig scheint es dabei, die thierischen Theile ınöglichst wenig $\mathrm{zu}$ verletzen, und in dem Feuchtigkeitszustande mit der Silberlösung zu behandeln, in welchem sie im Körper existieren."

Befolgt man diese Vorschriften, so erhält man nach v. Recklingh a u sen beim Bindegewebe gewöhnlich die erste Wirkungsart (gefärbte Grundsubstanz, farblose Kanäle). Für das Zustandebringen der zweiten Wirkungsart (Füllung der 
Kanäle mit einem Niederschlag), also für das ttberführen der sog. „negativen“ in die „positiven Silberbilder“, empfiehlt er Eintauchen der Objekte nach prolongiertem Aufenthalte in der Silberlösung in ganz verdünnte Salzsäure oder Kochsalzlösung. Die Bemessung der Dauer der Einwirkung des Silbers ist nach den Erfahrungen v. Reckling hausens verschieden je nach der Beschaffenheit der Oljekte, er bemerkt aber, dass das Silbersalz immer nur in die relativ oberflächlichen Schichten eindringt: „man darf nicht erwarten, durch einen langen Kontakt eine Reaktion in der Tiefe hervorzurufen."

Bezüglich der Erforschung der Ursachen und Bedingungen der einzelnen Wirkungsarten ist v. Recklinghausen zu keinem befriedigenden Resultat gekommen, er glaubt aber im Gegensatz zu His (1861, Lit. 50), dass die beiden Arten der Wirkung beim Bindegewebe nicht einfach von der Konzentration der Lösung abhängen. Zuweilen hat er beide in den verschiedenen Schichten eines und desselben Präparates (Conjunctiva) wahrgenommen, allerdings (den Erfahrungen $\mathrm{H}$ i s' entsprechend) gewöhnlich die erste Wirkungsart in den oberen, die zweite in den tieferen Schichten. És sei noch erwähnt, dass v. ReckI inghausen auch verschiedene Wirkungsarten am gleichen l'räparat nebeneinander sah, selbst in Fïllen, wo er sich bemähte, alle Teile unter ganz gleiche äussere Bedingungen zu bringen (diffuse Fürbung neben Markierung der Kanäle). Als Lrklärung verweist er zum Teil wenigstens auf Faltenbildungen der eingetauchten Membran und auf die enorme Empfindlichkeit der heaktion.

His (1862, veröffentlicht 1863, Lit. 52) macht dann die Frage der linwirkung des salpetersauren Silberoxyds auf die Hornhaut zum Gegenstand einer besonderen Arbeit. Er behandelt die Corneagrundsubstanz meist nach Entfernung des Epithels. Von seiner früheren Angalee (1861, Lit. 50), dass schwache Lösungen die intra-, starke die extracellulären Aus- 
scheidungen zur Folge hätten, kommt er zurück und glaubt jetzt, dass die Zeit, welche nach der Ätzung (noch immer mit Höllenstein in Substanz!) verstrichen ist (bis zur Tötung des Versuchstieres), auf die Lage des Niederschlages Einfluss hat. Primär liege er immer in der Intercellularsubstanz der Cornea, löse sich aber dann wieder in den das Gewebe durchtränkenden Säften. So kann dann das wieder gelöste Salz in die Zellen eintreten, in denen es aufs Neue unter dem Einfluss des Lichts oder besonderer in denselben entháltener Stoffe niedergeschlagen wird. Diese Ansicht stützt $\mathrm{H}$ is auf das Ergebnis einiger Versuche: Er befasst sich ferner mit der chemischen Natur der extracellulären Niederschläge. Soweit er aus blossen Reaktionen bei seinen Untersuchungen einen Schluss ziehen $z u$ dürfen glaubt, scheint ihm allerdings der durch Silbernitrat in Eierweiss oder Blutserum entstehende Niederschlag reines Silberalbuminat zu sein, ob dagegen die resultierende $A$ uflösung dieses Niederschlages in Kochsalzlösung das Silber etwa in Form einer löslichen Doppelverbindung enthalte, bedarf seines Erachtens weiterer Untersuchung. Aus dem Ergebnis seiner Untersuchungen an f ris ch mit Silber behandelten Hornhäuten, an denen die "Trübung“ bereits eingetreten, die Reduktion aber noch ausgeblieben war, schliesst er, dass der Niederschlag, der in der Grundsubstanz der Cornea entsteht, kein Silberalbuminat, sondern Chlorsilber ist. Da nun eine Auflösung von Chlorsilber in Kochsalzlösung bei Belichtung selbst nach Tager jede Spur eines Niederschlages vermissen lässt, auch nach Beteiligung von Eiweiss, so kommt $\mathrm{H}$ is bei der Frage nach der Art des Zustandekommens des intracellulären Niederschlages aus. dem extracellulären zu der Annahme, dass in den Zellen eine Substanz vorhanden sein müsse, welche die Chlorsilberlösung zersetze, er sagt von der Substantia propria der Hornhaut: „man wird in dieser Annahme durch die Beobachtung bestärkt, dass an den mit Silberlösung und nachher 
mit Kochsalz behandelten Hornhautschnitten die äusseren Contouren der Zellen und ihrer Ausläufer es sind, die zuerst scharf hervortreten und mit Körnern besetzt werden, während der mittlere Theil der Zellkörper erst später mit Niederschlägen sich erfüllt. Unter den möglicher Weise in Betracht kommenden Substanzen sind es vor allem die phosphorsauren Salze, die eine genauere Berücksichtigung verdienen." Während alle aus Zellen oder Zellderivaten bestehenden Organe ungemein reich an phosphorsauren Alkalien sind, dürfen wir nach $\mathrm{Hi}$ is in den von ausgetretenem Blutplasma durchtränkten, quellungsfähigen Intercellularsubstanzen allenthalben ein starkes.Vorwiegen des Chlornatriums erwarten. Diese phosphorsauren Alkalien hat $\mathrm{H}$ is nun bereits früher (1856, Lit. 49) in der Hornhaut nachgewiesen, man wird daher wohl auch für die Substantia propria der Hornhaut in ihren Zellflüssigkeiten vor allem diese Salze, in ihrem Intercellularsaft Chlornatrium annehmen können. Seine Vermutungen prüft $\mathrm{H}$ is noch durch den Versuch, der ein für die Annahme günstiges Ergebnis zeitigt. Eine Auflösung von Chlorsilber in Kochsalzlösung ergibt bei Zusatz von einer Lösung gewöhnlichen phosphorsauren Natrons (2 $\mathrm{NaO} . \mathrm{HO} \mathrm{PO}_{5}$ ) einen weissen Niederschlag, der bei Belichtung sich unter Volumabnahme grau färbt, auch bei Beteiligung von Eiweiss entsteht "derselbe Niederschlag". Uber die chemische Natur desselben erlaubt sich $\mathrm{H}$ is kein Urteil, er bemerkt nur, dass er in Salpetersäure und in Essigsäure sichnicht löst, dass er sich dagegen in Ammoniak rasch und beinahe vollständig, d. h. mit Hinterlassung nur geringer Mengen sehr feiner Flocken löst, desgleichen auch in Cyankalium und unterschwefligsaurem Natron. Ganz dieselben Löslichkeitsverhältnisse zeigt auch der unter Einfluss von Kochsalzlösung $\mathrm{f} r$ is ch entstandene intercelluläre Niederschlag der Hornhaut, während der ältere allerdings in Ammoniak unlöslich, dagegen in Salpetersäure unter Gasentwickelung löslich ist, somit wohl 
als reduziertes Silber angesehen werden darf. Rätselhaft bleibt $\mathrm{H}$ is der die Fällung befördernde Einfluss des Lichts; er betont, dass für obige Annahmen mannigfache Wahrscheinlichkeitsgründe sprechen, dass aber kein Beweis als vorliegend erachtet werden könne und dass die Möglichkeit im Auge zu behalten sei, noch andere Substanzen aufzufinden, die sich bei den Vorgängen beteiligen.

Schliesslich äussert $\mathrm{H}$ is bei seiner Stellungnahme gegen die v. Recklinghaus en schen Anschauungen die bekannten sog. „Saftkanälchen" betreffend noch, dass die bei der Behandlung der Cornea mit Silbernitrat und mit Kochsalz entstehenden Silberniederschläge in den Z ellen und in i hren $\Lambda$ uslä ufern selbst, nicht zwischen ihnen und der Grundsubstanz, liegen.

K öll i k er (um 1863, Lit. 62), der übrigens mit v. Reck linghausens Schlussfolgerungen nicht einverstanden ist, macht die Angabe, dass $\mathrm{H}$ is (1) in der Behandlung der Hornhaut mit Silberlösungen ein Mittel gefunden habe, die Hormhautkörperchen prachtvoll sichtbar zu machen, und ruft dadurch einen kleinen, unbedeutenden Prioritätsstreit zwischen v. Recklinghausen und $\mathrm{H}$ is (1863, Lit. 90 u. 51, nachträgliche Bemerkungen) hervor. Die F lin z er sche Dissertation bei Coccius wird bei diesem berücksichtigt, nicht aher der weit zurückliegende Versuch C. Krauses, der überhaupt wenig bekannt geworden zu sein scheint. $\mathrm{H}$ is sugt, dass er im Winter 1855/56 durch einen Aufsatz Gosselins in der Gazette Hebdomadaire veranlasst worden sei, die Bildung von Niederschlägen, und zwar insbesondere von Silberniederschlägen, in der Hornhaut weiter zu verfolgen, spricht aber schliesslich selbst v. Recklinghausen das Verdienst $z u$, die Silberbehandlung der Gewebe zu einer allgemeinen histologischen Methode erhoben zu hahen.

v. Recklinghausen (1863, Lit. 89) teilt dann eine 
Verbesserung der Silbermethode mit. Er kann jetzt „mit voller Sicherheit" in der ganzen Ausdehnung des Centrum tendineum die Lymphnetze kontinuierlich hervorrufen und sagt darüber: „Hierzu ist es erforderlich, das Zwerchfell fortwährend mit einer albuminösen Flüssigkeit, am zweckmässigsten Pericardialtranssudat feucht zu erhalten, es nach Entfernung des Epithels der Serosa auf einer mit diesem Fluidum getrünkten Unterlage von Filtrirpapier auszubreiten und hiernach die Silberlösung höchstens 2 Minuten einwirken zu lassen."

Weitere hier erwähnenswerte Angaben macht $\mathrm{H}$ is (1863, Lit. 51) in einer Arbeit ,über das Epithel der Lymphgefässwurzeln und über die v. Recklinghausenschen Saftkänälchen“. Die Gleichförmigkeit der Linien der netzförmigen Zeichnungen in den Lymphgefässen, die Gleichmässigkeit ihrer Stärke (keine Verfeinerung bei der Teilung), die Häufigkeit stumpfer Winkel (keine Verzweigung unter meist spitzen Winkeln), die einfache Ausbreitung in den Flächen an Schrägoder Längsschnitlen (keine Überlagerungen in mehrfacher Schichle) sprechen für die Auffassung als Grenzlinien eines Plattenepithels und gegen die Deutung als Fasernetze. Es gelingt ihm ferner durch Behandeln feiner Schnitte der mit Silber imprägnierten Diaphragmen mit starker $\left(35^{\circ}\right)$ Kalilauge Fetzen einer dünnen Membran zu isolieren, an der die Zeichnung noch sichtbar ist. Bildingen, die auch seines Erachtens kaum für etwas anderes als für intercelluläre „Stomata“ angesehen werden können, finden sich nach seinen Beohachtungen wicht überall, da, wo sie auftreten, alher meist sehr reichlich beisammenliegend. Dass sie natürlich präformiert sind, hält er für am wahrscheinlichsten, er spricht aber auch von der Möglichkeit, dass sie künstliche Rissspalten darstellen können. H is hält die Silberpräparate auch für sehr geeignet zur Verfolgung von Muskeln.

Öd $\mathbf{m}$ an s s on (1863, Lit. 82) benutzt bei Untersuchungen 
zur Lehre von dem Epithel Versilberungen. Seines Erachtens spricht für die Annahme der Darstellung einer Kittsubstanz durch die Methode ausser den von v. Recklinghausen angeführten Gründen auch der Umstand, dass man durch Abpinseln häufig Bruchstücke der gefärbten Grenzlinien entweder vollkommen frei oder noch mit einem Teil einer übrigens zerfallenen Zelle verbunden isolieren kann: „A usserdem sind sie auch bei sehr schwacher, jedoch gleichförmig ausgefallener Färbung von sehr verschiedener Breite, welcher Umstand auch wohl andeutet, dass eine $Z$ wischensubstanz sich vorfindet. Indess zeigt die Breite der Grenzlinien, auch bei mässiger Färbung, wahrscheinlich nicht immr die ursprüngliche Breite der Zwischensubstanz an, weil es als Regel gilt, dass die mehr gefärbten Grenzlinien breiter sind, als die weniger gefärbten." Er bespricht dann noch Gebilde von verschiedener Form zwischen den Zellen, d. h. in den Grenzlinien, die er teils für öffrungen verschiedener Art, teils für junge Epithelzellen, die in der Tiefe gebildet werden, hält.

Cornil (1863, Lit. 23) schliesst sich im wesentlichen der Ansicht v. Recklinghausens an.

Auf Veranlassung des letzteren untersucht Tommas $i$ (1863, Lit. 118) die Lymphgefässe des Hodens unter Verwendung einer Silberlösung entweder durch Injektion oder durch Behandlung frischer, feiner Schnitte.

Chrzonsczewsky (1863, Tit. 16) benützt zur Untersuchung von Lungen, die mit gefärbter Leirnmasse injiziert wurden, die Silberbehandlung und macht die Alveolarepithelien (deren Existenz zu jener Zeit fraglich war) deutlich sichthar, er schliesst eine Fürbung der Schnitte mit wässeriger Carminlösung an.

lm Jahre 1864 macht Frommann (Lit 36) die Beobachtung, dass Achsencylinder unter Einwirkung von Höllenstein dunkle Querstreifen zeigen, Linien, die heute allgemein 
nach ihrem Entdecker benannt werden. - Der Autor beschränkt sich auf die Beschreibung der wohl allgemein bekannten Erscheinung, ohne eine Deutung ihres Wesens zu versuchen. Inzwischen traten aber sehr bald eine Reihe von Forschern als eifrige Gegner der Silberimprägnation auf. Sie deuteten die entstehenden Zeichnungen als Kunstprodukte oder zufällige Niederschläge des Silbersalzes, man warnte vor Trugschlüssen und suchte in der verschiedenartigsten, oft sehr gezwungenen Weise die zierlichen Silberlinien der Präparate zu erklären. Ein heftiger Streit erhob sich und förderte eine umfangreiche Literatur zutage, die heute zum Teil nur historisches Interesse hat:

A d le r (1864, Lit. 6) hält (in einer vorläufigen Mitteilung) die netzförmigen Figuren am Epithel für Fasernetze, die den elastischen verwandt sind. Er untersucht Nerven vom Frosch, Sehnenscheiden, Neurilemm, Darmzotten, Hodenkanälchen und lindet überall übereinstimmend diese Netze. Den Niederschlag selbst hält er für kein Chlorsilber, da er auf Zusatz von $\mathrm{NO}_{5}$ verschwindet, auch führt er hierbei den Unterschied an „zwischen dem röthlich braunen körnigen Niederschlag von. $\mathrm{AgCl}$ neben den tief schwarzen Fasern“. Ferner sagt er: „Es ist daher nicht nöthig $\mathrm{NaCl}$ oder $\mathrm{HCl}$ hinzuzusetzen, um die Netze hervorzurufen, . . . sie entstehen im Dunkeln eben:o wohl als unter dem Einfluss des Lichtes, werden von concentrirter Ac. nicht gelöst, daher auch kein metallisches Ag. Man muss also wohl auf eine besondere Verbindung schliessen, vielleicht AgS, indem auch diese Fasern wie die elastischen schwefelhaltig sein könnten; andererseits möchte ich eine besondere Silberverbindung vermulhen, da eine Lösung von gereinigtem (schwefelfreiem) Elastin mit $\mathrm{AgO} . \mathrm{NO}_{5}$ einen schwarzbraunen Niederschlag giebt, der aber noch nicht vollständig untersucht ist. - Schwierig ist die Conservirung der Präparate, da Glycerin allmälig den Niederschlag verschwinden macht; ... . 
Broueff und Eberth (1864, Lit. 15) wenden sich vor allem gegen A d ler: (1864, Lit. 6) und bestatigen dagegen die Resultate und die Deutung der Silberbehandlung des Epithels nach $\mathrm{v}$. Recklinghausen. Sie isolieren an Rückennerven des Frosches, die einige Stunden in reinem Cilycerin gelegen haben, bei Untersuchung in Wasser unter wiederholtem Zusatz von, verdünnter Essigsäure eine zarte, anfangs scheinbar strukturlose Membran oder Fetzen einer solchen. In dieser erscheinen da und dort Kerne, dazwischen zart gezackte leicht wellige helle Linien, die ein Netzwerk wie die durch Höllenstein hervorgerufenen Linien bilden. Färbung mit Jod, Carmin oder Anilin lïst alle diese Teile deutlicher hervortreten. Nach längerem Tiegen der Nerven in Glycerin und abwechselnder Behandlung mit Glycerin und verdünnter Essigsäure isoliert man auch kleine membranöse Platten mit Kern und Umrissen wie bei den Silberfeldern. Entsprechende Bilder erhält man nach Wirkung von 35\% igem Kali auf Nerven oder Lymphraumwände nach vollständiger Höllensteinwirkung. Wirkt Kali länger ein und übt man einen geringen Druck auf das Deckglas aus, so treten bald in den dunklen Linien feine Spältchen auf, die sich bei fortdauerndem Druck verlängern und erweitern, schliesslich zerfällt die Membran in einzelne je einen Kern enthaliande Plättchen, denen Reste der dunkeln Linien anhaften. Dass es sich nicht um elastische oder mit diesen verwandle Fasern handelt, beweist ihr Verhalten gegen verdünnte und konzentrierte Kalilauge, nie gelingt es mit verdünntem Kali ein ähnliches Netz hervorzurufen, während konzentriertes (35\% iges) nie elastische Fasern, wohl aber die Kittsubstanz zwischen den Zellen löst. Nach B roueff und $\mathrm{E} b$ erth wird das Silbersalz in der Kittsubstanz zwischen den Zellen niedergeschlagen. Sie werfen Adler auch vor, nicht zu der Annahme gekommen zu sein, dass das Epithel der Lymphräume, die - wie bekannt war - bei Amphibien und Reptilien die 
Historische Darstellung zur Deutung des Wesens der Silbermethode etc. 95

einzelnen Organe umgeben, auf die einzelnen Organe sich fortsetze.

E l enz (1864, Lit. 27) benützt die Imprägnation nit Höllenstein bei Untersuchungen über das Lungenepithel; seines Erachtens darf diese Methode'so ziemlich als das feinste Reagens auf Epithel angenommen werden.

Harpeck und $\mathrm{H}$ artmann (1864, Lit. 44 u. 46) erklären jedoch die nach der Silberbehandlung auftretenden Zeichnungen in dem Bindegewebe (u. a. Cornea) und in den epithelartigen Geweben für Trugbilder. Harpeck untersucht die Cornea und glaubt die Silberbilder als den Ausdruck künstlich erzeugter Spalten ansehen zu müssen. Hartmann untersucht Zwerchfelle, Nabelschnuren, Darmzotten und Aorten, er hält die netzförmigen Linien für Kunstgebilde, d. h. eigentümlich geformte Niederschläge, die aus der Verbindung des Silbers mit Bestandteilen der organischen Gewebe (Chloralkalien, Albuminaten?) entstehen. Er hat auf verschiedenen Substraten (Glas, dünnen Schichten von Collodium, Traganth und arabischem Gummi) ähnliche Liniennetze entstehen sehen, wenn diese in Silberlösung einige Zeit lagen. (Siehe das bezüglich einer Arbeit von' Robinski, Lit. 96, vom Jahre 1869 Angegebene.)

K le hs (1864, Lit. 60), der das Epithel der hinteren Hornhautfläche untersucht und dabei sich auch der Versilberung bedient, beobachtet, dass die versilberten Zellkonturen, die äusserst scharf hervortreten und tief ineinander greifende 'Zacken bilden, an einzelnen Stellen getrennt sind durch verschiedene breite, helle Zwischenräume. Gegen die Auffassung, dass die „Zackenzellen", wie er diese Epithelzellen nennt, infolge der Präparation voneinander gelöst seien, spricht seines Erachtens das sehr feste Anhaften der Eipithelzellen nach der Silberbehandlung und das Auftreten solcher Gruppen mit hellen Zwischenräumer immitten von dicht ineinander gefügten Zellenmassen, er glaubt daher, dass es sich bei diesen Zellen, bei denen er 
eine Kontraktionsfähigkeit annimmt, um eine Abhängigkeit der entstehenden Bilder von dem jedesmaligen Kontraktronszustande handelt. Der Autor weist auf die Möglichkeit einer nahen Verwandtschaft dieser "Zackenzellen“ mit den "Stachelzellen" hin und teilt mit, dass auch die sehr viel kleineren Zellen der tieferen Schichten des vorderen Hornhautepithels dieselben tiefgezackten Ränder zeigen. Schliesslich nimmt Klebs Stellung gegen $H$ arpeck (1864, Lit. 44).

$\mathrm{H}$ is (1864, Lit. 53) hält an seinen früheren Angaben fest. Er macht einige Mitteilungen für die Injektion von Gefässen mit Silberlösung, wendet sich vor allem gegen Adler und Hartmann (1864, Lit. 6 u. Lit. 46) und widerlegt deren Einwände gegen die Versilberungsmethoden.

In einer Arbeit „Zur Anatomie der Lymphgefässe, im Besonderen derjenigen des Darmes" äussert sich A uerbach (1864, Lit. 9) sehr eingehend zur Deutung der bei der Silberbehandlung entstehenden Linien. Auf Grund eigener Untersuchungen, zunächst genau nach v. Recklinghausens Vorschriften, dann unter verschiédenen Variationen, kommt A u e r b a ch zu der Erklärung, dass er absolut empfehlenswerte Vorschriften für die Technik nicht aufstellen kann, da sich ihm die Methode als höchst unsicher, in ihrem wesentlichen Erfolge von schwer zu regulierenden Nebenbedingungen abhängig erwies. Er erwähnt hierbei zunächst eine Beobachtung, die hier angeführt sei : Namentlich nach Anwendung stärkerer Lösungen bei der Injektion der Lymphgefässe zeigt sich das Gelingen der letzteren zuweilen dadurch an, dass die Lymphgefässe sofort eine weisse Farbe annehmen, die am Lichte in eine braune übergeht. Er bemerkt, dass dieser Umstand ,zuweilen durch reichliche dunkelkörnige Niederschläge im Innern der Röhren bedingt ist, in welchem Falle dann auch die Zeichnung der Wandung fehlen kann; es ist dies wohl so zu erklären, dass die Gefässe eine kochsalz- oder eiweissreiche Flüssigkeit in 
grösserer Menge enthielten, welche das Silbersalz zersetzte oder band, hevor es auf die Wandung wirken konnte". Nach A u erbach schlagen die gleichmässigen Form- und Grössenverhältnisse der Linien selbst, beziehungsweise der von ihnen begrenzten Felder jeden Verdacht auf unwesentliche Niederschläge nieder, wie sie auch der Deutung der Linien als umspinnende elastische Fasern nicht günstig sind. Die letztere widerlegt sich ausserdem durch den Umstand, dass die dunklen Linien nicht über die Randlinie der Lungengefässkontur prominieren. Bezüglich der Kerne der die Lymphgefässe auskleidenden Zellen stellt A u e r b a ch fest, dass sie unter der kombinierten Wirkung von salpetersaurem Silber, Holzessig beziehungsweise Essigsäure, Alkohol und Wasser in dreifacher Form erscheinen, er schreibt: „In der ersten bleiben die Zellenplatten selbst ganz hell und klar, höchstens sind einzelne zerstreute feine Körnchen an ihnen bemerklich; die Kerne selbst aber erscheinen unter demselben Bilde, wie sorist Zellkerne, etwa an Essigsäurepräparaten, zeigen eine dunkele, bei genauer Einstellung doppelt contourirte Begrenzung, und häufig auch noch deutliche Nucleoli." Sie sind "ab und zu etwas geschrumpft" und haben „von ihrer regelmässig elliptischen Form verloren“. Andere Male zeigt sich folgendes: „Die Zellen sind zunächst. ihren dunklen Contouren ebenfalls hell; in einer gewissen Entfernung von diesen jedoch beginnt ein feinkörniger gebräunter Niederschlag, welcher nach der Mitte der Zelle hin immer dichter wird, und in dieser dunkelkörnigen Materie zeigen sich die Kerne nur als helle, zuweilen sehr scharf begrenzte Flecke. Oder man findet drittens in den sonst hellen Platten, deren Mitte nahe, nur ein dichtes Häufchen dunkler Körner, zuweilen von deutlich elliptischer Form, meist an den Rändern diffus sich verlierend, und zwar so regelmässig in jeder der Platten, dass man nicht zweifeln kann, Niederschläge um die Kerne herum vor sich $\mathrm{zu}$ haben. Die beiden letzteren Erscheinungs- 
weisen ... beweisen, dass nicht alle diese Wandungszellen ganz und gar verhornte Platten geworden sind, sondern zum Theil in ihrer Mitte noch eine weichere, chemisch leichter angreifbare Inhaltsmasse besitzen, welche zumeist um den Kern angehäuft ist und nach den Rändern hin dünner wird."

Auch $\mathrm{A}$ ue $\mathrm{rbach}$ ist der Ansicht, dass die dunkeln Linien die Zellgrenzen markieren, es ist aber seiner Ansicht nach fraglich, warum gerade an diesen Grenzlinien der Silberniederschlag entsteht und was aus dieser Tatsache über die Art, wie die Zellen aneinanderhaften, zu schliessen ist. Für die Auffassung v. Recklinghausens (mit Hilfe der Kittsubstanz) spricht nach A u erbach der Umstand, dass auch in anderen Geweben, deren Elemente loser zusammenhängen, nach der Behandlung mit Silberlösungen zwischen den einzelnen Zellen schwarze Niederschläge sich bilden, wie denn z. B. in glatten Muskeln die einzelnen Faserzellen dadurch aufs schärfste begrenzt werden. Als gegen die v. Recklinghausensche Deutung sprechend aher führt er an: „Zunächst der Umstand, dass die dunkeln Linien je nach äusseren Bedingungen ein sehr verschiedenartiges Ansehen darbieten können. Sie sind bald fein, dass sie nur mit stärksten Vergrösserungen wahrzunehmen sind, bald von beträchtlicher ... Breite; im letzteren Falle sind sie nicht immer scharf begrenzt, und greifen meistens auf die Fläche der Zellen über, wodurch die lichten Felder sichtlich verkleinert sind. Zum Theil hängt diese Verschiedenheit von der Concentration des angewandten Reagens $a b$, je stärker diese, desto breiter die Linien; doch scheinen gelegentlich auch andere Verhältnisse mitzuwirken. Ferner sind die Linien zwar. häufig continuirlich und gleichmässig, manchmal aber auch nur durch Reihen von Punkten und Strichelchen vertreten. Es sind diess schon Erscheinungen, welche sich schwer auf eine gesetzmässig die Zellenränder trennende Schicht von bestimmter Dicke beziehen lassen; vielleicht wird man aber die erst- 
Historische Darstellung zur Deutang des Wesens der Silbermethode etc. $\quad 99$

genannten aus einem Aufquellen, respective therquellen der Kittsubstanz, die letzteren aus zu sparsam herantretendem Reagens zu erklären geneigt sein."

Der Autor macht ferner darauf aufmerksam, dass die Präparate bei nicht ganz vorsichtiger Behandlung mit Essigsäure oder auch mit. Glycerin oder bei Verwendung von essigsaurer Silberlösung zuweilen nach einiger Zeit (Stunden und Tagen) völlig verändert sind, die dunkeln Linien verschwinden teilweise oder auch gänzlich wieder, wobei dann die vorher unsichtbaren Kerne der Zellen hervortreten. Es müsste diese Veränderung von einer Lösung und einem Ausziehen des Silberpräcipitats aus der Kittsubstanz herrühren, wobei es auffällig bliebe, dass dabei der membranöse Zusammenhalt der Zellen nicht irgendwie alteriert würde. „Fasst man aber diesen Zerstörungsprocess der dunkeln Linien in seinem Beginne in's Auge, so sieht man, dass dieselben stückweise von der Gefässwand sich verlieren und erkennt oftmals Trümmer derselben in Form schwarzer Körnchen, Stäbchen und schleifenförmig gebogener Fäserchen im Innern der Gefässe. Unter solchen UImständen kann man die Zerstörung auf mechanischem Wege befördern; durch einen Druck auf das Deckgläschen gelingt. es zuweilen, die noch vorhandenen Linien gänzlich zu zertrümmern, ohne dass doch isolirte Zellen sichtbar würden.“

$\mathrm{Zu}$ diesen gegen die Auffassung v. Recklinghausens sprechenden Momenten kommen noch die Gründe, welche A uerbach für folgenden Imstand vermutet. Gewöhnlich zeigen nämlich seine Imbibitionspräparate keine markierten. Zellgrenzen in den Lymphgefässen, sondern nur stellenweise, sehr sicher und gleichmässig hingegen wird dieser Effekt durch Injektion in die Lymphgefässe erreicht und $A$ u e r b a ch glaubt daher, dass auch bei der Imbibition das Zustandekommen eines Niederschlages an den Zellgrenzen in den Gefässen davon abhängig ist, ob das Reagens Gelegenheit habe, durch natürliche 
Offnungen oder künstliche Rissstellen in das Lumen der Gefässe einzudringen und die innere Fläche ihrer Wand zu bespülen. „Vielleicht" - so meint A uerbach - „rührt die grosse Brauchbarkeit des Zwerchfells zur Demonstration der bewussten Erscheinung auf dem Wege der Imbibition gerade davon her, dass seine Lymphgefässe nach der peritonealen Oberfläche sich öfnen, wie v. Recklinghausen nachgewiesen, und dass durch diese öfnungen die Silberlösung in die Höhlung der Lymphgefässe hineinfliesst." Lieferte aber eino die Zellenränder trennende Kittsubstanz das Material zu den schwarzen Linien, so müsste solche von aussen her der Einwirkung des Silbersalzes ehenso zugänglich sein, wie von innen.

A u erbach kommt so schliesslich zu der Annahme, dass die dunkeln Linien aus einem Silberniederschlage bestehen, welcher der inneren Fläche der Gefässwandung längs der Zellgrenzen a ufgelagert ist, und somit zu dem weiteren Schlusse, dass an diesen Stellen eine hesondere Disposition zur Bildung oder Absetzung solchen Niederschlages vorhanden sein muss. Dies erscheint wohl möglich, selbst unter der Voraussetzung, dass die platten Zellen der Wandung gänzlich zu einer kontinuierlichen Haut verschmolzen wären oder dass eine ihre Ränder etwa verkittende Substanz an dem Vorgange doch nicht beteiligt wäre. Sehr nahe scheint dem Autor namentlich folgende Möglichkeit zu liegen: „Die Zellen sind in ihrer Mitte, um den Kern herum dicker, gegen die Peripherie hin verdünnt; denken wir uns nun die Ränder besonders von innen her zugeschärft, so müssen an den Grenzen der Zellen auf der inneren Gefässfläche feine Furchen entstehen, in welchen auch nach Entleerung der Gefässe Reste von deren eiweiss- und kochsalzhaltigem Inhalte haften bleiben, unter Umständen auch als fadenförmige Gerinnungen sie ausfüllen und bei eindringendem Silbersalze dieses zunächst anziehen werden." Von diesem. 
Historische Darstellung zur Deutıng des Wesens der Silbermethode etc. 101

Gesichtspunkte aus hält $\mathrm{A}$ uerbach die vorhin erwähnten Erscheinungen für sehr einfach erklärlich, doch scheinen ihm auch noch andere Modi denkbar. Er bemerkt noch, dass die Existenz einer minimalen Menge weicherer Zwischensubstanz zwischen den Zellen durch seine obigen Äusserungen nicht ganz ausgeschlossen sein soll. Schliesslich kommt A u e r ba c h noch auf die Gebilde zu sprechen, die als ,Stomata“ bezeichnet und als Mündungen der von v. Recklinghausen aufgestellten sog. „Saftkanälchen“ derzeit angesehen wurden. Bei den Bildern, die diese Gebilde bei Silberbehandlung bieten, unterscheidet er zwei Kategorien. Bei der einen werden die kleinen Figuren dadurch gebildet, dass eine der dunkeln Linien sich in zwei Schenkel teilt, welche in geringer Entfernung sich wieder gegeneinander neigen und bald wieder zu einer Linie zusammenstossen. Die Auffassung dieser Figuren als öffnungen hält nun nach $\mathrm{Auerbachs}$ Ansicht bei diesem Bilde nicht Stich, am wenigsten erscheint ihm verständlich, wie diejenigen hier Lücken annehmen konnten, welche die dunkeln Linien als den Ausdruck einer Kittsubstanz der Zellen ansehen, da doch an solchen öffnungen nichts zu. verkitten wäre. Auch scheinen ihm noch andere Umstände gegen diese Annahme zu sprechen. Er hält diese durch die Silberlinien umgrenzten Felder für geschlossen durch kleine Platten, bezeichnet sie als Schaltplatten und macht ihre Entstehung durch Abschnürung der umgebenden Zellen, besonders solcher von stark buchtiger, unregelmässiger Form wahrscheinlich. $\mathrm{Zu}$ der Deutung als derartige Schaltstücke würde dann auch A u e r. bachs obige Auffassung vom Zustandekommen der Silberlinien durch Auflagerungen in den erwähnten Furchen passen. Bei 'der zweiten Kategorie der kleinen Figuren liegt ein anderes optisches Verhalten vor, sie erscheinen im Vergleich zu den umgebenden Zellen dunkel und sind häufig, auch wenn letztere weiss geblieben, gebräunt usw. Auch sie hält Auerbach 
nicht für öffnungen, führt seine Gegengründe an und hemerkt, dass auch über die Fläche der Zellen zerstreut ganz ähnliche Dinge zu finden sind. Er erklärt diese fraglichen Gebilde, die häufig bald hier, bald dort als kleine Kreise, Ellipsen oder kurze Spindeln, zuweilen aher auch beträchtlich grösser, namentlich verlängert, keulenförmig, dałei knotig und geschlängelt, gelegentlich auch sehr verbreitert, überhaupt von den mannigfachsten Gestalten (wie sie seine Fig. 17 darstellt) als Gerinnungen kleiner Inhaltsportionen in den Gefïssen, welche an deren Wandung haften. Wenn sie besonders an den Grenzregionen der Zellen entstehen, wie A u e r bach dies beobachtet, so passt hierzu wiederum, wie er bemerkt, seine Auffassung vom Zustandekommen der Silberniederschläge in Furchen.

Henle (1864, veröffentlicht 1865, Lit. 47) macht gegen die Anschauungen Adlers (1864, Lit. 6), dass die Silbernetze der Ausdruck von Fasernetzen, die den elastischen verwandl wären, seien, den Umstand geltend, diss die letzteren sich durch Imbibition mit silbersalpeter nicht färıten. Bei Besprechung der Arbeit Hartmanns (1864, Lit. 46) leilt auch Henle Beobachtungen mit, nach denen gewisse Stoffe (feinkörniges Fett im Chylus, sog. Glas- oder Eiweisskugeln) unter gewissen Verhältnissen in dendritisch verzweigten Figuren erscheinen.

Hoy e r (1865, Lil. 55) hält die Versilberungsmethode für ein in vieler Beziehung unschätzbares Mittel und sagt, dass die Höllensteinlösung den Kern gewöhnlich undeutlich mache, dafür aber mit der grössten Klarheit die Grenze zwischen den einzelnen Zellen darstelle. Hoyer bespricht genauer seine Untersuchungen der Hornhaut der Katze mit. der Versilberungsmethode. Hierbei äussert er sich über die Versilberung des einschichtigen Epithels der Descemetschen Membran wie folgt: „Die Zellen dieses Epithels selbst werden nicht so diffus braun gefärbt, wie das Hornhautgewebe, sondern bedecken sich 
mit einem körnigen braunen Niederschlage; am stärksten bildet sich derselbe gewöhnlich entlang den Zellenrändern, gleichsam wie eine Verbreiterung der schwarzen Linien, welche die Contouren der Zellen begrenzen. Mit einem Pinsel lässt sich dieser Niederschlag oft mit. Leichtigkeit entfernen, - ein Beweis, dass er nur oberflächlich abgelagert ist; die feinen schwarzen Linien dringen dagegen tiefer zwischen die Zellen ein (wie man dies am umgeschlagenen Saume zusammen gefalteter und mit Kali oder Essigsäure durchsichtig gemachter Stückchen des abgelösten lipithels beobachten kann), und lassen sich nie ganz vollständig beseitigen." H o yers Anschauungen über das Wesen der Versilberung bei der Hornhaut finden in manchen Punkten eine Bestätigung heziehungsweise eine Erweiterung durch seine weiteren Untersuchungen an den Sehnen der Hinterfüsse vom Frosch. Er folgert schliesslich aus seinen Beobachtungen, dass die Wirkung des Höllensteins auf tiefer gelegene Teile gehindert oder wenigstens erschwert wird durch die Anwesenheit des Epithels und dass man zur Erzielung einer Einwirkung auf tiefer gelegene Teile das Epithel zuvor entfernen muss.

A e by (1865, Lit. 7) untersucht mit der Silbermelhode das Endothel der Blutkapillaren. Durch Isolierung der Zellen (Froschlunge) mittels langer Maceration in Kalilauge stützt er die Ansich1 v. Recklinghausens.

Frey (1865, Lit. 34), der sich auch mit seiner Ansicht im wesentlichen an $\mathrm{v}$. Recklingha usen anschliesst, kann sich weniger davon überzeugen, dass alle die nach Silberbehandlung entstehenden Figuren ,ein sicheres Kennzeichen von Epithelium" sind. Er hält die Bilder dringend der Kontrolle durch andere Methoden bedürftig.

Bei der Untersuchung der feineren Struktur der Blut-

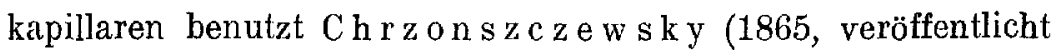
1866, Lit. 18) die Injektion einer mit Silbersalz versetzten 
Gelatinelösung (nachfolgende Belichtung). Dies Verfahren bietet viele Vorteile vor den bisher geübten Injektionen einfacher Silbersalzlösungen. Er sieht an den feinsten Arterien und Venen dann scharf vom Silberniederschlage begrenzte Muskelzellen und Epithelien (Kernnachweis durch Carmin oder Essigsäure). Er sagt: „Ohne den Lichteinfluss bleibt die Wirkung des Höllensteins aus." Seines Erachtens kam die Zeichnung nicht als Kunstprodukt des Silberniederschlages in den Kapillaren betrachtet werden.

In einer anderen Arbeit wendet sich $\mathrm{Chrzons} z \mathrm{c} z \mathrm{ew} \mathrm{sky}$ (1865, veröffentlicht 1866, Lit. 17) nochmals entschieden gegen die Deutung der Silberzeichnung in den Blutkapillaren als etwas Zufälliges (Konstanz und Gleichmässigkeit, Begrenzung sonst. bekannter ('ebilde usw.). Er betrachlet die silberlinien als die Grenzen von Gefässepithelien.

H. u eter (1866, Lit. 57) wendet sich in einem kritischen Vorwort über die Versilberungsmethode bei seiner Arbeit zur Histologie der Gelenkflächen und Gelenkkapseln zunächst scharf gegen $\mathrm{Harpeck}$ und $\mathrm{Hartmann}$ (1864, Lit. 44 u. 46). In gründlichem Eingehen auf deren Arbeiten widerlegt er ihre Einwendungen. Er glaubt, dass die Kittsubstanz der Epithelien durch die Silberbehandlung dargestellt werde, bestäligt die $\Lambda \mathbf{n}$ gaben v. Recklinghausens über die Silberbilder und stimmt im grossen und ganzen auch hinsichtlich ihrer Deutung mit ihm überein. Nach seinen Beobachtungen dringt die Silbersolution überhaupt nur in eine äusserst geringe Tiefe des imprägnierten Gewebes und es gibt keine wirksamere Schranke für das weitere Vordringen, als eine durch eine impermeable feste Kittmasse innig verschmolzene Lage von Epithelzellen. Bei der Besprechung seiner Untersuchungen über die Histologie der Gelenkflächen und -kapseln - er untersucht hauptsächlich die Gelenkfläche der Patella -.. sagt er: „Die Gelenkflächen 
wurden möglichst frischen Leichen entnommen, doch kann man bei diesem Material ohne Bedenken über die von $r$. ReckI ing h a u s en gegebene Vorschrift hinausgehen, ... I leichen voll 2--3 Tagen, welche nicht gefroren gewesen sind, liefern noch brauchbares Material, doch werden die Bilder um so schöner, je frischer die Leichen sind, und sobald der Knorpel beginnt, blutig durchtränkt zu werden, werden die Präparate völlig unbrauchbar." H ueter unterscheidet an der Intimal der Synovialhaut, der er epithelialen Charakter abspricht, zwei Formen von Bindegewebe, „epithelioides und keratoides". In vieler Beziehung findet er seine Untersuchungsergebnisse mit denen Hoyers (1865, Lit. 55) übereinstimmend.

Federn (1866, Lit, 29) hal wieder grosse Bedenken in bezug auf die Resultate der Silbermethode. Er bedient sich auch der Injektionen. Federn unterwirlt die Silberzeich. nungen in den Gefässen einer genaueren Untersuchung mit starken Systemen und findet unter anderem die Tatsache, dass die braunen oder schwarzen linien im Querschnitt nicht länglich -... was zu erwarten wäre, wenn sie von der Färbung einer zwischen den Zellen liegenden Kittsubstanz herrührten --, sondern drehrund sind. Weiter findet er die Maschen des Silbernetzes oft so unregelmässig, dass er ihre Deutung im Sinne von Zellgrenzen für unmöglich hält. Dritlens gelingt. es ihm, eine Überkreuzungsstelle zweier brauner Linien zu sehen, an welcher er die eine nach der anderen einstellen und sich davon überzeugen kann, dass dieselben ein und derselben Wand des Gefässes angehören, was nicht sein dürfte, wenn die Linien zwischen Zellen lägen und dann also wie ein Kreuz aus einem stück geschlagen erscheinen müssten. Schliesslich deckt er den Umstand auf, dass der Körper der Fäden zuweilen über die Capillarwand prominiert. Alle diese Feststellungen hält Federn für einen Beweis, dass die Silberlinien nicht Zellgrenzen entsprechen. Ubber die Natur der Jinien, welche 
also nun nicht Zellgrenzen darstellen sollen, gibt Federn aber keinen Aufschluss.

Henle (1866, veröffenllicht 1867, Lit. 48) schliesst sich der Ansicht A uer bachs an. Er hält ,die Substanz, welche durch die Silberlösung geschwärzt wird, für eine Ablagerung in den Furchen des Epithels und für verschieden von der Kittsubstanz, welche die Epithelzellen in frischem Zustande zusammenhält und mit Beginn der liäulniss sich von selbst löst".

Schweiggel-Seidel (1866, Lit. 104) macht die Frage nach dem eigentlichen Wesen der Silberwirkung zum Gegenstande einer eingehenden Untersuchung. Bezüglich der Wirkung auf die -.. namentlich einschichtigen - E pithelien spricht er sich zunïchst gegen die Auffassung der Silberlinien als zufällige Bildungen aus, ebenso gegen die Auffassung als Fasern. Der Forderung der an der Deutung als Zellen geübten Kritik (Henle, 1866, Lit. 48), die vermutliche Epithelmembran zu isolieren und durch die gewöhnlichen Lösungsmittel der Kittsubstanz in cinzelne Plättchen zu zerlegen, genügt $S \mathbf{c h}$ w eig ger-Sejdel durch Isolation der Epithelschicht an serösen Häuten in Jodserum vor oder nach Versilberung. Auf gleiche Weise demonstriert er unter Bezug auf die Controverse «wischen Adler und Broueff-Eberth (1864, Lit. 6 u. 15), die Auskleidung der Lymphsäcke der Frösche durch polygonale Zellplatten. Bezüglich der Lymphgefässe verweist er auf die einschlägigen nouesten Arbeiten seiner Zeit, besonders auf die Untersuchungen A u e r b chs (1864, Lit. 9), die Lymphgefässe der Darmmuscularis betreffend.

Dann wendet sich Schweigger-Seidel der Frage zu, auf welche Weise dic schwarzen Linien entstehen, als was dieselben zu deuten sind. Er geht davon aus, dass die in Betracht kommenden Häute im frischen Zustande von einer dünnen Schicht Serum bedeckt sind und dass bereits v. Reckling hausen (1862, Lit. 88) die Abhängigkeit des Gelingens der 
Versilberung von dem Umstande der Serumdurchfeuchtung des Objektes erkannt habe. Nach Besprechung der regen Beziehungen zwischen Höllenstein und Eiweiss (Schilderung einiger Experimente) nimmt er im speziellen Stellung gegen dic Deutungen $\mathrm{Hartmanns}$ (1864, Lit. 46) und sagt, dass „die Linien zwischen den Zellen in gesetzmässiger Weise und zwar, wie die direkte Beobachtung lehrt, momentan auftreten, sodass sie auch vor der Reduktion der Silberverbindung erkannt werden können. Der starke Glanz der frisch entstandenen Leistchen bedingt die auffallende Dunkelheit der Färbung nach eingetretener Reduktion." Das Einzige, was nach Ansicht des Autors im Gegensatz zu Hartmann aus dem Verhalten der Silberlösung gegen Eiweiss geschlossen werden kann, ist die Möglichkeit, dass beim Entstehen der v. Recklingha usenschen Linien gleiche Beziehungen zur Geltung kommen. Zur Ermittelung dieses Punktes hat $\mathrm{Schweigger-Seidel} \mathrm{Ver-}$ suche angestellt: 'Zunächst sagt er, er „habe schliesslich gelernt, die Substanz, welche bei der Epithelversilberung hauptsächlich in Wirksamkeit tritl, zu entfernen, ohne die Zellen selbst zu zerstören"; hierzu nimml, er eine etwa 4\%ige Zuckerlösung. Je nach der Gründlichkeit des Abspülens erkennt er dann nach Anwendung der Silberlösung ,entweder ein fast vollständiges Fehlen der Liniennetze " oder solche „nur in äusserster Feinheit". Auch nach dieser Behandlung gelingl die Isolation durch Jodserum ohne oder mit Versilberung. Verschiedene Modifikationen der Versuche, die immer denselben Erfolg zeigen, legen dar, dass es übrigens nicht etwa die llüssigkeitsschicht der Zuckerlösung ist, welche eine energischere Linwirkung des Silhers verhindert, obwohl man sich zu dieser Annahıne für berechtigt halten könnte, „da die Dicke der schwarzen Leisten bekanntlich von der Concentration der angewendeten Lösung des Höllensteins abhängt (A u e r bach)" (1864, Lit. 9). Dass Zuckerwasser nicht etwa eine Veränderung des Gewebes 
bedingt, welche die silberwirkung unmöglich macht, stellt er durch einen Kontrollversuch fest.

Diese Beobachtungsergebnisse sprechen gegen die Jeutung der schwarzen Linien als Fasersysteme, sie sprechen auch gegen die Annahme einer durch die Methode dargestellten organisierten Kittsubstanz. Schweigger-Seidel erklärt die Dinge hingegen in der Art, ,dass zwischen den mit ihren Rändern nicht verschmolzenen Zelle!r dünne schichten einer eiweissartigen Substanz abgelagert sind. Dieselbe mag immerhin eine zähflüssige Beschaffenheit besitzen; sie wird als Kitt wirken können und darf demnach in diesem Sinne die v. R e ck lingha usensche Bezeichnung beibehalten werden. So wird auch eine gewisse Verbindung mit der $\mathrm{A} u \mathrm{er}$ a ch schen Annahme erzielt". Der Umstand, dass sich die Epithelien nach der Maceration im Jodserum in zusummenhängenden Fetzen isolieren lassen, scheint gegen diese Auffassung zu sprechen, doch hat Schweigger-Seidel aus seinen Erfahrungen über das genannte Mittel den schluss ziehen können, dass es eine wahrnehmbare Erhärtung eiweissartiger Stoffe zu bewirken imstande ist. Unter anderen Umständen dürfte die Kittsubstanz nach Schweigger-Seidels Ansicht eine grössere Festigkeit erlangen, wie z. B. an der Oberhaut der Frösche; sie verliert dadurch, wie ihn scheint, die Fähigkeit, „sich so momentan mit dem Silber zu verbinden, ist aber auch ohne dies sichtbar, während wir an frischen Epithelien einer Serosil deshalb Nichts wahrnehmen können, weil die feinen $Z$ wischenräume zwischen den Zellen von einer mit dem gleichen Lichtbrechungsvermögen begabten Substanz ausgefüllt sind. Hinzu kommt noch, dass das dichle Bindegewebe unter den Zellen die Erkenutnis derselben in natürlichem Zustande geradezu unmöglich macht und muss desshalb auf den directen Nachweis der Furchen und der Zwischensubstanz verzichtet werden. Bei der geringen Dicke des Zelllagers gewähren auch 
Historische Darstellung zur Deutung des Wesens der Silbermethode etc. 109

Schnitte keinen sicheren Entscheid. Das Charakteristische der Silberwirkung beruht in einer Verdichtung der Zwischensubstanz und theilweise auch der Zellsubstanz selbst". „Im Allgemeinen werden wir die Masse zwischen den Zellen wohl als eine minimale Intercellularflüssigkeit ansprechen können, und würde sich hieraus eine gradweise Immunität der zelligen Gebilde gegen das Argentum nitricum ergeben." Dann gedenkt S.chweigger-Seidel noch der Möglichkeit, dass die Zwischensubstanz an einzelnen Punkten besonders angehäuft sein kann, so werden die kugeligen oder spindelförmigen Anschwellungen entstehen, die-mitunter in das Liniennetz eingeschaltet sind. Die von einer feinen schwarzen Linie begrenzten, stellenweise auftretenden hellen Lücken kann man sich nach Ansicht des Autors durch ein Auseinanderweichen der Zellgrenzen erklären, ,und braucht alsdann nur noch die Annahme hinzuzufügen, dass beim Auseinanderweichen ein Theil der \%wischensubstanz an den Rändern hängen bleibt. Dieser Saum muss bei der Versilberung eine schwarze Grenzlinie geben."

Ferner wendet sich Schweigger-Sejdel zu dem Bindegewebe. Er hatte von vornherein Bedenken gegen die v. Recklinghausen schen "Saftkanäle". Auf Grund der Ergebnisse mannigfacher Versuche erklärt er, dass die Silberbehandlung, soweit die Darstellung der „Saftkanälchen“ in Frage kommt, Trugbilder liefert, beruhend auf Gewebsveränderungen infolge der Präparation. Sehweigger-Seidel stellt schliesslich den Satz auf, „dass die sogenannten Saftkanälchen in den hier behandelten Fällen mit Bindegewebe garnichts zu thun haben". Er nimmt hingegen eine dünne Schicht eiweissartiger Substanz unter den serösen Epithelien an, die wohl die Aufkittung der Epithelien bewirkt, sie soll dieselbe sein, welche in die Furchen zwischen die Zellen eindringt und derren Verklebung veranlasst, soll aber nicht überall gleich- 
mässig entwickelt auftreten; ferner erscheint es von vornherein nicht abzusehen, inwieweit sie für die Ernährung und eine etwaige Regeneration der Zellen von Bedeutung ist. Besser als durch Silberlösting scheint sie Schweigger-Seidel nicht demonstriert werden zu können.

Schliesslich behandelt Schweigger-Seidel noch die Synovialmembranen. Zunächst wendet er sich gegen $\mathrm{H}$ u e ter (1866, Lit. 57). Seines Erachtens kann die Ansicht $\mathrm{H}$ ueter $\mathrm{s}$ nur bedingt sein durch die ausschliessliche Anwendung der Versilberungsmethode, denn die Gelenkkapseln besitzen ein wirkliches Epithel, das aher hei dor gewöhnlichen Anwendungsweise dieser Methode nicht sichtbar gemacht werden kann. Er stellt seine Beobachtungen gegen die $\mathrm{H}$ u eters, schildert seine Untersuchungen und äussert schliesslich die Vermutung, dass dic bedeckende oberflächliche Eiweissschicht, welche sich mit dem Silber verbindet, so dünn geworden sei, dass die Kerne durch sie hindurchragen, und erklärl dann das Zustandekommen der gewonnenen Bilder. Auch an serösen Häuten werden nach Schweigg er-Seidel die Kerne mitunter nur dadurch sichtbar, "dass sich um dieselben herum ein Silberniederschlag auf der Zelloberfläche einfindet". Der Unterschied zwischen „epitheloiden" und „keratoiden" Bildungen beruht seiner Meinung nach einzig auf der Dicke der aufgelagerten Eiweissschicht. „Dadurch, dass man dieselbe zum Schwinden bringt, kann man eine Form in die andere überführen." Diese Beobachtungen und Überlegungen zieht er zur Stütze seiner Annahme die Entstehung der sog. „Saftkanälchen“ des Bindegewebes betreffend heran. -

Der Streit der Meinungen und die zahlreichen gegen die Zuverlässigkeit der Versilberungsmethode ausgesprochenen. Bedenken verhinderten ihre weitere Ausbildung. Es kam zunächst darauf an, festzustellen, ob sie überhaupt ein brauchbares Hilfsmittel der mikroskopischen Forschung sei. Einen 
Historische Darstellung zur. Deutung des Wesens der Silbermethode etc. 111

längeren Zeitraum hindurch, bis 1867, brachte keine Arbeit in bezug auf die Versilberung technisch Neues und Wesentliches, während in diesen Jahren die eben angeführten Streitschriften exschienen. 1867 schien die Methode wenigstens als brauchbar anerkannt zu sein. Jetzt wurde auch neu experimentiert und das Verfahren modifiziert.

So untersucht C. F. M üller (1867, Lit. 80) die Hornhaut mittels Behandlung mit Silbersalpeter, zum Teil auf Anregung von $\mathrm{Eb}$ erth verbunden mit einer nachträglichen Behandlung in Jodsilber sowie einer nachträglichen Tinktion in Hämatoxylin. Vor allem sucht C. F. Müller sich ein Urteil zu bilden über die Hoyerschen Angaben (1865, Lit. 55), er erkennt in manchen Punkten dessen Anschauungen nicht an. Ferner führt $M \ddot{u} l l e r$ bezüglich der einschlägigen Arbeit von Schweigger-Seidel (1866, Lit. 104) an, dass er bei der Cornea niemals Anfass fand, an eine Entstehungsweise der weissen Lücken zu glauben, wie sie von $\mathrm{Schweigger-}$ Seidel angenommen wird. Schliesslich kommt M äller nochmals auf Hoyer zurück, indem er dessen Ansicht, dass die weissen Flecke der Comea nach Silberbehandluatg keine Kunstprodukte seien, auch als die seine bezeichnet. In der Deutung der sie durchsetzenden schwarzen Linien weicht er aber von Hoyer ah. Bej seinen weiteren Untersuchungen hat sich Müller auch der Injektionen mit Silbersalzlösungen und anderen Injektionsmassen bedient. Er kommt bei diesen schliesslich zil dem Schlusse, dass weder die Hornhautzellen selbst, noch die sie bergenden Lücken Membranen besitzen, und dass alle durch Injektion dargestellten Bahnen in der Substanz der Cornea, im Grunde genommen, Kunstprodukte sind. Die von den Corneazellen ausgefüllten kommunizierenden Lücken sind identisch mit den übrigen interfibrillären Räumen; ihre ganze Eigentümlichkeit besteht nur darin, dass sie eben die kommunizierenden Zellen beherbergen und daher bei ihrer Injektion ein 
nelzförmiges Kanalwerk darstellen; damit fällt auch die Bedeutung, die ihnen v. Recklinghaus en zuschreiben wollte, wenn er sie Saftkanälchen genannt hat.

Cohnheim (1867, Lit. 22) arbeitet bei Untersuchungen über Entzündung und Eiterung mit der Silbermethode am Hornhautgewebe. Als Grund dafür, dass die Behandlung mit. Argentum nitricum seine Erwartungen nicht ganz crfüllt, vermutet er den Umstand, „dass das Argentum nitricum, wie bekannt, nur ganz oberflächlich wirkt und nicht in das Gewebe eindringt." Er beschreibt die von ihm erzeugten Silberbilder. Dass mittels der Silbermethode die v. Recklinghausen. schen Bilder gewonnen werden, liegt für ihn (Gegensatz zu Sch weigger-S̈eidel) ausserhalb jeder Diskussion. Zu den Untersuchungsergebnissen von Federn (1866, Lit. 29) u. a. stellt er sich so, dass er sagt, durch das Argentum nitricum würden in Capillaren zwei verschiedene Liniensysteme zum Vorscheir kommen können, eines, welches in Gestalt geschlängelter Faden, wie es scheint, das Gefäss umwindet, und ein zweites, das einer epithelialen Kittsubstanz entspricht; seines Erachlens; bedarf es weiterer Klärung, unter welchen Bedingungen das eine oder das andere der Systeme durch silber kenntlich wird. Cohnheim beschreibt auch im Gefiassepithel Gebilde, die denen von anderen Autoren für andere epitheliale Häute beschriebenen sog, „Stomata" entsprechen. (Injektion der Gefässe mit Silberlösung.)

Ranvier (1867, Lit. 85) kombiniert die Silbermethode mit einer Goldmethode und färbt die Kerne noch mit Carmin (Hornhaut vom Frosch).

Legros (1868, Lit. 75) behandelt die Objekte, um das Nachdunkeln zu verhüten, mit einer Lösung von unterschwefligsaurem Natron. Ir behauptet, dass bei der Silberbehandlung die ganze \%elle eine schwache Färbung erhalte und die 
Historische Darstellung zur Deutung des Wesens der Silbermethode etc. 113

schwarzen Linien die Berührungsstellen zweier schwach gefärbter Zellen bezeichneten. Zum Beweise stellt Legros folgende Versuche an: Er giesst eine geringe Quantität Blut in eine Silberlösung, und es zeigen sich alsdann an den Berührungsstellen der Blutkörperchen die dunklen Linien; dann legt er kleine farblose und schwach gefärhte Glaskegelchen aneinander und sieht an der Berührungsstelle gleichfalls dunkel gefärbte Linien usw. Er ist der Meinung, dass die Versilberung des Epithels nur an lebenden Tieren und beim Menschen nur zum Beispiel an amputierten Gliedern ausgeführt werden könne.

In einem Beitrag zur Kenntnis der Imprägnationsmethoden der Hornhaut und ähnlicher Gewebe äussert Leber (1868, Lit. 73) sich, wie folgt: „Was die negativen Silberbilder betrifft, so scheint es sich dabei nur um eine Fällung des Silbersalpeters durch die Chlorverbindungen zu handeln, welche in der dic Hornhautgrundsubstanz durchtränkenden Flüssigkeit enthalten sind, mit nachfolgender Schwärzung des entstandenen Chlorsilbers unter dem Einflusse des Lichts;" er nimmt bezüglich der chemischen Natur des Niederschlags ferner Bezug auf $\mathrm{H}$ is (1863, Lit. 52) und sagt, dass mit dessen Erklärung auch die Tatsache übereinstimme, dass Goldchlorid, wenigstens für gewöhnlich, keine negativen Bilder liefert, weil es durch die in der Hornhaut enthaltenen Salzlösungen keine Fällung erleidet. Leber hat auch auf anderem Wege Niederschläge in der Hornhaut erzeugt und so den Silberbildern ganz ähnliche Präparate gewonnen.

G. Schwalbe (1868, Lit. 102) erklärt (nach einem Zitat von W erner, 1894, Lit. 121) das Zustandekommen der Silberlinien durch „Reduction der Silberverbindung durch die auf der Oberfläche der Membran befindliche dünne Flüssigkeitsschicht, die sich in den Furchen zwischen den Zellgrenzen am reichlichsten findet". (Betrifft vermutlich glatte Muskulatur, in der zitierten Arbeit jedoch nicht gefunden!) - 
Nach kurzer l'ause begannen aber wieder im Jahre 1869 mit einer Arbeit von Robinski die polemischen Schriften. Robinski (1869, Lit. 96) verwendet Lösungen von 1:500-1:1000, in denen er die Gewebe eine halbe Minute lang dem Licht aussetzt. $\mathrm{Er}$ ist autorisiert, Hartmanns (1864, Lit. 46) frühere Behauptung, dass die Silberzeichnungen 'lrugbilder seien, zurückzunehmen. Er protestiert gegen die Auffassung v. Recklinghausens.- bezüglich der Kittsubstanz und erinnert daran, dass auch Luftblasen und Fetttropfen an ihrer Begrenzung optische Effekte zeigen, ähnlich den Silberlinien. Robins.ki glaubt, dass anfangs die ganzen Flïchen der Zelle (,surface", gemeint ist wohl das periphere Protoplasma, das als äussere Begrenzung des Zellkörpers gegen die Nachbarzellen differenziert ist) leicht gefärbt werden und dass solche, sobald sie von der Kante gesehen werden (Seitenflächen) besonders dunkel erscheinen. Zur Erklärung des Zusammenhangs der Zellen liegt seines Erachtens kein Bedürfnis nach der Annahme einer Zwischensubstanz vor, es karn sich hier um eine Erscheinung handeln, analog dor Adhärenz zwëier platter, aneinander gelagerter Körper.

Grandry (1869, Lit. 42) kommt auf die früher von I. r ommann (1864, Lit. 36) beschriebene Erscheinung der Querstreifung der Achsencylinder nach Silberbehandlung zurück. Er behandelt Teile verschiedener nervöser Organe nach ausführlich beschriebener Technik möglichst bald nach dem 'ode, wenigstens so früh, dass eine bemerkenswerte kadaveröse Veränderung noch nicht anzunehmen ist; diesen Umstand hält er für wichtig. Grandry beschreibt die Erscheinung für die Achsencylinder im wesentlichen entsprechend Frommanns (1864, Lit. 36). Befunden, sagt, dass das Silbernitrat auf gewisse Teile des Achsencylinders eine "action speciale" habe, andere allenfalls nur schwach angreife, und schliesst aus seinen Beobachtungen bezüglich des Baues des Achsencylinders, dass 
er aus zwei physikalisch und chemisch differenten Substanzen, dic vollkommen voneinander getrennt sind, bestehe, $d$. h. dass er wahrscheinlich von übereinander gelagerten Scheiben, die durch anders geartete Substanz getrennt sind, zusammengesetzt wird. Er sagt aber, dass weitere Untersuchungen noch angestellt werden müssen, „pour déterminer rigoureusement l'élément fondamental du cylindre de l'axe". Bezüglich der Nervenzellen und ihrer Fortsätze weichen seine Befunäe von denen Frommanns (1864, Lit. 36) ab, was wohl als Grund die verschiedene Technik hat. Während Frommann die Zellkörper g]eichmässig braun gefärbt, die Kerne ungefärbt, die Zellfortsätze längsgestreift fand, aber keine Querstreifen beobachtete, kann Grandry eine sehr deutliche Querstreifung des Zellkörpers und der Fortsätze erkennen. Er schliesst aus seinen Wahrnehmungen bezüglich des Baues der Nervenzelle, dass sie aus zwei physikalisch und chemisch differenten Substanzen bestehe, $d . h$. dass auch hier vielleicht eine Anordnung in Scheiben vorliege, wie beim Achsencylinder, und dass die Zellen und die Achsencylinder nach Silberbehandlung unter gewissen Bedingungen die gleichen Charaktere bieten. (Der Autor weiss seine Auffassung wenigstens zum Teil gestützt durch die Ansicht Schwanns.)

In einer Arbeit „Uber die Grundsubstanz und die Zellen der Hornhaut des Auges" kommt Schweigger-Seidel (1869, veröffentlicht 1870 , Lit. 105) auf seine früheren Besprechungen zurück. Er findet, dass seine früheren Behauptungen keine Widerlegung erfahren hätten trotz verschiedener Aussprachen gegen dieselben, und sucht sie nun zu erweitern und durch neue Beobachtungen an diesem bisher von ihm unberücksichtigten Objekt, der Hornhaut, zu stützen. Er prüft unter anderem die Frage, inwieweit die früher (1866, Lit. 104) von ihm gegebene Erklärung der Silberwirkung, die er als eine koagulierende Wirkung des Silbersalzes auf eine formlose 
mehr oder weniger fest anhaftende dünne Schicht einer eiweissartigen Substanz, infolge deren Reduktion kanalartige Zeichnungen in einer gefärbten Grundsubstanz auftreten, charakterisiert hat, auf die Hornhaut passe. Zunächst bespricht er im Eingehen auf die Arbeiten von $\mathrm{H}$ is (1862, Lit. 52) und Leber (1868, Lit. 73) und auf eine Abhandlung von M. Traube (1867, I'it. 120) über sog. „Niederschlagsmembranen" die Möglichkeiten des Zustandekommens der HornhautSilberbilder und die Vermutungen bezüglich der chemischen Natur der Niederschläge in der Cornea. Ihm scheint die Eiweissnatur des Silberniederşchlags dưrch viele Umstände sichẹ gestellt. Durch eingehende Betrachtungen kommt er zu der Vorstellung, „dass die Substanz der strahligen. Körperchen es selbst isl, welche hei bestimmter Fixierung die negativen Silberbilder liefert.", die strahligen Körperchen verschwinden hierbei scheinhar. Sie können wieder sichthar werden durch Behandlung der frisch versilberten Hornhäute mit Chlorverbindungen, wodurch man die negativen in die positiven Bilder ïberführt. Nach Schweigger-Seidels Ansicht tritt hierbei eine bestimmte Zerlegung des extracellulär gelegenen Silberalbuminats ein, er sagt: „In Kochsalz löst sich Chlorsilber nur schwer, Silberalbumin leicht. Die Lösung des ersteren verändert sich :um Lichte nicht, die des letzteren bräunt sich. Bringt man versilberto. Hornhaut, alsogleich in stärkere Kochsalzlösung und setzt sie unter dem Deckgläschen dem Lichte aus, so bräunt sich die Substanz diffus, besonders die Kerne, .... Wird Kochsulz in geringen Quantitäten dem Silberalbumin zugesetzt, so wird dasselhe zwar nicht gelöst, aber in einer Weise zerlegt, die unser volles Interesse beansprucht. Man wäscht den in Eiweisslösungen erzeugten Silberniederschlag rein aus, setzt die etwa 10 fache Menge einer 1 proc. Kochsalzlösung hinzu und erhält eine Verlindung des Chlors mit Silber, welche sich am Lichte schwärzt, während ein Eiweisskörper, frei von Silber 
in Lösung übergeht und als solcher durch die bekannten Mittel nachgewiesen werden kann. Während Silberalbumin in destilliertem Wasser ausser der Farbenveränderung keine Umsetzung erleidet, wird es durch Kochsalz in der angegebenen Weise gespalten; in dünner Salzsäure quillt es, wird unter Umständen fast gallertartig und bildet schliesslich eine fein vertheilte mit Chlorsilberkörnchen vermischte durch Filtriren nicht mehr abscheidbare Substanz. Das Freiwerden der Eiweisssubstanz und das Aufquellen und Erweichtwerden des Silberniederschlages ist für uns desshalb von besonderer Wichtigkeit, weil dieselbe Zerlegung eintritt, wenn man ... aus den sog. negaliven Silberbildern die positiven erzeugt.... Unter der Annahme, dass der Hornhautniederschlag Chlorsilber, kann man, wie aus den Angaben von $H$ is selbst folgt, die Umwandlung der negativen in die positiven Silberbilder nicht erklären." SchweiggerSeidel glaubt für die Cornea durch seine Untersuchungen den Nachweis zu erbringen, ,dass es ein und dieselbe Substanz ist, welche in ungleicher Verbindung mil dem Silber sowohl die negativen a's die positiven Bilder liefert, and dass die letzteren aus den ersteren sich bilden durch eine Umsetzung und Umlagerung der von Argentum nitricum primär niedergeschlagenen Eiweissmassen." Seine Deutung der Silberbilder steht nicht im Widerspruch mit dem Ergebnis anderer damals geübter Präparationsmethoden.

G. Schwal be (1869, veröffentlicht 1870 , Lit. 103) gelangt durch Untersuchungen mit Silbersalzlösungen besonders am Endothel des Perichorioidalraumes zu ähnlichen Resultaten wie A uerbach und Schweigger-Seidel. Er nimmt Stellung gegen die Auffassung v. Recklinghausens, dass durch die Versilberung eine "Kittsubstanz" dargestellt werde, da man auch bei den Endothelmembranen, denen eine Kittsubstanz mangele (Perichorioidalraum-Endothel, Endothel der Darmlymphcapillaren, End̈othel der Gelenkkapseln und der 
Tenonschen Kapsel), immer die schönsten Silbernetze erhalte. Ferner bringt $\mathrm{Schwalbe}$ an ein und demselben Präparate die ungefärbte beziehungsweise diffus gefärbte Kittsubstanz und die oberflächlichen schwarzen Silbernetze zur Anschauung, sowohl beim einschichtigen Endothel seröser Häute (von Embryonen oder jungen Tieren) wie auch beim geschichteten Epithel (Cornea vom Frosch), er unterscheidet die Bildung oberflächlicher schwarzer Nelze, wahrscheinlich auf einem Niederschlag, d. h. reduziertem Metall, beruhend, und die braune Färbung der Kittsubstanz in den tieferen Schichten, erst viel später eintretend und wohl auf der Bildung einer sich durch längere Belichtung bräunenden Verbindung des Silbers mit der Kittsubstanz beruhend. Für diese homogene Bräunung der Kittsubstanz hält er die Bezeichnung als Niederschlag für nicht zulässig. Bei seinen weiteren Betrachtungen schliesst er sich im wesentlichen neben Schweigger-Seidel vor allem A u e r bach an, auch bezüglich der Schaltplättchen oder Stomata. Hinsichtlich der Erklärung der von Hueter (1866, Lit. 57) beschriebenen Silberbilder stimmt er vollkommen Schweigger-Seidel bei. „Epithelioides" und keratoides Bindegewebe' lassen sich durch die Silberimprägnation fast von jeder mit Endothel bekleideten Fläche gewinnen." Er erhält beispielsweise den $\mathrm{Hu}$ eter schen ganz entsprechende Bilder von dem Endothel der Lymphsäcke des Frosches und dem des Perichorioidalraums des Schweins.

F el t z (1870, Lit. 30) hingegen erklärt wieder das Zustandekommen der Silberbilder als ein ,résultat d'accidents de surface ou de modalités operatoires". Auf Häutchen von Eiweiss, Collodium usw. entständen bei Behandlung mit Silber dieselben NetzZeichnungen, ebenso auf photographischem (also mit Silbersalzen präpariertem) Papier, das dem Licht ausgesetzt wird. Er verwirft das Silbernitrat nicht absolut als Mittel für die Be- 
Historische Darstellung zur Dentung des Wesens der Silbermethode etc. 119

handlung der Epithelien, weist aber ausdrücklich auf die vorerwähnten .Umstände.

Robinski (1871, Lit. 97) stellt in einer Arbeit „Die Kittsubstanz auf Reaktion des Argentum nitricum" eingehende mikroskopische und mikrochemische Untersuchungen über diesen Gegenstand an. Zunächst erwähnt er, dass von $K \ddot{~ u ̈ h n ~} \mathbf{e}$ (1870, Lit. 69) als einzige, aber ganz charakteristische, die „,Kittsubstanz" auszeichnende mikrochemische Reaktion die „merkwürdige" Eigenschaft angegeben sei, sich leicht mit Silbersalzen unter gewissen Umständen zu imprägnieren. Er wiederholt im wesentlichen seine bereits früher (1869, Lit. 96) geäusserten Ansichten, vor allem nimmt er entschieden Stellung gegen die Annahme einer „Kittsubstanz" auf Grund der Schwärzung durch Höllenstein. Ferner führt Robinski an, dass bei Sehnen, denen nach anderen Autoren eine Kittsubstanz zwischen einzelnen isolierbaren Fibrillen zukomme, durch Argentum nitricum keine Kittsubstanz gefärbt werde. Auch gegen die Auffassung der Silberbilder beim Bindegewebe als Ausdruck von "Saftkanälchen" spricht sich der Autor entschieden aus, er erhält auch auf blossem Glase mit Hilfe von Filtrierpapier, das mit Silberlösung durchtränkt ist, unter Einwirkung des Lichtes nach Hinwegnahme des Papiers entsprechend der Technik v. Recklinghausens Zeichnungen, die ganz den von diesem und anderen beschriebenen Saftkanälchen und Lymphgefässen ähnlich sind. Er sagt schliesslich: „Nur durch physikalische, optische Gesetze sind einige Erscheinungen, ... zu erklären, man kann aber nicht besondere „merkwürdige“ chemische Reaktionen darauf gründen oder gar neue chemische' Substanzen damit demonstrieren."

S everin (1871, Lit. 106) warnt vor Trugschlüssen. Auch ihm kommt der Verdacht, dass es sich bei den Silberlinien um Kunstprodukte handelt. Er behandelt zur Aufklärung intermuskuläres Bindegewebe aus dem Schenkel des Frosches mit: 
schwacher Silberlösung, es entstehl ein Netz von Silberlinien, in dessen Maschen keine Kerne nachweisbar sind. Er sagt. dann: „Es hat sich nun gezeigt, dass auf Membranen, denen doch gewiss Niemand ein Pflasterepithel octroyiren wird, durch das Silber auch derartige Netze erzeugt werden. . " Er hält. es also für nicht statthaft, ohné weiteres vom Auftreten der Silbernetze auf das Vorhandensein eines Epithels zu schliessen.

Ausgehend von der Überlegung, dass es sich ... wie A uerbach es vermutet - bei den Silberlinien wohl un den Ausdruck mikroskopischer Rinnen handelt, versucht Severin durch kurzes Eintauchen des Mesenteriums (Frosch) in schwache Carminlösung und nachträgliches Fällen des Carmins durch Essigsäure in diesen Rinnen eine Markierung hervorzurufen, seine Experimente bleiben aber erfolglos. Danach versucht er in entsprechender Weise Eisenchlorid, das er, soweit es in die Rinnen eingedrungen (nur durch das nachfolgende kurze $\Lambda$ bspülen von der Zellenoberfläche entfernt), mit Ferrocyankaliurn. nachzщweisen bemüht ist, und gelangt zu günstigen Ergebnissen. Er beschreiht seine Melhode genau. Die Frage, wie die Eisensalzlösúng wirkt, ob die Voraussetzung gefüllter Rinnen zutrifft, oder ob eine Verbindung mit einer Kiltsubstanz anzunehmen ist, prüft er durch Umkehren des Verfahrens. Bei der ersten Vermutung glaubt Se verin bei Behandlung erst mit Ferrocyankaliurn-Lösung and nachfolgendem Linbringen in Eisenchloridlösung das gleiche Resultat erwarten zu dürfen; wie vorher bei umgekehrter 'Technik, ,existirt jedoch eine Kittsubstanz, zu der das Ferrocyankalium keine Verwandtschaft besitzt, so wird dasselbe bei der nachträglichen Abspülung entfernt und die Kontouren der Zellen treten nicht hervor". Die Ergebnisse seiner Versuche sprechen ihm mehr für die Annahme einer Kittsubstanz, sie scheinen aber nicht eindeutig. Severin wagt auch noch aus seinen Beobachtungen gewisse Schlüsse auf die Natur des Bindemittels 
Historische Darstellung zur Deutung des Wesiens der Silbermethode etc. 121

zu ziehen. Er bemerkt, dass seine Eisenchlorid-Ferrocyankalium-Methode vor dem Silberverfahren manche Vorteile biete (Vermeidung der Färbung des Protoplasmas oder des Kernes, Vermeidung der Schrumpfung der Zellsubstanzen).

Nach dieser zweiten Periode der theoretischen. Diskussion dachte man wieder über Verbesserungen der Technik nach. Mit dem Beginn der siebziger Jahre hört die Polemik im wesentlichen auf. Die wenigen später gegen die Versilberungsmethode erhobenen Stimmen konnten ihr unmöglich noch Abbruch tun. Jetzt erschienen neben den weiteren kritischen Betrachtungen neue Vorschläge für Modifikationen.

Hansen (1871, Lit. 43) rät (wie vor ihm schon Ranvier, 1868, Lit. 85), die Versilberung and Vergoldung zu kombinieren.

Genersich (1871, Lit. 38) bedient sich bei der Untersuchung der Saftkanälchen der normalen und entzündeten Cornea auch der Versilberung. Die durch Silberbehandlung hervorgerufenen Bilder sind in entzündelen Hornhäuten andere, als in den normalen, das sprichl seines krachlens wohl gegen dic Annahme, dass die Sillerbilder Kunstprodukte sind. Er transplantiert versilberte Hornhäute vom Frosch, die lange in Glycerin gelegen haben, nach Behandlung in Kochsalzlösung in den Lymphsack eines Frosches -und stellt an den diesem wieder entnommenen Corneen innerhalb der durch die Zeichnung begrenzten Kanäle amöboid wandernde Zellen fest. G e n e r s i ch glaubi, dass diese Beobachtung vorzüglich geeignel ist, zu beweisen, „dass die durch Silberfärbung erhaltenen Figuren wirklichen Hohlräumen entsprechen, welche durch Zweigkanäle mit einander communiciren, und in welchen sich Wanderzellen bewegen können". 
Sobor off (1872, Lit. 110) ist wieder ein Anhänger der v. Reckling h a u s n schen Lehre. Für seine Untersuchungen am Epithel normaler und ektatischer Venen bewährt sich ihm die Chrzonszczewskysche Methode (Injektion einer Mischung von Silberlösung und Gelatine) (1865, Lit. 18) nicht (Veränderung des Silbersalzes schon in der Gelatine), dagegen leistet ihm die Methode von Slawjansky (Injektion erst der Silber- und alsdann der Gelatinelösung) (1867, Lit. 109) gufe Dienste. Er bespricht seine Technik ausführlich. Bezüglich der Deutung der Silberbilder sagt Sobor off: „Dass es eine besondere, die Epithelzellen mit einander verbindende Substanz gibt und dass dieselbe vornehmlich vom Silber gefärbt wird, davon kann man sich bei sorgfältiger mikroskopischer. Untersuchung leicht überzeugen, oft sieht man, wie eine unversehrte Epithelzelle sich absondert und ihrer Nachbarin einen schwarzen Streifen als Anhängsel zurücklässt - andererseits kann die gleichmässig braune oder völlig dunkle Färbung, sowie das leichte Durchschimmern in der. Mitte der Epithelzellen dem Beobachter kaum noch irgendwelchen Zweifel darüber lassen, dass auch die Zellen selbst gefärbt werden." Sobor off führt seine Untersuchungen teils an noch warmen Leichen erwachsener Menschen aus, teils an bereits erkalteten Kadavern 5-10 Stunden nach dem Tode, wo die Leichen bereits Spuren der eingeleiteten Verwesung zeigen. Da überall die Versilberung gelingt, so schöpft er die tbberzeugung von der Wahrheit der Aussagen Küsters (Lit. 70), der auch sehr schöne Silberbilder (Lymphgefässepithel) erhielt an Geschwülsten mehrere Stunden nach der Exstirpation,. selbst nach mehr als 48 Stunden, und andererseits von der Haltlosigkeit der Meinung Lègros' (1868, Lit. 75).

Reich (1873, Lit. 93) injiziert zur Versilberung des Getăssendothels die Silberlösung direkt in die Gefässe und sendet spältel eine warme Gelatinelösung nach. Die Unregelmässigkeit 
der Silberlinienfelder der F e de rn schen Bilder (1866, Lit. 29) erklärt er durch den Umstand, dass bei dessen Arbeiten die nachträgliche Gelatineinjektion noch nicht geübt wurde. Bei prall gefüllten (Gelatine) Gefässen hat Reich immer regelmässige Verhältnisse gefunden. Fedeins Angabe, dass die braunen oder schwarzen Linien im Querschnitt an den Gefässcapillaren drehrund sind, kann $\mathrm{R}$ e i $\mathrm{ch}$ vollkommen bestätigen. Nach seinen Beobachtungen zeigen die Silberlinien an Epithelien anderer Orte auch überall denselben Charakter. Dieser Umstand spricht dafür, dass die Linien auch in den Capillaren, wie an diesen Epithelhäuten, als Zellgrenzen aufzufassen sind. Dann sagt Reich: „Aber :Eins geht freilich aus $F$ edern s Beobachtungen hervor: man kann sich nicht schlechthin mit dem Ausdrucke „gefärbte oder versilberte Kittsubstanz" abfinden. Eine solche müsste in platten, lamellenartigen Schichten vorkommen. Hier hat offenbar jede Zelle, wenn man sie sich isolirt vorstellt, eine Halbrinne, die mit der correspondirenden der anderen einen drehrunden Canal bildet. In diesem mag eine feste Substanz liegen; aber man hat keinen bestimmten Grund, sie Kittsubstanz zu nennen, da man nicht weiss, ob die Zellen nicht auch abgesehen von ihr fest miteinander zusammenhängen. Es ist aber auch ebenso möglich, dass sich in dem Canale Flüssigkeit befindet, ja es hat dies eine gewisse Wahrscheinlichkeit.“. „Es ist bekannt, dass Silberlösungen, wie Lösungen anderer Salze, die mit Eiweissstoffen Niederschläge geben, sich zwar leicht in Flüssigkeiten verbreiten, sich aber schwer in die feste Substanz der Gewebe imbibiren, wahrscheinlich weil sie gleich an der Oberfläche durch die Berührung mit der organischen Substanz zersetzt werden. So sah ich auch in meinen Versuchen die Silberlösung in den Arterien in die Zwischenräume der Muskelfasern der Media eindringen, die Faserzellen selbst aber ungefärbt bleiben. So wäre es nun auch möglich, dass die Silberlösung den flüssigen 
Inhalt eines Canalsystemes zwischen den Epithelzellen färbt, die feste Substanz der Zellen aber noch ungefärbt lässt." Rejch ist bestrebt die Lage der Silberlinien oder Silberfäden bezüglich der Zellen mit grösserer Bestimmtheit als bisher festzustellen. Genauere und sichere Ermittelungen sind ihm jedoch nicht gelungen. Er bemerkt noch, dass ihm auch eine 24 Stunden nach dem Tode gemachte Silberinjektion des Hundeauges noch gute silberbilder gab. An guten und dünnen Querschnitten der Venae vorticosae spricht nach $\mathrm{Reich}$ alles zugunsten der intercellulären Lage der Fiden; , ,auch hier lassen sich dieselben nicht abstreifen oder isoliren, ohne dass die Verbindung der Zellen aufgehołen wird". Von der Oberfläche eines versilberten Froschmesenteriums gewinnt $R$ ei $\mathrm{ch}$ einige von den äusserst platten, absolut ungefärbten Zellen isoliert abgelöst, bei deren Untersuchung mit starkem System sich ergibt, „dass diese Zellen am Rande mit schwarzen drehrunden Fäden umsäumt" sind. An einer Zelle, welche nahezu senkrecht gestellt ist und flottiert, sieht man den drehrunden Faden dem schmalen Rande aufliegen und einen Teil desselben als soliden Strang schwach bogenförmig in die umgebende Flüssig. keit hineinragen. Reich kommt so schliesslich zu der Annahme, dass die schwarzen Silberfäden der ,Ausdruck einer geschwärzten Substanz zwischen Zellen" sind. Er meint, dass F edern (1866, Lit. 29) dieselben silberfäden vor sich hatte, und weicht nur in der Deutung von diesem Autor ab. Schliesslich weist $\mathrm{Reich}$ noch darauf hin, dass man die geschwärzte Zwischensubstanz zwischen den Zellen isoliert bekommen kann, und sagl, dass es auch nicht selten gelingt, Präparate zu bekommen, in denen die Zwischensubstanz stellenweise isoliert als Netz zurückbleibt, aus welchem die Zellen ganz oder teilweise herausgefallen sind; „die schwarzen Fäden des Netzes mit regelmässigen sechseckigen Maschen (Chorioidea) hängen hier continuirlich mit denen zusammon, welche zwischen 
noch an Ort und Stelle liegenden Zellen laufen. Die isolirten Fäden sind drehrund im Querschnitt und mässig biegsam. Nie lassen sie sich von den noch zusammenhängenden Zellen ablösen, weil sie èben zwischen ihnen, nicht auf ihnen liegen".

Ro uget (1873, Lit. 98) behandelt die Gewebe wiederholt. mit dünnen Lösungen von Silbernitrat und schliesst daran eine Nachbehandlung mit Glycerin (Belichtung) und einer Mischung von Ammoniakcarmin, Glycerin und Alkohol. Auf diese Weise sollen Zellgrenzen (Zellinterstitien) und Zellsubstanz gleich nach der Silberbehandlung deutlich erscheinen.

v. Pfungen (1873, Lit. 83) empfiehlt, wie vor ihm schon andere Autoren, die Kombination der Gold- und Silbermethode. Er bedient sich derselben zur Untersuchung entzündlicher Prozesse in der Cornea. Er findet eigentümliche Silberstreifen ,in den Zellen" der Hornhaut, die er als Kittsubstanzstreifen deuten möchte, und nimmt auf Grund seiner so gemachten Beobachtungen bei entzündeten Corneen eine Teilung der fixen Hornhautzellen an:

$\Lambda$ lferow, Serge (1874, Lit. 8) zieht organische Silbersalze dem Höllenstein vor (Silberpikrat, -acetat, -citrat und besonders -lactat). Besonders benutzt er milchsaure Silberlösung, der etwas freie Säure zugesetzt wird. Dies letztere empfiehlt sich deshalb, weil dadurch alle Niederschläge mit Ausnahme des Silberalbuminats und Silberchlorürs zerstört werden, das Präparat also viel klarer und schöner wird. Im übrigen verfährt man mit dem Silberlactat wie mit dem Silbernitrat.

Skworzow und Adamkiewicz (1874, Lit. 108 u. 5) handeln über die. Deutung der Silberbilder im Epithel und Endothel. Skworzow hält die dunklen nach Silberbehandlung zwischen den Zellen auftretenden Linien nicht durch eine Kittsubstanz, die er überhaupt anzweifelt, bedingt; vielmehr stellen sie seines Erachtens Abzugsrinnen für die seröse Flüssigkeit dar. Die v. Reck] ing ha usen schen Saftkanälchen sind 
nach ihm durch das Silber hervorgerufene Kunstprodukte. A damki ew ic z dagegen glaubt, dass die dunklen Silberlinien der Gefässe einer Kittsubstanz ihre Entstehung verdanken, welche dicht unter dem Endothel liegt und dies mit der Media verbindet. Die Linien verhalten sich wie Silberalbuminate und sind gegen konzentrierte Säuren resistent.

Stricker (1874, Lit. 115) gibt an, dass die Imprägnation der Hornhaut am lebenden Tier andere Bilder ergibt, als die an der ausgeschnittenen toten Cornea. Bei der ersten Methode, die er durch Aufträufeln der Silberlösung ausführt, werden die Hornhautkörperchen mit ihren Ausläufern als freie granulierte Massen hervorgehoben. Bei der Färbung der toten Hornhaut aber heben sich nur die Saftkanälchen der diffus braun gefärhten Grundsubstanz hervor.

Im Jahre 1875 giht dann Ranvier (Lit. 86) in seinem lehrbuch der Histologie ausführliche Vorschriften ïber die Silberbehandlung. Er bezeichnet die Silbermethode als ein Verfahren, das bei richtiger Anwendung die besten Resultate gebe. Das Silbernitrat könne entweder in Lösung oder - seltener in Substanz angewandt werden. Die Anwendung des festen Silbernitrats empfiehlt er für die Cornea und das Bindegewebe, dagegen nicht für das Epithel; bezüglich der Technik macht er nähere Angaben. Bei der Anwendung des Silbernitrats in Lösung hält $\mathrm{R}$ anvier die Beachtung gewisser Vorsichtsmassnahmen, z. B. Ausspannen von Membranen, Abspülen mit destilliertem Wasser vor der Behandlung mit der Silberlösung zur Entfernung von Albuminaten und Blut, beständiges Bewegen in der Silbersalzlösung für angezeigt zwecks Vermeidung der Bildung von Silberchlorür und Albuminat an der Oberfläche. Er gibt genauere Regeln für diese Behandlung und die Herstellung von Dauerpräparaten (Glycerin- und Canadabalsampräparate sowie trockene Aufbewahrung). Es kann auch das mit Silber imprägnierte Gewebe noch mit Goldchloridlösung 
behandelt werden. Man sieht die Zellen durch Linien voneinander getrennt, die mehr oder weniger dunkelbraun, respeklive bei nachträglicher Goldchloridbehandlung violett gefärbt sind. Die Zeichnung beim Endothel entsteht durch die „Reduktion des Silbers in dem intercellulären Kitt“. Zur Sichtbarmachung der Kerne benützt Ranvier eine Pikrocarminlösung.

Durch Verwendung des Silbernitrats bei der Untersuchung der markhaltigen Nervenfasern erhält Ranvier Einblick in. wichtige Einzelheiten ihrer Struktur. Er wendet zwei Verfahren an, je nachdem er dünne oder dicke Nerven untersucht, und gibt genauere Regeln für die Anwendung der Silberlösung. Er entdeckt mit Hilfe seiner Technik die bekannten, nach ihm benannten kleinen Kreuze. Ferner gibt Ranvi er Rezepte zu. Infektionen an (reine Silbernitratlösung, Gemisch von Leimund Silbernitratlösung, erst Silbernitrat-, dann Leimlösung).

Tourne ux und Herrmann (1876, Lit. 119) empfehlen. eine Modifikalion der Technik und die Verwendung künstlichen Lichtes.

An Stelle des Silbemitrats verwendet H o y e r (1877, Lit. 56) eine Lösung von salpetersaurem Silberammoniak. Die auf von ihm geschilderte Weise hergestellte Lösung lässt die umlỉegenden Gewebe ungefärbt und hebt um so deutlicher die Endothelzeichnung hervor.

Eosin und Silber wird von J. Renaut (1877, Lit. 94) bei der Untersuchung der Sehnenzellen kombiniert. Er sagt von diesen, dass sie in Kettenform aneinander gelagert und voneinander gesondert sind durch ein Cement, den man leicht mit Silber imprägnieren kann.

R u mpf (1878, Lit. 99) beschäftigt sich mit der Histologie der Nervenfasern und des Achsencylinders. Er benützt die Löslichkeit des letzteren im Körper nach doppelter Durchschneidung und behandelt so vom Achsencylinder befreite 
Nervenfasern mit $\Lambda$ rgentum nitricum-Lösung. Es zeigen sich Ranviersche Kreuze und Frommannsche Linien, durch Kontrollpräparate stellt er sicher, dass der Achsencylinder wirklich verschwunden war. Daraus folgert er, dass es sich bei der Behandlung mit Silbernitrat nur um die Darstellung nicht dem Achsencylinder angehöriger, sondern anderer Gehilde handeln könne.

v. Morochowetz (1878, Lit. 79) untersucht ebenfalls die Wirkung des Silbernitrats auf die Nervenfaser. Er hält das Ranviersche Kreuz für eine scheibenförmige Platte mit durchgesteckter Achse und erklärt mit Hilfe dieser Auffassung die immer etwas verschiedenen Bilder. Der Querbalken dieses Kreuzes stellt die „ringförmige Grenze zweier Abschnitte der Schwàn n schen Scheide" dar, die er "für eine der häufigen silbergefärhten Kittlinien" halten möchte. Die Frommann'sche Querstreifung ist für v. Morochowetz zweifellos eine durch Niederschläge in ringförmigen Räumen uın den Achsencylinder bedingte Erscheinung.

K och (1878, veröffentlicht 1879, Jit. 61 , s. auch G erlach, 1878, Lit. 39) arbeitet über die Marksegmente der doppeltkonturierten Nervenfasern und deren Kittsubstanz. Hierbei hedient er sich auch einer Modifikation der silbermethode. Nach Zerzupfen der Nervenfasern in $1 \% 2 \%$ iger Kochsalzlösung bringt er sie in eine sehr schwache Silberlösung, ebensogut können die Nerven auch gleich in der Silberlösung zerfasert werden. Nach kurzem Verweilen in dieser werden die Nervenfasern rasch ausgewaschen und zwei Tage in Chloroform gelegt, Nachbehandlung mit weiteren Färbemitteln, wie Pikrocarmin oder Anilinrot, und. Einschluss in Glycerin oder Canadabalsam ist möglich. Er beschreibt genauer das Bild solcher Präparate, in welchen die von ihm angenommene Zwischensubstanz der Marksegmente als Trichter. kenntlich werden soll. Schliesslich geht $\mathrm{Koch}$ noch kurz auf die Frage 
Bistoriscbe Darstellung zur Deutung des Wesens der Silbermethode etc. 129

nach der Beschaffenheit, $\mathbf{d}$. $\mathbf{h}$. der Konsistenz dieser zwischen den Marksegmenten gelegenen heterogenen Substanz ein. Er kommt zu dem Schluss, dass diese Trichter nicht membranöse Beschaffenheit (wie andere Autoren innahmen) haben, sondern eine weichere Kittsulsstanz darstellen.

Zum Ausspannen der Haut und anderer Objekte werden von G. und F. E. Hoggan (1879, Lit. 54) besondere Kautschukringe angewandt, die Autoren vereinigen im übrigen die Silber- mit der Goldimprägnation.

v. Thanhoffer (1880, Lit. 117) sowie seine Schüler Krauss und Oppilz modifizieren die Technik bezüglich der Reduktion des Metallsalzes, die sie nicht allein dem Licht überlassen.

Engelmann. (1880, Lit. 28) erachtet durch die nach Silberbehandlung bei markhaltigen Nervenfasern entstehenden Bilder eine Dikontinuitäl des Achsencylinders für erwiesen. Er spricht von Konlinuitätstrennungen des Achsencylinders an den Einschnürungen als den regelmässigen Befunden bei den Silberpräparaten. Er schildert eingehender die etwas wechselnden Bilder und zeigt ferner, dass der Achsencylinder gerade in der die Einschnürung quer halbierenden Ebene gegen Silberlösungen wesentlich dasselbe charakteristische Verhalten zeigt, welches seit v. Recklinghausen von den Berührungsflächen der verschiedensten Zellen bekannt ist. Es tritt nämlich hier unter der Einwirkung jener Lösungen in der Regel eine seines Erachtens die ganze Dicke des Achsencylinders ununterbrochen durchsetzende braune Schicht auf, keineswegs färbt sich, wie andere behaupten, nur ein ausserhalb des Achsencylinders gelegener Ring. Im Gegenteil sind speziell bei mässigen Graden der Einwirkung die Fälle gar nicht selten, wo ausschliesslich die Achsencylindersubstanz Sitz der Färbung ist. Der zwischen $\mathrm{Schwann}$ scher scheide und Achsencylinder oft entstehende Raum ist im Niveau des Schnürringes 
ausserordentlich häufig der Sitz słarker Niederschläge, sie bilden zu einem wesentlichen Teil den horizontalen Schenkel der bekannten Silberkreuze. Sehr häufig ist es nach Ausbildung des Niederschlages unmöglich, zu erkennen, wieviel von ihm auf den Achsencylinder, wieviel auf seine Umgebung komme. Engelmann erblickt als hauptsächlichste Ursache für das Zustandekommen der Kontinuitäts-Unterbrechung eine aktive Schrumpfung der Achsencylinder. Nach seiner Anschauung ist als interfibrilläre Substanz beim Achsencylinder wahrscheinlich eine seröse Flüssigkeit anzunehmen, in der die Fibrillen gleichsam flottieren.

Nach Z o erner (1881, Lil. 123) findet sich zwischen den einzelnen Epithelzellen „eine in Wasser lösliche Eiweisssubstanz", die durch salpetersaures Silberoxyd schwarz gefärbt wird und so die Mosaik der Zellen schön hervortreten lässt. Bei einer Bemerkung über die als Stomata benannten Gebilde sagt er, sie enthielten „nur jene Eiweisssubstanz“.

Sattler (1882, Lit. 100) empfiehlt den Höllenstein in Substanz für die Erforschung des Epithels. Er reduziert. in mit Essig- oder Ameisensäure leicht angesäuertem Wasser bei Sonnenlicht. Nach Sattle r bleibt hei dem vorderen Corneaepithel vom Frosch die intereclluläre Kittsubstanz klar, während das Protoplasma der Zellen gewöhnlich eine hellbis dunkelbraune Färbung erhält, der Kern bleibt hell mit scharfen Umrissen, das Kernkörperchen wird ähnlich wie das Protoplasma bräunlich gefärbt, jedoch heller. Er betont das scharfe gute Hervortreten nur einer, und zwar der am meisten oberflächlich gelegenen Zellenschicht und sagt, dass die dunkle Färbung der Zellen auch auf ihre Verbindungsbrücken, die Bizzozeroschen Linien (Intercellularbrücken Pfitzners), übertragen wird, so dass man an solchen Silberpräparaten vortrefflich die leitersprossenähnliche Verbindung der Zellen untereinander demonstrieren könne. Ferner bringt die Methode seines 
Erachtens eine amöboide Bewegungsfähigkeit der Zellen und Kerne sicher und-klar fixiert zum Ausdruck und ist in mancher Beziehung auch für die Demonstration der Kernteilung verwendbar.

Solge r (1883, Lit. 11.2) empfiehlt die kombinierte Anwendung von Osmiumsäure und Argentum nitricum, manchmal fügt er auch noch etwas Salpetersäure hinzu. Periphere markhaltige Nerven zeigen bei Behandlung mit dieser Mischung bei schmaler oder breiter Versilberung des Querschenkels des bekannten Ranvierschen Kreuzes keine oder eine erst allmählich hervortretende Bräunung des Längsschenkels. Bei $\mathrm{Zu}$ satz von etwas Salpetersäure tritt dagegen die Silberimprägnation des Längsschenkels in den Vordergrund, während die des Querschenkels fehlt oder erst allmählich erscheint. Bei den Endothelien werden auch Versuche angestellt. Bei Applikation von Osmiumsäure vor Argentum nitricum und bei $\mathrm{Zu}$ satz von Salpetersäure zeigt sich eine Verzögerung der Reduktion. Im tberschuss zugesetzt, löst Salpetersäure den braunen Niederschlag auf. Solg e r spricht von der Behandlung mit Argentum nitricum als von einer Reaktion auf eine Kittsubstanz an den Verlötungsstellen der Scheidensegmente beziehungsweise an den Grenzen der Endothelzellen. Von Vorteil bei dem Verfahren ist auch die gleichzeitig fixierende Wirkung der Osmiumsäure.

Bezüglich der Behandlung von Seetieren mit Silberlösungen macht Harmer (1884, Lit. 45) Angaben, nach der Versilberung kann Osmiumsäure und Pikrocarmin angewandt werden. Die Silberlinien bezeichnen nach $\mathrm{Harmer}$ die Zellgrenzen. Mitrophanow (1884, Lit. 78) äussert sich in einer Arbeit über die Intercellularstruktur im Epithel dahin, dass die durch Höllenstein hervorgerufenen Grenzen noch nicht die Existenz einer besonderen Kittsubstanz beweisen. Er sieht keine Notwendigkeit, eine besondere Kittsubstanz (wenigstens 
nicht für das Epithel der Amphibien) anzumehmen. Nach Mitrop han ow reduziert das Silber sich, auf der Oberfläche der Zellen, weshalb diesellen gewöhnlich braun aussehen. Von der Kante aber erscheint eine solche versilberte fiäche als cine schwarze linie".

Bei Studien zur Entwickelungsgeschichte des Cöloms und des Cölomepithels der Amphibien bedient sich Solger (1884, Lit. 112 a) wieder der Versilberungsmethode. Er benutzt seine Mischung von Argentum nitricum und Osmiumsäure (1883, Lit. 112). Solger nimmt Stellung gegen die Deutung der Silberlinien als Kunstprodukte. Bezüglich der hin und wieder auftretenden Schaltplättchen sagt er, dass ,die Silberniederschläge, die den Kittleisten folgen“, über den schmalen Substanzbrücken, welche die oft schmalen und langen Fortsätze mit den Zelleibern verbinden, zusammengeflossen sind.

G i erke (1885, Lit. 41) gibt in einem Aufsatz „Färberei zu mikroskopischen Zwecken “ eine ausführliche Übersicht über die Imprägnationen. Seines Erachtens verbindet sich bei den Endothelien die Kittsubstanz zwischen den Zellen mit dem Höllenstein, es entsteht Silberalbuminat, die Reduktion wird „durch die Einwirkung des Sonnenlichtes sehr wesentlich gefördert". -

Nach dem Jahre 1885 wurden wieder vielfach Arbeiten veröffentlicht, welche das Wesen der Silberwirkung einer eingehenderen Prüfung unterzogen beziehungsweise an ihrer Deutung eine Kritik äbten. Daneben wurden weitere Vorschläge bezüglich der Technik und Verwendung gemacht.

Boveri (1886, Lit. 14) untersucht sehr genau den Bau der Nervenfasern, vorzüglich der peripheren markhaltigen Nervenfasern, zunächst der Amphibien und höheren Vertebraten. Dabei bedient er sich auch der Versilberung, deren Wirkung er eingehend darstellt. Er ermittelt an Längsschnitten von Nervenstämmen, die er einer Behandlung mit Osmiumsäure 
unterworfen hat, dass die Schwannsche Scheide in dem Abschnitt zwischen zwei Schnürringen (anneau constricteur, Ranvier) aus zwei Blättern besteht von der Form zweier konzentrisch ineinander gesteckter, an beiden Enden ineinander übergehender cylindrischer Röhren (,inneres und äusseres Neurilemm“), und sagt dann: „Damit erledigt sich auch der Widerspruch, der hinsichtlich des Schnürringes (. . .) die Literatur beherrscht, indem derselbe einerseits als Verdickungsring der $\mathrm{Schw}$ an $\mathrm{n}$ schen Scheide erklärt wird, während er sich andererseits durch seine Schwärzung in Silbernitrat als Kittlinie dokumentiert. Nach dem Gesagten kann der Schnürring nichts anderes sein als der optische Ausdruck des bald breiteren, bald fast verschwindenden Zwischenraumes zwischen den Umschlagsrändern, durch welche je zwei aneinander stossende Segmente der Schwannschen Scheide mit den zugehörigen inneren Membranen in Verbindung stehen." Eine Diskontinuität des Achsencylinders kann Boveri nicht feststellen. Der Autor bespricht dann sehr eingehend die Silberbilder. Er unterscheidet algesehen von Färbungen, wie der rostbraunen Tinktion der Nervenfibrillen, dreierlei Arten des Silberniederschlages je nach der örtlichkeit: erstens Niederschläge, die in engen Spalträumen entstehen, und zwar zwischen benachbarten "Scheidenzellen" (,inneres" und ,äusseres Neurilemm"; einschliessend das sog. "Mark"), zwischen Scheidenzellen und Nervenfibrillen und zwischen den Nervenfibrillen selbst, zweitens Niederschläge, die in regelmässiger Schichtung den ganzen freien Achsenraum einnehmen (F r o m man nsche Linien), und drittens Niederschläge, die an die Oberfläche der Markscheide gebunden erscheinen und meist nur bei besonderer Behandlungsweise hervortreten. Er teilt mehrere Tatsachen mit, die über die Bedingungen der „Kittlinien“ (im Sinne v. Recklinghausens) einigen Aufschluss geben: „Wenn man einen Nerven ohne Zusatz einer Flüssigkeit auf 
dem Objektträger rasch zerzupft und nun die Silberlösung hinzutreten lässt; so kann man häufig die Beobachtung machen, dass, gleichzeitig mit den Silberbildern an den Einschnürungen und von gleichem Hahitus mit diesen, ein Niederschlag zwischen den einzelnen Nervenfasern auftritt, der ganz den Eindruck von Kittlinien hervorruft, derselbe findet sich nie an einer isolierten Faser, sondern nur da, wo zwei Fasern einander bis zur Berührung genähert sind. Lineíı gleichen Niederschlag kann man; obgleich viel seltener, zwischen Bindegewebsfibrillen und Remakschen Fasern beobachten. Man könnte glauben, dass auch zwischen diesen Elementen eine Kittsubstanz vorhanden sei. Allein einmal müsste eine solche Substanz bei der Isolation an den einzelnen Fasem haften bleiben und auch an frei liegenden einen Niederschlag hervorrufen, sodann aber muss für die markhaltigen Fasern die Annahme einer Verkittung deshalb ausgeschlossen werden, weil, wie mun sich an jedem Querschnitt überzeugen kann, dieselben durch relativ weite : Zwischenräume von einander getrennt sind. Die innige Aneinanderlagerung kann also nur eine Folge der Präparation sein und der Niederschlag, der an diesen Contakt geknüpft. ist, kann nur als eine Folge desselben erklärt werden." l'erner entsteht nach Boveri z. B. bei Versilberung des FroschMesenteriums in den Gefässen an den Berührungsflächen dicht anẹinander gelagerter Erythrocyten, die gewöhnlich eine gegenseitige Abplattung erkennen lassen, der gleiche Niederschlag, wie er zwischen Epithelzellen erscheint, er endigt mit dem Punkte, wo die innige Berührung ihr Ende erreicht. ;Dass nun in diesem Falle keine specifische das Silluer reducierende Substanz oder gar ein Kitl vorliegen kann, ist selbstverständlich; der Niederschlag kann nur durch den Contakt selbst verursacht sein." Schliesslich führt der Aulor folgendes an: „Wenn zwei Zellen, die im Leben eng aneinander liegen und nach silberhehandlung eine Kittlinie zwischen sich zeigen würdern, durch 
einen Zufall der Präparation von einander gelöst werden, was allerdings bei der Festigkeit der Adhäsion nur selten der Fall ist, so tritt, wenn nun erst die Silberlösung zugesetzt wird, nicht etwa an einer oder an beiden der einander vorher berührenden Flächen ein Niederschlag auf, sondern derselbe entsteht überhaupt nicht mehr. Lässt man ein Stück eines Froschmesenteriums, ohne es zu fixieren, eintrocknen, so behalten die Grenzen der Endothel-Zellen noch auf mindestens einige Stunden die Fähigkeit bei, aus einer Höllensteinlösung Silber zu reducieren. Wird das Mesenterium dagegen fixiert und zwar dadurch, dass man es flach auf einen Objektträger ausbreitet, so muss dadurch, dass nun mit der Schrumpfung der einzelnen Zellen nicht mehr eine entsprechende Verkleinerung der ganzen Fläche Hand in Hand gehen kann, ein Auseinanderweichen der Zellen verursacht werden. So lange dieses einen gewissen Grad nicht überschreitet, tritt der Niederschlag, nun entsprechend breiter, noch auf. Bald jedoch, nach höchstens einer halben, Stunde, ist die Grenze erreicht, von der an der Niederschlag nicht mehr zur Ausbildung kommt. Dass hieran die Eintrocknung. Schuld sei, kann nach dem oben Gesagten nicht angenommen werden." Aus diesen Tatsachen folgt nach Boveri ohne Zweifel, „dass für die als Kittlinien bezeichneten Niederschläge, die durch Behandlung frischer tierischer Gewebe mit verdünnter Höllensteinlösung auftreten, nicht eine specifische Substanz bedingend ist, sondern nur der innige Contakt zweier Gewebselemente, vielleicht darf man direkt sagen: die. Adhäsion. Es folgt daraus weiter, dass Niederschläge, die unter den genannten Umständen auftreten, auf nichts anderes schliessen lassen, als auf eine innige Berührung, gleichviel, ob diese in der Natur des Geweles begründet oder künstlich hervorgebracht ist". Der Autor kommt dann auf die Silberbilder bei Nervenfasern zurück und leitet diese auf Grund der gewonnenen Anschauungen sehr einfach aus seinen Lüngsschnittbildern ab. 
Der seines Erachtens erforderliche enge Kontakt findet sich zwischen den beiden aneinander stossenden Scheidenzellen, zwischen den Scheidenzellen und Nervenfibrillen (in der „Enge des Achsenraumes") und zwischen den Nervenfibrillen selbst. Am ersten Ort ergibt sich ein Ring, der die Stelle des ,Schnürrings" einnimmt (imponiert optisch als Querbalkén des Ra.n. vierschen Kreuzes"), „er ist vollkommen mit den zwischen anderen Zellen auftretenden Kittlinien zu homologisieren und wird auch allgemein in diesem Sinne erklärt, allerdings nur als Kittlinie zwischen den Segmenten der Schwan nschen Scheide, was danach $\cdot z u$ berichtigen ist". Am zweiten Ort tritt ein Niederschlag auf, welcher der Form des verengten Achsenraumes der Schnürstelle entspricht, also im allgemeinen einen. (periaxialen) kurzen Cylindermantel darstellt. Die beiden genannten Niederschläge können jeder für sich allein auftreten, meist aber sind sie miteinander kombiniert und rufen dann das Bild des „Ranvierschen Kreuzes" hervor. Hieran schliessen sich verschiedene Modifikationen („,renflement biconique", Verlängerung des Längsbalkens, Lücke im Längshalken in Höhe des Querbalkens und Kombinationen dieser). Zwischen den Nervenfibrillen selbst (an dritten vorher erwähnten Ort) kommt ein Niederschlag in Gestalt feiner Längslinien, seltener in Längsreihen angeordneter Silberkörnchen, zustande. Er ist nicht an eine bestimmte Örtlichkeit gebunden, doch findet er sich in der Regel mit den oben beschriebenen periaxialen Niederschlägen in der Enge des Achsenraumes (verdeckt durch letztere im Längsbalken des „R anvierschen Kreuzes"). Auf die besprochenen Arten des Silberniederschlages glaubt Boveri auch die Bilder zurückführen zu müssen, die Engelmann (1880, Lit. 28) beschrieben hat, er hält dessen Ansicht von der Diskontinuität des Achsencylinders für unrichtig und betont die Ring-Form des Niederschlags zwischen den beiden aneinander stossenden Scheiden- 
zellen, gegenüber der ihm von Enge lman n beigelegten Form einer Schicht durch "die ganze Dicke". des Achsencylinders. Sodann kommt der Autor zur Besprechung der sog. FromIn an $n$ schen Linien, er unterwirft die Angaben $R u m p f s$ und v. Morochowetz's (1878, Lit. 99 und 79) einer Kritik. Boveri hält die Behauptung dieser Forscher, dass die Silberschichten den Achsencylinder stets umgreifen, für nicht völlig richtig. Nach seinen Beobachtungen ist dies nur in gewissen Fällen festzustellen, sonst lagert sich der Niederschlag „,in der ganzen Dicke des Achsenraumes überall da ab, wo er Platz findet". Er hält deshalb eine Abhängigkeit der Bilder von einem präformierten Schichtenbau für sehr unwahrscheinlich und führt auch noch andere gegen einen solchen sprechende Gründe an. B o ve r i schildert ein von anderer Seite (A. B o e h m in München) vorgenommenes Experiment, durch welches in engen Glasröhren, die mit Eiweïss gefüllt und dann in Silbernitratlösung getaucht waren, ganz entsprechend geschichtete Niederschläge erzeugi wurden. Er erklärt die Frage der Entstehung dieser Bilder für eine rein physikalische. Seines Erachtens ist der chemische Vorgang bei der Behandlung von Nerven, wie überhaupt auch bei der von Blutplasma und Lymphe, mit Silbernitrat der, dass sich zunächst in Umsetzung mit dem Kochsałz der in Wirksamkeit tretenden lymphatischen Flüssigkeit des Achsencylinders Chlorsilber bildet, das bei Belichtung $\mathrm{zu}$ schwarzen Körnchen von Silber reduziert wird. Schliesslich bespricht B overi die von ihm aufgestellte dritte Art der Silberniederschläge an der Oberfläcne der Markscheide. Er schildert verschiedene hier weniger interessierende Niederschläge dieser Art und erklärt sie mit Hilfe der gewonnenen Anschauungen. Der Forscher empfiehlt auch eine Mischung von Silberlösung und Osmiumsäure, gibt genau seine Technik an und sagt, dass hierbei die deutlichsten silberbilder fast momentan und auch unter Ausschluss des Lichtes auftreten. 
Für die gewöhnliche Silbermethode jedoch hält er zụ Erzeugung des Niederschlags die Einwirkung des Sonnenlichtes für nötig.

Was die Silberbilder Kochs (1878, Lit. 61) anbetrifft, so macht Boveri gegen ihre Deutung als Reaktion auf Kittsubstanz den Umstand geltend, dass sie nicht durch direkte Behandlung frischer Fasern mit Silberlösung gewonnen werden könnten. (Diesen Linwand weist später $\mathrm{s} \mathrm{ch}$ i efferdecker [1887, Lit. 101] mit. Recht zurück.) Sschliesslich betont der Autor, dass grosse Vorsicht bei der Deutung aller Silberbilder geboten erscheine. Er dehnt auch seine Untersuchungen aus auf die peripheren markhaltigen Nerven der Fische, die Nervenfasern des Sympathicus und die des Olfactorius.

Schiefferdecker (1887, lit. 101) untersucht den Bau der Nervenfasern. Er gewinnt an Silberbildern die Auffassung, dass an jeder Einschnürungsstelle zwischen den beiden Enden der Markscheide eine aus einer andersartigen Substanz bestehende Scheibe liegt, durch die der Achsencylinder hindurchgeht, es: schlägt vor, dieselbe „\%wischenscheibe“ zu nennen. Nach seinen Beobachtungen schlägt sich das silber auch in den sog. „Lantermann schen Einkerbungen" nieder. Den Einwand $\mathrm{B}$ overis gegen $\mathrm{Kochs}$ Methode (1886, Lit. 14 und 1878, Lit. 61) verwirft er, dieser habe gewiss den frischen Nerven $z$ uer $\mathbf{t}$ nit Silberlösung behandelt. Auch $\mathrm{S}$ ch i effer d ecker erkennt eine Kittsubstanz ,oder neutraler gesagt eine Zwischensubstanz" in den Lan terman $\mathbf{n}$ schen Einkerbungen an. Ferner hat er an centralen Fasern besonders deutliche Frommann sche Linien erzeugt, er schildert den Achsencylinder als ein plattes, mehr oder minder breites Band und sagt, dass ,auf dessen Oberfläche jene eigenlümlichen Querstreifen hinlaufen". Nach seinen Wahrnehmungen stehen die braunen Querstreifen am Rande des Achsencylinders über diesen etwas vor (Achsencylinder aus dem Rückenmark des Rindes). Er konstatiert,; dass der Achsencylinder selbst nicht 
gefärbt ist, sondern dass die in dem von einer wahrscheinlich der Lymphe ähnlichen Flüssigkeit erfüllten ,pperiaxialen Spaltraum" entstandenen Gerinnsel die Färbung zeigen. Ferner beschreibt er, dass der geschrumpfte, oft bandförmig erscheinende Achsencylinder von den Stellen der Zwischensubstanz aus nach beiden Seiten hin mehr oder weniger weit von einer braun gefärbten, körnig geronnen erscheinenden Scheide umgeben ist (im periaxialen Spaltraum), die ihn durch die Zwischenscheibe hindurch begleitet und in der unmittelbaren Nähe dieser häufig mehr oder weniger bedeutende, mehr oder weniger auf beiden Seiten gleichmässige Verdickungen zeigt, die vielleicht den „renflements hiconiques" von Ranvier entsprechen. Zur. Erklärung der F'rom ma.n n.schen Linien erscheint ihm die Hypothese Boveris noch die beste zu sein.

Nach K ul t s ch i tzk y (1887, lit. 71) ist die Silberreaktion für die Kittsubstanz nicht beweisend, sie kann nicht darüber Aufschluss geben, ob zwischen den Zellen eine eigentliche Kittsubstanz vorhanden ist, welche die Zellen miteinander verklebt, sondern sie beweist nur als unzweifelhafte Tatsache, dass zwischen den Zellen sich eine Substanz befindet, die eine grosse Menge Chloride enthält.

Jose ph (1888, Lit. 59) untersucht unter anderem die Frage, ob als Bestandteile des Achsencylinders eine einzige oder vielleicht mehrere chemisch differente Substanzen anzusehen sind. Zur Entscheidung zieht er die Resultate der Silbernitratwirkung heran. Er gelangt zu einer besonderen Methode (Silbernitrat-, Salpetersäure-Lösung, Lösung von doppelchromsaurem Kali) der Darstellung der Querstreifen (F rommann) nicht nur in der Nähe des Schnürringes, sondern auch weit von demselben entfernt. Er hält es nicht für gewagt, sich der Ansicht zuzuneigen, dass im Achsencylinder zwei Substanzen vorhanden sind, von welchen eine die Eigenschaft besitzl, aus 
der Silberlösung das Metall zu reduzieren, während diese der anderen fehlt.

Jakimovitsch (1888, Lit. 58) studiert eingehend die Frommannschen Querstreifen nach Silberbehandling an den Achsencylindern der centralen und peripheren Fasern und weist dieselben auch an den grossen Nervenzellen der Vorderhörner nach. Er gibt genau eine besondere Technik an (Reduktion am Licht in einer Mischung von-Osmiumsäure, Amylalkohol und Wasser). Die Reaktion gelingt noch 24 Stunden nach dem Tode und später, Jakimovitsch hält aber die intakte Funktionsfähigkeit des Nerven zum Gelingen der Reaktion für nötig.

Als beste Methode der Versilberung, bei der die Kerne gut konserviert werden, empfiehlt Dekhuyzen (1889, Lit. 24) für das Froschmesenterium eine besondere Technik mit einer sauren Silbernitratlösung. Als Kernfärbung wendet er AlaunHämatoxylin, Safranin oder Methylgrün an.

Bei Untersuchúngen über die Struktur des Pleuroperitonealund Gefässepithels (Endothels) kommt Kolossow (1893, Lit. 64) auch auf das Wesen der Versilberung zu sprechen. Seine Arbeit lässt erkennen, dass trotz der Kritik vieler Autoren (A uerbach, Schweigger-Seidel u. a.) die Hypothese von der Kittsubstanz mit ihrer Fähigkeit der Reduktion von Silbersalzlösungen und ihrem Charakter als halbflüssiger oder flüssiger Albuminstoff auch noch zu seiner Zeit die herrschende Anschauung ist. Er behandelt nach Ausdehnung des subendothelialen Gewebes durch Aufblasen die Objekte mit Silbersalzen (daran anschliessend Fixation in absolutem Alkohol) und kombiniert diese Behandlung auch mit einer Fixierungs- und Färbungsmethode mit Osmiumsäure, zur Reduktion der Osmiumsäure verwendet er vorzugsweise starke Tauninlösungen. (Bereits 1892 hat Kolos ow (Lit. 63) eine Arbeit veröffentlicht, welche über die dieser Biethode zugrunde liegenden Unter- 
Historische Darstellung znr Deutung des Wesens der Silbermethode etc. 141

suchungen handelt and ähnliche technische liragen betrifft, u. a. Injektionen von Blutgefässen in entsprechender Weise er. wïhnt.) Bei der blossen Versilherung derartig vorbereiteter Fndothelien miisste man bei Vorhandensein der hypolhetischen Kittsubstanz, die sich dehnen müsste, breitere Silberlinien erwarten, man erhält jedoch gerade feine Linien, die aber vielfach von Stigmata und Stomata unterbrochen werden, letztere sind bezüglich Zahl und Grösse dem Grade der Ausdehnung proportional. Das Resultat ist bei Anwendung verschiedener Silbersalze dasselbe, vorheriges gründliches Abspülen in destilliertem Wasser verhütet das Zustandekommen letztgenannter Bildungen nicht. Dieses Ergebnis spricht nach Kolos sow dafür, dass die Elemente des Endothels nicht mittels eines flüssigen oder halbflüssigen Cements verbunden sein können. Um die Ursache des partiellen Auseinanderweichens der Zellränder und überhaupt den komplizierteren Aufbau des Pleuroperitoneal- und Gefässepithels zu erforschen, zieht $\mathrm{Kol}$ os sow die Osmiumsäure heran. Das Ergebnis seiner. Untersuchungen ist folgendes: Seiner Überzeugung nach sind die Endothelzellen des Pleuroperitoneum aus zwei verschiedenen Teilen aufgebaut: einem oberflächlichen, vom Ansehen eines dünnen homogenen Plättchens (,Deckplatte") und einem tieferen, anscheinend von schwachkörnigem Protoplasma gebildet (,Zelle in strengem Sinne"). Die tiefen Teile sind durch protoplasmatische Fortsätze untereinander organisch verbunden, die Deckplatten, welche als metamorphosiertes Protoplasma, als eine Zugabe der Zelle anzusehen sind, sind nicht miteinander verbunden, sondern berühren nur mit ihren Rändern einander auf der Oberfläche dicht. Dicht unter der Oberfläche, also dicht unter den „Deckplatten", an deren Unterfläche herziehend, liegen die obersten Anastomosen der "Zellen in strengem Sinne". Nach Osmiumbehandlung erscheinen diese Verhältnisse, wie er schildert, deutlich. Bei Kombination beider Behandlungen (Silber 
und Osmium) erhält man sehr instruktive Präparate. Kolos sow äussert sich bezüglich des Pleuroperitonealepithels: „Der Zusammenhang der Zellelemente dieses Epithels durch Anastomosen entzieht dem hypothetischen flüssigen oder halbflüssigen Cement jegliche Bedeutung. Die schwarzen intercellulären Linien, die auf den versilherten Präparaten des erwähnten Epithels zu sehen sind und die bisher als Ausdruck der intercellulären $Z$ wischenschichten dieses Cements angesehen wurden, haben offenbar solche Bedeutung schon deswegen nicht, weil sie eigentlich nicht zwischen den Zellen.liegen, sondern zwischen den Rändern ihrer Deckplatten; das Vorhandensein aber eines besonderen Cements hier zuzulassen, haben wir nicht die geringste Ursache, da die Ränder der Deckplatten ohne dies durch Anastomosen von unten verbunden sind; das Zusammenhalten derselben zu vervollständigen ist das flüssige oder halbflüssige Cement so wie so nicht im Stande." Die schwarzell Silberlinien entsprechen ,den Grenzen nur zwischen den Deckplatten“, die Zellen in strengem Sinne liegen tiefer und sind voneinander durch helle von Anastomosen durchkreuzte Zwischenräume getrennt. „Diese Zwischenräume, welche von oben mit den verbundenen Rändern der Deckplatten bedeckt sind, sind im lebendigen Gewebe selbstverständlich mit einer eiweisshaltigen Flüssigkeit, der Lymphe, gefüllt, welche, das Grundgewebe der serösen Haut durchtränkend, unvermeidlich sowohl in derselben, als auch bis zur freien Oberfläche des Epithels zwischen den Deckplatten dringen muss. Die Capillarschicht derselben, welche sich zwischen den Rändern dieser letzteren befindet, hedingt hier gerade, ohne Zweifel, die Erscheinung der schwarzen Linien bei Silberimprägnation des Epithels, da die albuminhaltige Flüssigkeit beim Zusammentreffen mil der Silbersalzlösung gerinnend, eine unlösliche Verbindung - ein Albuminat, das sich am Licht schwärzt ... geben muss. Infolge der Unauflöslichkeit dieser Verbindung 
kann die Silberlösung nicht weiter in das Innere der intercellulären $Z$ wischenräume eindringen, weshalb wir in versilberten Präparaten feine schwarze Linien erblicken. . . . Wenn aber die Silberlösung in die intercellulären Zwischenräume eindringt, wie das zuweilen geschieht, so sind anstatt der dünnen schwarzen Linien ziemlich breite schwarze Streifchen mit unregelmässigen Contouren zu sehen, entsprechend den Hervorragungen an den Seitenflächen der Zellen, den Abgangsstellen anastomosirender Fortsätze von ihnen." Das Zustandekommen der Stigmata beziehungsweise Stomata erklärt sich Ko lo s s ow in der Art, dass bei Ausdehnung die Berührungsränder der Deckplatten über den oberen protoplasmatischen Anastomosen (direkt unter ihnen) aneinander liegen bleiben, während sie über den Zwischenräumen zwischen diesen Anastomosen auseinander weichen. Das Gefässepithel zeigt nach Kolossow vollkommen analogen Bau, vom Vorhandensein eines Cements (Kittsubstanz) kann keine Rede sein, da die Zellen untereinander organisch verbunden sind. „Dié bei Silberbehandlung zum Vorschein kommenden schwarzen Linien stellen wahrscheinlich nichts anderes vor, als eine versilherte Capillarschicht des Blutplasmas, welche sich zwischen den Rändern der Deckplatten befindet" (Kolossow berücksichtigt auch die Verhältnisse bei Entzündungen).

Fischel (1893, Lit. 31) bearbeitet die Erscheinung der sog. Fromman $n$ schen Linien. Er erzeugt eine Querstreifung auch bei sicher nicht mehr funktionsfähigen Nervenfasern und hält es also für nicht berechtigt, dem funktionierenden Nerven allein die Fähigkeit zuzusprechen, nach Silberbehandlung quergestreift zu werden (Gegensatz zu.Jakimovitsch [1888, Lit. 58」u. a.). Der Typus der Streifung steht nach Fis chel. in keiner Beziehung zum Zeitabstand zwischen Tod des Tieres und Entnahme des Objektes, dagegen hat die Art des Reagens Einfluss auf: die Form der Querstreifung (Farbe und Grösse 
der Körnchen), Er benulzl bei seinen Untersuchungen hauptsächlich ein Gemisch von silhernitral, Imeisensiume und Wasser. Die Streifen sind seines Erachlens der Ausdruck von Scheiben und bestehen aus schwarzen Körnchen verschiedener Grösse, die manchmal Anordnung in regelmässigen Reihen erkennen lassen, gewöhnlich jedoch regellos nebeneinander liegen. Diese Körnchen finden sich auch in den hellen $Z$ wischenräumen zwischen den Querscheiben; sie ungreifen niemals den Achsencylinder oder die Zellen als Ringe, sīe lassen sich vielmehr durch die ganze Dicke des Achsencylinders verfolgen, der oft scharf durch eine Achsencylinderscheide begrenzt ist. Dies alles zeigt auch der Querschnitt. Fischel macht die Erscheinungen durch einen erläuternden Hinweis auf den Umstand, dass die Ganglienzelle und vor allem der Achsencylinder reich mit Flüssigkeit durchtränkte Gebilde sind, erklärlich. Nach Fischels Ansicht stellen die "renflements biconiques" (Ranvier) nicht Verdickungen des Achsencylinders dar. Die Körnchen in diesen Gebilden liegen in einer lymphatischen Flüssigkeit zwischen den abgestutzten Enden der cinander zugekehrten Marksegmente. „Vollen Beweis nun dafür, dass wirklich die Querstreifung in der lymphatischen Flüssigkeit von Zelle und Achsencylinder zustande kommt, bietet der Umstand, dass man sie überall dort erzeugen kann, wo in den Geweben sich reichlich lymphatische Flüssigkeit befindet und günstige Verhältnisse für das Eindringen des Silbersalzes besteben." So beobachtet man sie in den um die kleineren und grösseren Capillaren und Gefässe des centralen Nervensystems befindlichen Lymphräumen, sie hat dort ihren Sitz nicht in, sondern ausserhalb der Muskelhaut. An den Gefässen kann man nach Fischels Angahe besonders deutlich erkennen, dass es eine lymphatische, durch das zugesetzte Reagens geronnene Flüssigkeit ist, in welcher die Streifen liegen. Entsprechende Verhältnisse hat $\mathrm{Fischel}$ an der Pia mater und an den verschieden- 
sten Gewebselementen und Organen aufgedeckt. Wie eine so regelmässige. Schichtung in den verschiedenen Gebilden zustande kommt, erklären nach $\mathrm{Fischel}$ physikalische Tatsachen (Kontraktionen und innere Spannungen beim Ubergang colloider Substanzen in den festen Zustand). Somit stellen die Querscheiben nichts für die Ganglienzellen und Achsencylinder Spezifisches dar, noch weniger aber berechtigen sie zu irgendwelchen Schlüssen über Bau und Tätigkeit dieser Organe.

R a bl (1893, Lit. 84) nimmt auch wieder die Untersuchung der Frommann schen Linien auf. Er geht auf die Natur des chemischen Prozesses bei der Behandlung der Gewebe mit Argentum nitricum ein und hält es neben der älteren Anschauung (Bildung eines Silberalbuminats) für möglich, dass sich das Silbersalz mit dem Albumin durch Zusammenlagerung der Moleküle zu einem Silbernitrat-Eiweiss verbindet, analog jenem Vorgange, der sich bei Fällung des Harnstoffs aus seiner Lösung durch Quecksilbersalze abspielt. Er hält die kleinen Körnchen der Querstreifen bei den Frommann schen Linien, nicht für metallisches Silber, da sie sich in thioschwefelsaurem Natron lösen; dasselbe gilt auch von dem Silberniederşchlage an den Endothelzellen der serösen Häute, der Blut- und Lymphgefässe, der Muskelfasern usw. Nach R abl muss der Niederschlag vielmehr eine Verbindung des metallischen Silbers, wahrscheinlich ein Oxydationsprodukt desselben darstellen. Er findet nun, dass man die Querstreifen der Frommannschen Linien auch an Bindegewebsbündeln hervorrufen kann. Wie Jaki movitsch (1888, Lit. 58) erklärt er die Erzeugung der Querstreifen auch 24 Stunden nach dem, Tode für möglich, auch bei Bindegewebsbündeln. Als Grundbedingung für das Gelingen der Methode betrachtet $\mathbf{R} \mathbf{a b l}$ nicht die Intaktheit des Zellprotoplasmas - diese (Lebensfähigkeit, Funktionsfähigkeit) ist wohl mehr als 24 Stunden nach dem Tode nicht mehr anzunehmen --, sondern die Anwesenheit noch gelösten unveränderten Eiweisses 
in dem Gewebe. Es ist unmöglich eine Querstreifung darzustellen, wenn die Stücke vorher der Einwirkung eines anderen Reagens unterworfen waren. Der Versuch im Reagenzglas lehrt, dass das durch Säuren oder Alkohol gefällte Eiweiss mit dem Silbernitrat keine durch Licht reduzierbare Verbindung eingeht, auch nach Auswaschen in fliessendem Wasser misslingt ein entsprechender Versuch. Rabl beschreibt genauer seine Feststellungen an seinen Präparaten. Er that auch bei Knorpel Streifen ähnlicher Art dargestellt, sowie solche in der die Fettzellen umgebenden Flüssigkeit. Er kann die von B o v e r i (1886, Lit. 14) ausgesprochene Ansicht, dass die Silberniederschläge überall dort häufig zur Beobachtung kommen, wo zwei Gewebselemente sich direkt berühren, durchaus bestätigen, fügt aber hinzu, dass er nur dort einen Niederschlag gefunden habe, wo man annehmen konnte, dass im Moment des Eindringens der Silberlösung noch eine Schicht verkittender Flüssigkeit zwischen den Gewebselementen vorhanden war. Er sagt: „Wenn um eine vorher isolierte Zelle bei Zusatz von Silbernitrat kein Niederschlag entsteht, während ein solcher entstanden wäre, wenn ihre Verbindung mit den übrigen Zellen erhalten geblieben wäre, so ist es nìcht nothwendig, die Adhäsion zwischen den Zellen als Ursache für die Entstehung des Niederschlages heranzuziehen, wie es B overi thut. Man kann diese Thatsache auch so erklären, dass die Kittsubstanz um die Zelle durch die umgebende Flüssigkeit aufgelöst oder weggeschwemmt worden sei. Es scheint mir also nicht die Adbäsion, sondern das Vorhandensein von Gewebsflüssigkeit das wichtigste Moment zur Erklärung des Silberniederschlages zu bilden. Ich glaube, dass man dạs Recht hat, den gebildeten Niederschlag, ..., dem lüngst bekannten zwischen Endothelzellen, Muskelfasern etc. vorkommenden an die Seite zu stellen. .... In allen Fällen handelt es sich jedoch nicht um eine specifische Kittsubstanz, als vielmehr un eine nicht organisierte, lymphatische Flüssig. 
Historische Darstellung zur Deutung des Wesens der Silbermethode etc. 147

keit, wie dies für die Kittsubstanz der Endothelzellen . . . mil Bestimmtheit ausgesprochen wurde." Was die Ursache der Querstreifung durch Silber anlangt, so hält $\mathrm{Rabl}$ wie Schiefferdecker (1887, Lit. 101) die Boverische Hypothese für die wahrscheinlichste und äussert noch einige Vorstellungen zu deren Ergänzung.

Eberth in dem von ihm bearbeiteten Lehrbuch der mikroskopischen Technik von Fried l a e nder (1894, Lit. 35) bemerkt, dass bei der Silbermethode, welche „die Kittsubstanz zwischen Epithelien und Endothelien, wie die Grundsubstanz des Bindegewebes braun oder tiefbraun ungemein deutlich hervortreten" lasse, die Wirkung des Silbersalzes nur sehr wenig in die Tiefe der Gewebe eindringe. Der Niederschlag werde durch verdünntes Ammoniak, leicht gelöst. Die Silbermethode ist seines Erachtens in der üblichen Weise nur an frischen Objekten, bei denen kadaveröse Zersetzungen noch nicht: eingetreten sind, anwendbar.

G. W erner (1894, Lit. 121) behandelt glatte Muskulatur des Darmes nach mechanischer Entfernung der Schleimhaut mit schwacher Silberlösung und erhält die bekannten Bilder. Er sagt, dass er sich selbst davon habe überzeugen können, dass die Dicke der Silberlinien in geradem Verhältnisse zur Konzentration und zur Einwirkungsdauer der Silberlösung steht. lhm scheint eine spezifische Reaktion einer Kittsubstanz nicht vorzuliegen. Die Ansicht, dass diese mikrochemische Reaktion der „Kittsubstanz" für die Existenz einer solchen volle Beweiskraft besitze, wird nach W ern er auch nicht unterstützt durch die Isolationsfähigkeit der, Zellen durch verschiedene Reagentien, welche die Kittsubstanz auflösen sollen, an Stellen, wo die Silberreaktion negativ ausfällt (feine Sehnen, quergestreifte Muskulatur). Für die glatte Muskulatur hält er das Vorhandensein einer Kittsubstanz nicht direkt nachweisbar, also auch nicht durch Argentum nitricum. 
Muscatello (1895, Lit. 81) bedient sich bei Untersuchungen über den Bau des Peritoneum der Versilberung. Er spricht von den „durch den Niederschlag von Silberalbuminat sichtbar gemachten Zellgrenzen". Die von anderen Autoren als Stigmata oder Stomata bezeichneten nach Silberbehandlung erkennbaren Bildungen hält er für zufällige Produkte (Zerrung der Objekte).

In Jahre 1895 kommt auch $\mathrm{Th}$. Gohn (Lit. 20) bei einer Arbeit über Intercellularlücken und Kittsubstanz auf die Versilberung zu sprechen. Er ventiliert die Frage bezüglich einer etwa möglichen Identität der schwarzen Umränderungen der Zellen, die man durch Silberreduktion erhält, und der durch $\mathrm{Heidenhainsches} \mathrm{Eisenhämatoxylin} \mathrm{in} \mathrm{intensiv} \mathrm{schwarzer}$ Farbe darstellbaren Kittstreifen und sagt, dass seines Erachtens diese Kittstreifen ihrer Art nach nicht identisch mit den Silberlinien sind. Bei den sog. Endothelien, die bei Silberbehandlung deutliche Zellgrenzen erkennen lassen, sind bisher Kittstreifen durch Eisenhämatoxylin nicht nachgewiesen. Es handelt sich um etwas ganz Verschiedenes. „Denn die S il be r $\mathrm{r}$ eduktion bringt vor allem die Zellgrenzen der Endothelien zur Erscheinung, und wenn sie auch Epithelzellen mit einem Netz schwarzer Linien umsäumt, so beschränkt sich diese Schwarzfärbung doch nicht wie in unserem Falle ${ }^{1}$ ) a uf die Oberfläche, sondern dringt in die Tiefe des Epithels ein, wie man z. B. leicht am vorderen Corneaepithel bei der Silberbehandlung sehen kann. Wenn man nun mit vielen neueren Autoren annimmt, dass die Intercellularräume in der Tiefe der Epithelien nicht von einer besonderen Kittsubśtanz, sondern nur von einer dem Lymphgefässsystem entstammenden, zur Ernährung der Zellen dienenden Flüssigkeit erfüllt sind, so folgt schon hieraus, dass bei der Silber-

1) Cohn spricht ron der Daretellung der Kittstreifen durch Eisen. hamatoxylin. 
reduktion entweder die peripherischen Grenzschichten des Zellenprotoplasmas gefärbt werden oder dass es sich um einen Niederschlag von fein verteiltem Silber $\mathrm{z} w$ is $\mathrm{ch}$ en den Zellen handelt. Weitere Untersuchungen sind noch zur Klärung dieser lirage erforderlich. Auf alle Fiallle kann man von der Silberreduktion nicht sagen, dass durch sie eine specifische Materie in specifischer Weise imprägniert werde, während in der Eisenhämatoxylinfärbung ein Mittel gegeben ist eine ganz bestimmte Materie fïberisch darzustellen, welche unter der Form der beschriebenen Kittstreifen in durchaus charakteristischer Lagerung sich zwischen den Zellen ausbreitet."

Flemming (1895, Lit. 32) knüpft an die Arbeit Cohns an, er hat bereits zwölf Jahre vorher den gleichen Gegenstand untersucht. Schon bei früheren Arbeiten hatte er gefunden, dass das Epithel der Salamanderlarvenhaut ausnehmend grosse Intercellularlücken aufweist. Der Lösung der Frage bezüglich des Inhaltes dieser Intercellularlücken sucht. F lem ming nun durch die Silberimprägnationsmethode näher zu kommen. Unter der Voraussetzung, dass diese Methode bei gelungenem „Negativbild“ lymphhaltige Räume als helle Bahnen auf dunklem Grunde darstellt (Saftkanälchen der Corneagrundsubstanz, gegenüber früheren abweichenden Deutungen, $\mathrm{Sch}$ weiggerSeidel u. a.) erwartet dieser Forscher, dass die Intercellularlücken, wenn sie Lymphe enthalten, im Silbernegativ sich ähnlich wie solche verhalten, also hell bleiben würden. Er sagt: „,Bisher waren solche Bilder bei Epithelversilberungen bekanntlich nicht erzielt, sondern es waren, wenn damit überhaupt in den tieferen Epithelschichten eine Reaktion zustande kam, hier ebenso wie in der oberflächlichen die bekannten Bilder von „Silbergrenzen“, also braun bis schwarz gefärbten dünnen Fachwerken zwischen den Zellen dargestellt worden. Aber da es sich in allen solchen Fällen bis dahin um relativ kleinzellige 
Epithelien gehandelt hatte, konnte dieses Ergebnis vielleicht nur daran liegen, dass die Intercellularlücken dort allzu eng waren, um, vorausgesetzt auch, dass sie Lymphe enthielten, eine Negativreaktion derselben deutlich zustande kommen zu lassen." Flemming erhält nun bei Versilberungen des Kiemenepithels und anderer Hautstellen der Salamanderlarve niemals ein Präparat, an dem die Intercellularlücken hell geblieben wären. Diese sind vielmehr bei allen üherhaupt tauglichẹn Präparaten mit feinkörnigen, sëhr dichten Silberniederschlägen erfüllt. Er beschreibt die Verhältnisse genau für das zweischichtige Kiemenepithel der Salamanderlarve. Auch erkennt er an den Silberpräparaten Wanderzellen in den Intercellularlücken. Bei den Silberbildern kleinzelliger Epithelien und auch bei ähnlichen Vergoldungsbildern war, so meint. Fle mming, noch Unsicherheit.darüber geblieben, was denn eigentlich durch die Metallimprägnation gedunkelt sei : „ob des Niederschlag in den peripheren Theilen der Zellen selbst läge oder auf der Oberfläche der Zellen, oder endlich ob er zwischen sie abgesetzt sei". Er erinnert an die Deutungen Werners (1894, Lit. 121) und die Äusserungen $\mathrm{Cohns}$ (1895, Lit. 20) und meint, dass der Forderung des letzteren nach weiterer Klärung durch seine Befunde in der Hauptsache wohl genügt sein dürfte, „denn sie zeigen bei den relativ kolossalen Verhältnissen des Salamanderepithels ja hinreichend deutlich, dass es in der That die intercellulär vorhandene Sub$\operatorname{stanz}$ ist, in welcher die dunklen Silberpräcipitate liegen". Fr fährt fort: „Aber diese Substanz reagiert demnach bei der Silberimprägnation $\mathrm{n} \mathbf{i} \mathrm{ht}$ so, wie Lymphe in Lymphgefässen oder Saftkanälchen dabei reagieren würde; sie schwärzt sich unter den Bedingungen, unter denen diese Lymphe hell bleibt." F l e m m ing hütet sich aber aus seinen Befunden den Schluss zu ziehen, dass der Inhalt der Lücken eine feste oder auch nur eine nichtflüssige „Kittsubstanz" sei und betont ausdrücklich 
die Möglichkeit, dass es Lymphe sein könne. Er stellt die Befunde von Key und Retzius (Injektionen der Intercellularlücken), Peremeschko (Vorkommen und Bewegungen von Leukocyten in diesen Lücken), Pfitzner (Bestätigung dieses Befundes), Mitrophanow (Erweiterung der Intercellularlücken bẹi Reizung), die für die Lymphnatur des Intercellularrauminhaltes sprechen und die er zum Teil selbst bestätigen kann, zusammen. Dass die Substanz in den Lücken nicht eine dichtere zähe Masse sein kann, ist erwiesen; „aber es würde mit den Befunden Cohns auch nicht in Widerspruch stehen, wenn sie eine weiche oder auch flüssige, von Lymphe aber dennoch verschiedene Masse wäre". Auch das Ergebnis der Untersuchungen A. Henles (Füllung der Intercellularräume mit einer Lösung von Olivenöl in Äther-Alkohol und Schwärzung der Ölmassen durch Osmiumsäure spricht seines Erachtens nicht gegen diese Auffassung. „Ein vollgültiger Beweis“, dass der Inhall der Intercellularräume Lymphe ist, ,steht" aber nach Flemming "bis jetzt noch aus". Er" sagt dann: „Machen wir trotzden die Annahme, dass die Lücken Lymphe führen, so scheinen mir nun meine Versilberungsergebnisse in physiologischer Hinsicht der Berücksichtigung wert. Denn sie zeigen, dass diese Epithellymphedann anders reagiert, als wir gewohnt sind, Lymphe im Bereiche der Bindesubstanzen unter gleichen Bedingungen reagieren zu sehen, dass also ersterevon letzterer chemisch verschieden sein muss." Ob dieser Reaktions-Unterschied lediglich so erklärt werden kann, dass der Inhalt der Gewehsspalten besonders reich an Chloriden wäre, erörtert der Autor nicht weiter und meint, dass es sich ja auch um kompliziertere chemische Vorgänge handeln könnte. Flemming spricht noch in der Erwägung eines centrifugalen Lymphstroms von der Möglichkeit, dass die Lymphe „mit dem Eintritt in das Epithel ihre Beschaffenheit ändert". Schliesslich äussert er sich: „Es wäre gewiss 
das beste, den Namen Kittsubstanz für solche Fälle zu reservieren, wo, wie es jetzt Cohn für oberflächliche Epithelschichten nachgewiesen hat, wirklich eine Masse von dichter Konsistenz zwischen den Zellen vorhanden ist." (Gemeint sind die „Kittstreifen" Cohns, 1895, Lit. 20.)

Solger (1896, Lit. 113), der den feineren Bau der Glandula submaxillaris des Menschen untersucht, äussert sich ebenfalls zu der Frage der Identität der Silberlinien und der Kittstreifen („Schlussleisten“ Bonnets). "Er kommt auf seine früheren Arbeiten (1884, Lit. 112 a und durch diese auf 1883, lit. 112) zurück und gibt an, dass es sich seines Erachtens ohne Zweifel bei den zarten Silberlinien und den Kittstreifen „um gleichwerthige Einrichtungen" handelt. Hiermit stellt er sich in Gegensatz zu Cohn (1895, Lit. 20). Er weist darauf hin, dass nach den Ausführungen Bonnets (1895, Lit. 13) dreierlei Material zwischen den Zellen anzunehmen sei : Lymphplasma, Kittsubstanz und „Schlussleisten“. Seines Erachtens, in Gegensatz zu der Auffassung zu Cohn (1895, Lit. 20), geht aus dessen Literaturhinweisen hervor, dass es sich bei den „Schlussloisten“ oder „Kittstreifen" nicht um eine Substanz handelt, die eine spezifische Verwandtschaft zum Hämatoxylin oder doch zur Eisenhämatoxylinfärbung besitzt. Ihm scheinen gewisse Umstände dafür zu sprechen, dass nur die Randbezirke der Leckplatten (Kolossow) imprägniert, werden, die bei dichtem Aneínanderschliessen das Vorhandensein einer einzigen blauen Leiste zustande bringen, er erkennt also keinen Zwang zur Annahme der Einfügung einer differenten Substanz zwischen den Zellen.

Im Jahre 1897 kommt Th. Cohn (Lit. 21) in einer Veröffentlichung über epitheliale Schlussleisten an embryonalen und ausgebildeten Geweben auf seine frühere Arbeit (1895, Lit. 20) zurück. Inzwischen war ihm auch an den sog. Endothelien der Nachweis der Kittstreifen („Schlussleisten“ B on- 
nets) durch Färbung mit $\mathrm{Heidenhains} \mathrm{Eisenhämatoxylin}$ gelungen, so dass seine damalige, mit Vorbehalt geäusserte Vermutung, dass das Vorliegen oder Fehlen dieser Gebilde möglicherweise ein durchgreifendes Unterscheidungsmerkmal zwischen Endothel und Epithel abgeben könne, nicht bestätigt werden konnte. Damit wird freilich einer der gegen die Identität der Schlussleisten und der Silberlinien von ihm vorgebrachton Gründe hinfällig. Er nimmt Bezug auf die Arbeiten Koloss ow s und Solgers (1893, Lit. 64 und 1896, Lit. 113). Die Beobachtung Kolossows, dass die Silberlösung zuweilen auch zwischen die "Zellen in strengem Sinne"eintritt und dann Silbergrenzen von unregelmässigen Konturen hervorruft, zeigt nach $\mathrm{Cohns}$ Ansicht, dass Schlussleisten und Silberlinien nicht identisch sein können. Fortsäıze in die Tiefe der Intercellularlücken kommen bei den Schlussleisten nicht zur Beobachtung und eine Färbung einfacher Lymphgerinnsel in so intensiver und distinkter Weise durch - Eisenhämatoxylin hält Cohn nach seinen umfangreichen Erfahrungen mit diesem liärbemittel für ausgeschlossen. Kolos sow zog aus dem Verhalten der Silberlinien bei starker Ausdehnung der serösen Härte (Stigmata- und Stomata-Bildung) den Schluss, dass zur Lrklärung der Erscheinungen eine stellenw e is e festere Verhindung der Zellen untereinander, wie sie die von ihm beschriebenen intercellulären Anastomosen abgeben, vorausgesetzt werden müsse und ferner dass durch dies Verhalten das Vorhandensein einer oberflächlichen Kittsubstanz ausgeschlossen sei. Diesen letzten Teil des Schlusses hält Cohn für unrichtig, seines Frachtens beweist die Beobachtung $\mathrm{Kol}$ oss ow $\mathrm{s}$ nur, dass die Zellen nicht a us schliesslich an der Oberfläche verkittec sein können, denn in diesem Falle würden allerdings die Zellen bei gleichmässiger Dehnung auch gleichmässig längs ihrer ganzen Grenze auseinander weichen. Die Erscheinungen låssen sich, 'wie er meint, dagegen leicht begreifen, wenn, 
wiè er aunimmt, „neben einer gleichmässigen Ver: kittung der Zellränder in der Höhe des freien Randes der Deckplatten eine $z$ weite unterbrochene Verbindung in der Tiefe durch Intercellularbrücken" besteht. Koloss ow Ansicht, dass die hypothetische Kittsubstanz zur Vervollständigung des Zusammenhaltes der Zellen (durch die protoplasmatischen Brücken) nicht notwendig, ja sogar nicht imstande sei, hält $\mathrm{Cohn}$ die Anschauung entgegen, dass das Cement, das er sich übrigens nicht „flüssig oder halbflüssig“, sondern ziemlich konsistent vorstellt, doch auch vielleicht eine andere Funktion haben könne, als die der mechanischen Aneinanderheftung der Zellen, nämlich die Bewirkung eines festen Verschlusses der Intercellularräume gegen die freie 0 berfläche, für den ja selbstverständlich die Intercchllularbrücken nicht in Betracht kommen können. Auch Cohn trkennt, wie Kolossow, einen Zusammenhang der serösen Höhlẹn mit dem Lymphgefässsystem (durch Stomata oder Stigmata) nicht an, er hält sogar den Abschluss durch die Schlussleisten für noch vollständiger und sagt: „Wenn wir nun an denselben Stellen, an denen wir, wie zum Beispiel am Peritonealüberzug der Kaninchenleber, durch Eisen-Hämatoxylin „Schlussleisten" färben, auch bei Silberbehandlung distinkte schwarze Linien finden (vgl. Abbildung 5 u. a. bei Kolos s.ow), so müssen wir natürlich daraus folgern, dass die Substanz der Schlussleisten bisweilen auch durch Silberimprägnation darzustellen ist. Allerdings wird sie wohl nur selten als solche rein und distinkt geschwärzt, meist werden wir eine gleichzeitige Schwärzung der Schlussleisten und der intraepithelialen Lymphe erhalten, wie dies ja auch bei Kolossows Untersuchungen vielfach der Fall war...." "Ich halte demnach Solgers Anschauung von der Identität der Silber- und EisenHämatoxylinbilder für nicht berechtigt, und ich glaube den Satz, den ich schon in meiner ersten Arbeit aufgestellt hatte, jetzt 
noch entschiedener vertreten zu können, dass nämlich durch die Silber-Reduktion nicht eine specifische Materie in specifischer Weise imprägniert wird, während in der Eisen-Hämatoxylinfürbung ein Mittel gegeben ist, eine ganz bestimmte Materie färberisch darzustellen."

Ge r ota (1897, Lit. 40) wendet bei seinen Untersuchungen über die Anatomie und Physiologie der Harnblase eine Doppelimprägnation mit Silbernitrat und Goldchlorid, wie sie von G. und F. E. Hoggan (1879, Lit. 54) empfohlen war, an. Neben der Reduktion im Licht reduziert er mit einer Hydrochinonlösung und fixiert mit unterschwefligsaurem Natron.

Bergh (1900, Lit. 10) stellt „die Zellgrenzen“ der Blutgetässe der Anneliden durch Behandlung mit verschiedenen Silbersalzlösungen dar.

Simarro (1900, Lit. 107) gibt eine neue Untersuchungsmethode des Nervensystems durch Imprägnation mit Silbersalzen an; sie soll für alle Organe und Gewebe anwendbar sein und beruht auf denselben Prinzipien, wie die Photographie bei ihrer Anwendung des Chlor-, Brom- und Jodsilleers. Nach Durchtrïnk ung mit Jod- oder Bromsalz wird das Objekt in Silbernitratlösung gebracht, so dass sich Jod- oder Bromsilber bildet. Es folgt Einbettung in Celloidin oder anderer Masse, Schneiden im Dunkeln, Belichtung der Schnitte und Hervorrufen des Bildes dirch einen Entwickler, Fixieren der Schnitte. An die Imprägnation kann sich eine Doppelfärbung mit Carmin, Anilintarben, Hämatoxylin usw. anschliessen. Simarro bespricht auch das Eindringen der Silberlösung in die Gewebsstücke. Von der natürlichen Oberfläche aus scheint die Silberimprägnation hauptsächlich der'Neuroglia zu folgen, deren Maschen intensiv schwarz erscheinen. An den Achsencylindern dringt das Silher an den Ranvierschen Einschnürungeh ein, deren Scheiden sich klar und ohne Niederschläge färben. Die Markscheide bleibt ungefärbt, die Achsencylinder werden imprägniert 
und erscheinen intensiv schwarz. Die Imprägnation ist dabei frei von Niederschlägen und es treten Frommann sche Streifen und Ranviersche Scheiben auf.

Einige Jahre vor 1903 nimmt Mos se (Lit. 26, II, S. 501, Anmerkung) dem Verfahren von Si marro ähnliche Versuche einer Art „vitaler Silberimprägnation" vor, kommt aber zu keinen voll befriedigenden Resultaten.

Rega ud (1901, Lit. 91) hat sich bei der Untersuchung des Hodens der Silbermethode bedient. Er weist die Endothelbekleidung der Tunica propria der Samenkanälchen nach durch interstitielle Injektion einer Mischung von konzentrierter Pikrinsäure, 1\%iger Osmiumsäure und 1\%igem Silbernitrat. Nach weiterer interstitieller Alkoholinjektion wird der Hoden, wenn er hart geworden ist, abgeschnitten, in Scheiben zerlegt, und diese Scheiben werden, in Balsam gebracht, im diffusen Licht reduziert.

Rega ud und D ubreuil (1903, Lit. 92) verwenden zur Versilberung seröser Membranen eine frisch bereitete $1 \%$ ige Protargollösung, zum Teil zu gleichen Teilen mit 1\% iger Osmiumsäurelösung, härten dann in Alkohol usw.

E. Cohn (1904, Lit. 19) benutzt zur Darstellung der v. Ku pfferschen Sternzellen der Jeber eine Injektion von $1 \mathrm{~g}$ colloidalen Silbers in $5 \mathrm{ccm}$ destillierten Wassers gelöst in die Randvenen des Kaninchenohrs. Die Sternzellen zeigen sich vollkommen von Silberkörmchen erfüllt. Zellgrenzen sind nicht, zu erkennen.

A chard und A y n a d (1906/1907, Lit. 1, 2, 3, 4) liefern wichtige Beiträge zu den Fragen der Silberimprägnation. Sie sagen, dass $Q$ uinton die Ansicht geäussert habe, die Imprägnation beruhe auf der Anwesenheit von Chlornatrium in den Intercellularlüicken und auf der Bildung eines Niederschlags von Chlorsilber, das sich am Lichte schwärze. Auch ihnen erscheint dies zweifellos. Nach Dechlorierung des Inhaltes der Inter- 
cellularräume bei Epithelien durch Einlegen der Gewebe in Natriumsulfat- oder Zuckerlösung ist die Versilberung unmöglich, nach Rechlorierung durch physiologische Kochsalzlösung oder auch durch andere chloride wird sie wieder ausführbar. Auch kann man das Chlornatrium der Intercellularflüssigkeit ersetzen durch Brom- und Jodsalze, die mit Silber einen am Licht schwarz werdenden Niederschlag geben. Ausser dem Silbernitrat können auch noch andere Silbersalze (Sulfat, Acetat, Citrat, Pikrat, Albuminat-Protargol u. a.) benutzt werden. Die Möglichkeit der Bildung eines Niederschlags ist eben für das Gelingen Bedingung. Entsprechendes gilt für die Querstreifung der Knorpelgrundsubstanz, die Kreuze markhaltiger Nervenfasern und die Frommann schen Linien. Neben dem Chlorgehalt der Gewebe ist die Möglichkeit des Eindringens des Reagens wichtig. Die Gegenwart von Eiweiss behindert dies, offenbar infolge der Viskosität, vor allem stört auch die Koagulation das Eindringen. Das nicht koagulierende Silberacetat gibt daher bessere Bilder. Unter anderem legen $\mathrm{A} \mathrm{ch}$ ard und A y na ud ein Stück seröser Haut in das Serum eines Tieres gleicher Art und versilbern dann mit Silberacetat. Man erhält keine guten Bilder, trotzdem schont das Serum die Zellformen und enthält eine zur Niederschlagsbildung mehr als gerrügende Menge Chlornatrium. Weitere Bedingungen für gute Bilder sind genügende Färbung und Dichte des Niederschlags, genügender Salzgehalt des Reagens und der Gewebsflüssigkeit. Die Silberimprägnation lässt sich auch umkehren, indem man dechlorierte Gewebe mit Silberacetat durchtränkt und dann durch ein Chlorid einen Niederschlag von Silberchlorid erzeugt. Die Autoren schliessen aus ihren Versuchsergebnissen, dass die Intercellularflüssigkeit reich an Chloriden, aber arm an Eiweiss ist. Sie haben auch Niederschläge anderer Art in den intercellulären Lücken erzeugt, so Preussisch-Blau aus Ferrocyankalium und schwefelsaurem Eisen, Palladiumjodid aus Jod- 
kalium und Palladiumchlorid usw. Schliesslich haben A chard und Aynaud eingehend die Widerstandskraft des Endothels gegen verschiedensle physiko-chemische Einwirkungen mit Silbermethoden studiert.

Merkel (1908, Lit. 76) berührt in einem Aufsatz über das Epithelium die Frage nach dem Wesen der Silberwirkung. Er weist darauf hin, dass man sich am optischen Querschnitt der Silberlinien bei jeder Umschlagsfalte einer dünnen ver. silberten Epithellage von der oberflächlichen Lagerung des Niederschlages an den Zellgrenzen überzeugen könne, und sagt, das's der Niederschlag in der eiweisshaltigen Ernährungsflüssigkeit seines Erachtens dort entsteht, wo der lebhafteste Säftestrom vorhanden ist, also an Stelle der Auflockerung des Protoplasmas, dass er aber viel zu grob ist, um in die überaus feinen Lücken einzudringen. In entsprechendem Sinne äussert. Merkel sich in seinem Lehrbach der Anatomie des Menschen (1913, Lit. 77).

Mosse (1910, Lit. 26, II, S. 501) stellt ähnliche Versuche wie früher (vor 1903, Lit. 26, II, S. 501) mit colloidem Silber an, aber ohne Erfolg.

Retzius (1910, Lit. 95) unterzieht die Frommannschen Querlinien der Achsencylinder einer erneuten Untersuchung. Er erhält an den markhaltigen Nervenfasern aus dem Trigeminus erwachsener Haie (Squalus, Acanthias) sehr schöne und reine Reihen von Frommannschen Linien. Die Querlinien bieten an diesen Präparaten hin und wieder ganz deutlich eine spiralige Anordnung dar, die besonders an solchen Fasern hervortritt, welche durch die Präparation etwas ausgezogen worden waren. Die Spirallinien verlaufen stets in derselben Richtung. Wie weit die Querlinien an dem Achsencylinder heraufziehen, hängt davon $a b$, wie weit dieser der Silberlösung zugänglich ist. Es handelt sich um ein Spiralband, das den Achsencylinder umgibt. Die Substanz desselben ist 
feinkörnig. Zuweilen findet man an abgerissenen Enden der ausgezogenen Achsencylinder auch das braune Spiralband abgerissen und stumpf hervorragend; an solchen Stellen ist. die spiralige Beschaffenheit des Bandes ganz besonders deutlich und auffallend. Die Deutung dieser Bilder ist schwierig. Die Regelmässigkeit in der Anordnung der spiraligen Bänder und die verhältnismässig reine Färbung derselben sprechen nicht tür Kunstprodukte. Es ist Retzius bis auf weiteres wahrscheinlicher, dass sie wirklich einer Art von Strukturverhältnis entsprechen und dass an oder in der Oberfläche des Achsencylinders eine solche spiralbandförmige Anordnung der Schicht vorhanden ist. Nur bei der Dehnung des Achsencylinders tritt aber die spiralige Beschaffenheit hervor, wobei auch die Bänder durch die Dehnung viel breiter werden. Die hier heschriebenen Strukturverhältnisse nahm Retzius bis jetzt nur bei den Haien wahr. Bei Knochenfischen und Kaninchen sind die Bilder nicht so deutlich.

Ferner verwendet Retzius die Silbermethode bei der Untersuchung cerebrospinaler Ganglien und der Körperobertäche gewisser Würmer.

In den neueren Lehr-und $\mathrm{Handbüchern} \mathrm{werden}$ verschiedene Deutungen der Silberniederschläge gegeben, manche bezeichnen sie als den Ausdruck einer verkittenden Substanz (Sobotta, 1902, Lit. 111; Böhm-Davidoff, 1903, Lit. 11; G a u p p, 1904, Lit. 37; K op sch, 1908, Lit. 65; Szymon owicz, 1909, Lit. 116; Stöhr, 1909, Lit. 114; Krause, R., 1911, Lit. 67).

\section{Bemerkungen allgemeiner Art, zum Teil auf Grund eigener Untersuchungen, Aufstellung verschiedener der Klärung bedürftiger Punkte betreffend das Epithelgewebe.}

Die Literatur-Besprechung zeigt den Wechsel der Meinungen, vieltach erscheinen die Ansichten direkt gegensätzlich, daneben 
sinil Anschauungen. geäussert, welche ausgleichend Ansichten wesentlich verschiedener Art verbinden. Zur näheren Prüfung de: Verhältnisse wurde zunächst das Epithelgewebe ausgewählt. Es wurden nach dem üblichen Verfahren (Silbernitrat $1 / 2-2 \%$, Reduktion im Licht) die verschiedensten Epithelien in frischem Zustand versilbert und dann die Flächen- beziehungsweise Schnittbilder genauer studiert.

Es lässt sich auf Grund dieser Untersuchungen an einschichtiger und mehrschichtigen Epithelien (Pleuroperitoneal-, Gefäss-, Alveolar-, hinteres Cornea-, Gallenblasen-, Tracheaflimmer-, Magen-, Dünndarm-, Dickdarm-Epithel; vorderes Cornea, Ösophagus- und Oberhaut-Epithel $u$. a. von Kalt- und Warmblütern) sagen, dass die bei der Silberbehandlung entstehenden Niederschläge $n$ ich t rein oberflächlich oder der Zelloberfläche nahe gelegen sind, sondern dass die Silberlösung in die tieferen Epithelschichten dringt beziehungsweise durch das Epithel hindurch in das darunter liegende Gewebe und dort ebenfalls Niederschläge bedingt. Der Grad des Eindringens ist je nach der verschiedenen Art der Epithelien, der Konzentration der angewandten Silherlösung und der Einwirkungsdauer, vielleicht auch je nach dem Funktionszustand der behandelten Gewebe verschieden.

Es ișt aus sogleich anzuführenden Gründen nicht zu erwarten, dass die Silbersalzlösung tiefer in die einzelnen Zellen der behandelten Epithelien eindringt. Es zeigen sich daher nach der. Reduktion im Innern der Zellbezirke meist relativ sehr spärliche oder gar keine Niederschläge. Die Einwirkung des Argentum nitricum erfolgt hier auf $\mathrm{f} r \mathrm{is} \mathrm{ch}$ e Gewebe, deren Zellen noch vitale Eigenschaften aufweisen. Wie L e be r (1868, Lit. 73) bereits in Erinnerung brachte, dringen nach den Untersuchungen von $\mathrm{Gerlach}$ und v. Wittich Farbstofflösungen nicht in die Zellen ein, so lange diese noch vitale Eigenschaften besitzen, erst nach dem Absterben färben sich die Zellen. In 
Historische Darstellung zur Deutung des Wesens der Silhermethode etc. 161

Anlehnung an. Lebers Überlegungen darf man sich den Vorgang vielleicht erklären durch die Annahme, dass die Substanz der Zellen an und für sich wegen ihrer physikalischen Beschaffenheit oder dieser ihrer vitalen Eigenschaften dem Eindringen der Lösungen einen grösseren Widerstand bietet. Aus letzteren könnten nun, ehe sie Zeit haben, in das Innere der Zellen einzudringen, bereits ausserhalb derselben Verbindungen gefällt werden, in denen es bei Belichtung zu einer Reduktion kommt. Aber es erscheint auch eine andere Annahme möglich, nämlich die, dass die äusserste Schicht der Zellen, also hauptsächlich wohl die als Begrenzung gegen die Nachbarzellen differenzierte Protoplasmaschicht, durch die Metallsalzlösung verändert (Abtötung der Zelle) oder koaguliert wird; hierdurch wäre das weitere Eindringen der Flüssigkeit verhindert oder erschwert, es entstehen dann hier und zwischen den Zellen die dunklen Niederschläge aus den Koagulaten. Von diesen beiden Annahmen scheint die erste die wahrscheinlichere zu sein, die Vorstellung der Exis̀tenz von Membranen zur Erklärung der Vorgänge erscheint nicht absolut erforderlich (entsprechend Lebers Auffassung), ja sogar gezwungen.

An den Präparaten der verschiedensten versilberten Epithelien kann man sich vielfach von der Richtigkeit der Wahrnehmungen überzeugen, die für $\mathrm{Schwalbe}$ (1869, Lit. 103) die Grundlage bildeten für seine Unterscheidung der Bildung oberflächlicher schwarzer Netze und der braunen Färbung der Kittsubstanz in den tieferen Schichten. (Auch Adler, 1864, Lit. 6, and Hoyer, 1865, Lit. 55, bemerkten bereits eine Verschiedenheit der Niederschläge.) Bei Flächenbildern versilberter Epithelien, abgesehen von dünnen einschichtigen Plattenepithelien, erkennt man ein scharfes Netz dunkelbrauner bis schwarzer Linien, an die sich, jedoch sehr deutlich davon unterscheidbar, eine hellere braune Färbung in die Tiefe erstreckt. Ganz entsprechende Verhältnisse zeigt die Betrachtung 
von Schnitten. Die schwarzen Linien werden beim Senken des Tubus unscharf, ihr Tiefendurchmesser ist gering, er entspricht etwa dem Dickendurchmesser, an sie schliesst sich direkt die in die Tiefe gehende Färbung an. Zunächst ist nicht ohne weiteres zu erkennen, ob das Netz dunkler Linien den Epithelzellen oberflächlich aufliegt oder ob es innerhalb des Gewebes aber der Oberfläche sehr nahe gelegen ist. Ferner ist die Entscheidung bezüglich des Sitzes der bräunen Färbung schwer, Querschnitte und Flachschnitte lassen aber erkennen, dass sie sich im wesentlichen in den Grenzbezirken, also zwischen den Zellen oder an den Begrenzungsflächen ausserhalb oder innerhalb des Zellinhaltes befindet; es lassen sich hier bei genauer Untersuchung oft in diffus gefärbten platten, lamellenartigen Schichten feine dunkle Körnchen erkennen. In der reinen Kantenansicht imponieren diese Schichten ebenfalls als Linien. Sie bilden beispielsweise bei Cylinderepithelien sozusagen ein Wabenwerk, dessen oberflächlichste Waben an ihren freien Säumen begrenzt werden von jenen braunen bis schwarzen scharfen Linien; in den Wabenhohluäumen liegen die Zellkörper, in den Maschen des Liniennetzes die freien Oberflächen der obersten Zellen.

Die Unterscheidung oberflächlich auf das Gewebe auf- beziehungsweise in das Gewebe eingelagerter Niederschläge und einer in die Tiefe dringenden braunen Färbung bei den meisten Epithelien erscheint sehr zweckmässig. Sie lehnt sich an die von $\mathrm{Sch}$ walbe unternommene Scheidung an, ohne damit die von diesem gleichzeitig geäusserten Anschauungen bezüglich des Sitzes des Niederschlages oder der Färbung - etwa in einer "Kittsubstanz" - zu übernehmen. Eine solche Unterscheidungsmöglichkeit ist später wenig beachtet, vielfach wohl, weil als Versilberungsobjekte leptodefmale Epithelien dienten, bei denen diese Unterscheidung wegen der Dünne der Zellschicht unmöglich ist. Man findet daher in der Literatur auch 
häutig Vermuțungen, welche für eine der beiden unterschiedenen Effekte vertretbar erscheinen, aber nicht für die andere, schlechtweg für die "Silberlinien" ausgesprochen. Da die oberflächlich auf- oder eingelagerten Liniennetze dunkler und distinkter erscheinen als die Färbung in der Tiefe, so sind es vor allem diese Silberliniennetze, auf welche die Hypothesen zum Teil bezogen wurden, oder - was ich betonen möchte - es sind wenigstens vielfach Auffassungen über die „Silberlinien" allgemein geäussert worden, ohne auszusprechen, dass sie lediglich für die eine oder andere Form, für die dunklen Netze oder die Färbung, für zutreffend erachtet werden.

Die Wirkung des Silbersalzes in der.Tiefe (Färbung) des Epithels ist bereits Gegenstand einer Untersuchung Flemming s (1895, Lit. 32) gewesen, der hierbei ein sehr günstiges Objekt (zweischichtiges Kiemenepithel der Salamanderlarve) verwandt hat. Sie wird nach diesem Forscher dargestellt durch einen Niederschlag dunkler Silberkörnchen in der intercellulär vorhandenen Substanz. Es lag daher vor allem nahe, auch die Verhältnisse jener oberflächlich auf- beziehungsweise eingelagerten Silberliniennetze zu prüfen. Dies wurde zunächst als Aufgabe betrachtet und, wenn im folgenden von „Silberliniennetzen“, „Silberlinien“, „Silbernetzen“, „Liniennetzen" und ähnlichem die Rede ist, so sind immer diese gemeint, falls nicht ausdrücklich anderes gesagt ist. Bei den leptodermalen Epithelien sind beide Niederschlagsformen nicht voneinander unterscheidbar.

Es kann kein Zweifel sein, dass diese Silberlinien bei den Epithelien natürlichen Gebilden entsprechen und die Zellen oberflächlich begrenzen, ihre Deutung als Kunstprodukte, wenigstens als solche, die in keiner Abhängigkeit vom Bau des Gewebes stehen, ist haltlos. Es wurde am Mesenterium von Rana (Larve und erwachsenem Tier) und Triton nach der Versilberung mit Hämatoxylin und Eosin sowie auch nach van Gies on 
gefärbt und es wurden genau mehrere Bezirke des Endolhels bei starker Vergrösserung mit dem Zeichenapparat gezeichnet; es fand sich immer für jede Masche ein Zellkern, und zwar für die Epithellagen beider Seiten der Peritonealduplikatur.

Nach der Behandlung der Epithelien mit Silbernitrat sind auch vor der Reduktion bereits den späteren Silberlinien entsprechend stark glänzende Leistchen zuweilen erkennbar, jedoch kommt diese Erscheinung nur seltén zur Wahrnehmung (s. auch Schweigger-Seidel, 1866, Lit. 104).

Die Dicke und Farbtönung der Silberlinien ist sehr wechselnd je nach der Konzentration der angewandten Lösungen, der Einwirkungsdauer, der Belichtungsweise (in diffusem Tagesoder in Sonnenlicht), der Belichtungsdauer, dem Grade der Serumdurchfeuchtung und wohl auch dem Funktionszustande der behandelten Epithelgewebe.

Solche gewöhnlichen Silberpräparate der verschiedenen Epithelien lassen nun nicht entscheiden, wo die Silberlinien liegen, ob sie dem Gewebe aufgelagert sind oder ob sie innerhalb des Gewebes, aber nahe dessen Oberfläche gelegen sind, sie lassen auch keinen Schluss zu auf das. Gebilde, welches durch dieses Liniennetz dargestellt wird. Auch die feinsten Schnitte gestatten kein sicheres Ürteil, so dass versucht werden muss, die Lösung der Frage auf anderem Wege anzustreben.

Angesichts der in der Literatur geäusserten Vermutungen, besonders der von Merke.l (1908, Lit. 76 und 1913, Lit. 77) angedeuteten Annahme, dass vielleicht gewisse Lebensvorgänge für das Zustandekommen der Silberbilder wichtig sind, erscheint eine Prüfung der Frage angezeigt, welcher Gewebszustand Voraussetzung ist für die der Erscheinung zugrunde liegende Reaktion.

Es muss ferner versucht werden, die chemischen Vorgänge bei der Versilberung zu erkennen.

Die vielfachen Schlüsse, welche ältere Autoren aus den 
Silberbildern auf die Intercellularstruktur zogen, scheinen einer Prüfung auf ihre Berechtigung bedürftig.

Schliesslich benötigt die gleichfalls in der Literatur bereits aufgeworfene Frage, ob die oberflächlichen auf- beziehungsweise eingelagerten Silberniederschläge mit den durch $\mathrm{H}$ e id en $\mathrm{h}$ at in s Tisenhämatoxylin darstellbaren Kittstreifen oder Schlussleisten identisch sind, genauerer Prüfung.

Somit sind es vor allem fünf Punkte, welche der eingehenderen Untersuchung und Überlegung bedürfen, die in folgenden Fragen nochmals präcis zusammengestellt sein mögen:

Punkt 1: Wo wird bei der Versilberung nicht fixierter Epithelgewebe der Niederschlag der Silberliniennetze abgelagert, was wird durch diesen Niederschlag zur Darstellung gebracht?

Punkt 2: Welcher Gewebszustand ist beim Epithel Voraussetzung für die der Erscheinung zugrunde liegende Reaktion?

Punkt 3: Was lässt sich bezüglich der chemischen Vorgänge für das Epithel sagen?

Punkt 4: Berechtigt die Art des Zustandekommens der Silberliniennetze zu Schlüssen auf die Intercellularstruktur des Epithels, gestattet das Wesen der Versilberung frischer Epithelien überhaupt, sie als beweiskräftig für die Richtigkeit gewisser Anschauungen bezüglich der Interecllularstruktur (Kittsubstanz-Hypothese) anzusehen?

Punkt 5: Sind die Silberlinien mit den durch Heidenhains Eisenhämatoxylin darstellbaren Schlussleisten (Bonnet) oder Kittstreifen ( $\mathrm{Th} . \mathrm{Cohn}$ ) identisch?

\section{Eigene Untersuchungen und Überlegungen bezüglich dieser Punkte betreffend das Epithelgewebe.}

Z u P unkt 1: Wo wird bei der Versilberung nicht fixierter Epithelgewebe der Niederschlag der Silberliniennetze abgelagert, was wird durch diesen Niederschlag zur Darstellung gebracht? 
Diese Fragen sind bereits vielfach in der Literatur aufgeworfen worden. Der Begründer der Methode, v. Reckling h a u sen (1862, Lit. 88), war der Meinung, dass der Niederschlag zwischen den Zellen läge und eine Kittsubstanz darstelle, viele spätere Autoren teilten im wesentlichen diese Auffassung (,Kittsubstanz" beziehungsweise "Zwischensubstanz"), so B rouef $f$ und $\mathrm{E}$ berth (1864, Lit. 15), Hueter (1866, Lit. 57), Severin (1871, Lit. 106), Sobor of f (1872, Lit. 110), Ranvi e r (1875, Lit. 86), S olger (1883, Lit. 112), Gi r r k e (1885, Lit. 41), Eberth (1894, Lit. 35). Die Bildung einer ganz anderen Ansicht bahnte die Arbeit $\mathrm{A}$ u e rbachs vom Jahre 1864 (Lit. 9) an. Dieser vermutete, dass die Niederschläge dem Gewebe aufgelagert seien und Reste einer eiweiss- und kochsalzhaltigen Flüssigkeit an den Zellgrenzen darstellten. Die Existenz einer minimalen Menge weicherer Zwischensubstanz zwischen den Zellen hielt er trotzdem nicht für ausgeschlossen. Schweigger-Seidel (1866, Lit. 104) schaffte dann eine gewisse Verbindung zwischen den beiden Anschauungen. Henle (1866, Lit. 48) sprach sịch entschiedener für die $\Lambda$ uerbachsche Ansicht aus. Ähnliche Anschauungen verirateu später noch viele andere Beobachter, so $\mathrm{Z}$ oe rner (1881, Lit. 123), Mitrophanow (1884, Lit. 78), B overi (1886, Lit. 14), Kolossow (1893, Lit. 64), Rabl (1893, Lit. 84) und Merkel (1908 bzw. 1913, Lit. 76 bzw. 77). Im Jahre 1.869 machte Schwal be (Lit. 103) die Unterscheidung zwischen oberflächlichen dunklen "Linien“ und einer in die Tiefe dringenden „Färbung der Kittsubstanz“. Entschieden gegen die Auffassung einer Kittsubstanz sprach sich Rob inski (1871, Lit. 97) aus. Später äusserten mehrere Autoren, so Reich (1873, Lit. 93), Flemming (1895, Lit. 32) und Th. Cohn (1897, Lit. 21) mehr oder weniger ausgleichende Anschauungen. (Näheres s. Literatur-Besprechung.)

Viele der-mitgeteilten Auffassungen sind jedoch in einer 
Forrn geäussert worden, die nicht erkennen lässt, ob sie für die Silberliniennetze, wie sie hier betrachtet werden sollen, oder für die Niederschläge in der Tiefe anwendbar erschieinen, wie bereits vorher erwähnt wurde.

Man kann sich eigentlich auf Grund der Angaben in der Literatur kein rechtes Urteil bilden und es fällt daher auf, dass in vielen der neueren Lehr- und Handbücher in verschiedener Fassung nur ausgesprochen ist, durch die Behandlung der Gewebe mit Argentum nitricum werde eine „Kittsubstanz" dargestellt, ohne dabei wenigstens des derzeitigen Mangels einer sicheren Erkenntnis Erwähnung zu tun.

Gerade für die hier zu betrachtenden Silberliniennetze erscheint wegen ihrer Lage an der Oberfläche die Möglichkeit, dass es sich um $\mathrm{A}$ uf lagerungen a uf das Gewebe, herrührend von einer oberflächlichen eiweiss- und kochsalzhaltigen Flüssigkeitsschicht, handelt, gross, ja dieser Umstand darf um so mehr vermutet werden, als viele Angaben der Autoren für ihn sprechen, wie die von A uerbach (1864, Lit. 9, weissliche Trübung des Lymphgefässinhaltes durch Gerinnung, Notwendigkeit des Eindringens des Reagens in die Lymphgefässe für das Zustandekommen der Endothelzellgrenzen in ihnen, Isolierung des Niederschlags), v. Reckling hau sen (1862, Lit. 88, Notwendigkeit der Serumdurchfeuchtung ; 1863, Lit. 89, Bespülungsversuche mil Pericardialtranssudat), B overi (1886, Lit. 14, Berbachtung an Erythrocyten), Hoyer, Sobor off beziehungsweise Reich (1865, Lit. 55; 1872, Lit. 110 bzw. 1873, Lit. 93, Isolierung oder Entfernung der Niederschläge), Schwe igg er-S ei del (1866, Lit. 104, Abspülen mit Zuckerlösung), Feder $\mathrm{n}$ beziehungsweise Rei ch (1866, Lit. $29 \mathrm{bzw}$. 1873, Lit. 93, drehrunder Querschnitt) und die bestimmte Erklärung Henles für die Ansicht A u erbachs (1866, Lit. 48) sowie Merkels Äusserung in neuerer Zeit (1908 und 1913, Lit. 76 und 77, optischer Querschnitt an Umschlagsfalten). 
Deshalb wurden zunächst in dieser Richtung die Angaben einiger Autoren wenigstens teilweise einer Nachprüfung unterworfen.

$E_{s}$ ist nicht gelungen, durch Druck auf das Deckglas die Silberlinien zu zertrümmern, wie das A u e r b a ch (1864, Lit. 9) für ausfïhrbar erklärt; auch durch chemische Reagentien eine Trennung der Silberlinien vom Gewebe herbeizuführen, wie einige Autoren angeben, gelang nicht, ausser mit grob das Gewebe schädigenden Reagentien. Bald wurde aber von diesen Versuchen Abstand genommen, da in Rücksicht auf die Schwierigkeit der Gradbemessung zu setzender mechanischer und chemischer Einwirkungen die Beweiskraft solcher Versuche bezïglich der Lagerung der Niederschläge überhaupt. zweifelhaft erscheint.

Schweigger-Seidel (1866, Lil. 104) gibt an, dass die dïnne, die Gewebsoberfläche bedeckende Schichte Serum, „welche bei Jer Epithelversilberung hauptsächlich in Wirksamkeit tritt", durch Abspülen in einer etwa 4\%igen Zuckerlösung entfernt werden könne und dass dann je nach Gründlichkei des Abspülens nach Anwendung der Silberlösung ,entweder ein fast vollständiges Fehlen der Liniennetze“ oder solche „nur in äusserster Feinheit" zu beobachten seien. Dies kann bestätigt werden, es wurden entsprechende Versuche an verschiedenen Epithelien gemacht, der Unterschied zwischen Objekten, die in Zuckerlösung abgespült waren, und solchen, die nicht so behandelt waren, bei sonst genau gleich ausgeführter Versilberung wurde stets sehr deutlich gefunden 1 ).

Nach Merkel (1908, Lit. 76) liegen die Niederschläge der Silberlinien nicht innerhalb der Oberhautschicht, sonderu sind ihr aufgelagert, was man am optischen Querschnitt, also an jeder. Falte einer versilberten Membran sehen könne. Auch diese Angabe wurde geprüft und es kann erklärt werden, dass

1) Siehe Fussnote auf S. 189. 
an solchen Umschlagsfalten z. B. 'versilberter Mesenterien die Silberlinien sehr deutlich oberflächlich gelagert erscheinen.

Alsdann wurden eigene Versuche unternommen:

Zunächst wurde geprüft, ob überhaupt an Oberflächen, die feinste Rinnen aufweisen, den Silberlinien tierischer Membranen entsprechende Bilder zustande kommen können, wenn sie von dünnen Schichten eiweiss- und kochsalzhaltiger Flüssigkeit bedeckt der Einwirkung von Argentum nitricum ausgesetzt werden.

Nach kurzen, nicht befriedigenden Versuchen an Haaren wurden sehr dünne mit dem Messer von schuppig kristallinischem Glimmer abgespaltene Blättchen gewählt und dieselben in Blutserum von Rana oder Bufo gelegt. Nach einiger Zeit wurden sie kurz in destilliertem. Wasser abgespült (mit der Pinzette ein- bis dreimal durch dasselbe gezogen) und in eine $1 / 2 \%$ ige Lösung von Silbernitrat geworfen, dort verblieben die Blätlchen 2-3 Minuten. Schliesslich wurden sie in destilliertem Wasser abgespült und in diesem dem Lichte (möglichst Sonnenlichto) ausgesetzt. Hierbei brüunten sie sich an manchen Stellen, schliesslich wurden die Blättchen dann in Canadabalsam eingedeckt. Um Tïuschungen etwa durch optische Effekte auszuschliessen, wurden Kontrollpräparate von nicht mit. Serum behandelten aber in sonst genau gleicher Weise versilberten und eingedeckten Glimmerblättchen angefertigt. Bei Untersuchung mil dem Mikroskop unter starker Abblendung zeigen letztere nuu algesehen von unwesentlichen Verunreinigungen deutlich gerade und mehr oder weniger scharf winklig geknickte Grenzen der einzelnen das Mineralblättchen zusammensetzenden dünnsten Schïppchen, von denen allerdings nur die gröberen schon mit blossem Auge wahrnehmbar sind. An dieșen Grenzen befinden sich infolge der Anlagerung benachbarter Schüppchen, deren Grenzen sich nicht decken, zwischen planen Flächen Jer einen Schüppchen und Kanten der benachbarten feine Rinnen, welche bei Auswahl des Substrates ins Auge gefasst 
waren. Bei offener Blende erscheinen diese Grenzen eben nur zart angedeutet. Bei den mit Serum und Silbernitrat behandelten Glimmerblättchen zeigt sich nun folgendes (Fig. 1): Die eben erwähnten Grenzen der Schüppchen treten an vielen Stellen der Präparate sehr deutlich dunkelbraun bis schwarz gefärbt hervor, es imponieren diese Grenzen als stellenweise sehr scharfe dunkle Linien, die an manchen Stellen eine sehr feine, dunkle Körnelung erkennen lassen, sie.erinnern in dieser Form sehr an die Linien versilberter Epithelien. An einzelnen Stellen ist die so entstandene Zeichnung nicht so scharf, die Färbung erstreckt sich auf der einen Seite der Grenze (Seite des Kontaktes der Schüppchen) meist heller braun werdend eine, wenn auch nur geringe, Strecke zwischen die sich berührenden Schüppchen, auch auf der anderen Seite der Grenze (Seite, an der ein Schüppchen unbedeckt vom benachbarten ist) greift die Bräunung stellenweise etwas weiter auf die plane freie Fläche des einen Schüppchens über. Die Linien erscheinen somit streckenweise etwas ,verwaschen“, enthaltèn aber in ihrer Mitte meist einen deutlich tief dunkel gefärbten feinen Streifen, welcher der eigentlichen Schüppchengrenze entspricht. An vielen Stellen jedoch entsprechen sie in Schärfe der Begrenzung und Farbtönung ganz den Silberlinien beispielsweise am Peritonealendothel. Dies alles ist auch bei offener Blende sehr deutlich wahrnehmbar. Mit Absicht wurde bei diesem ersten Versuch in Rücksicht auf später zu besprechende Vermutungen als geeignete Oberflächen bietendes Substrat ein anorganisches Gebilde gewählt.

Ähnliche feinste Rinnen sind auch bei Haaren infolge der Überlagerung der Cuticulaschüppchen vorhanden, und es wurden nunmehr die vor dem Glimmerversuch als nicht befriedigend zunächst aufgegebenen Versuche wieder aufgenommen und die Verhältnisse unter Verwendung dieser organischen Substanz als gewünschte Oberflächen hietendes Substrat erneut und gründ- 
licher geprüft. Benutzt wurde weisses Haar der Katze, Schafwolle, weisses Kopf- und Barthaar des Menschen, letzteres erwies sich als besonders geeignet. Nach Entfettung in Schwefelather oder vereinzelt in Xylol wurden die Haare in Blutserum von Rana gebracht und darin einige Zeit belassen. Danach wurden sie kurz in destilliertem Wasser wie die Glimmerblättchen abgespült und meist mit einer $1 / 2 \%$ igen Silbernitratlösung für 2-3 Minuten behandelt. Schliesslich wurden die Haare in destilliertem Wasser gründlich abgespült, in diesem dem Lichte (möglichst Sonnenlichte) ausgesetzt, wobei sie sich bräunten, und in Canadabalsam oder Glyceringelatine eingedeckt. Wieder um Täuschungen besonders etwa durch optische Effekte auszuschliessen, wurden Kontrollpräparate angefertigt erst von gleichartigen, entfetteten, nicht mit Serum behandelten, aber in sonst genau gleicher Wieise versilberten und eingedeckten Haaren, zweitens von gleichartigen, nur entfetteten, weder mit Serum noch mit Silbernitrat behandelten, in genau gleicher Weise eingedeckten Haaren und schliesslich von gleichartigen, nur entfetteten trocken eingedeckten Haaren.

Bei vergleichender mikroskopischer Betrachtung zeigen sich auch innerhalb der einzelnen Behandlungsgruppen bei den versilberten Objekten sehr verschiedene Effekte, ein Zeichen der hochgradigen Abhängigkeit der Methode von äusseren Umständen, deren Gleichartigkeit der Beobachter nicht immer mit erwünschter Sicherheit herzustellen vermag. Diese Abhängigkeit wurde auch von anderen Untersuchern beobachtet und erschwert die ganze Beurteilung sehr.

Bei den nicht mit Serum, nur mit Argentum nitricumLësung behandelten Haaren zeigt sich - von gänzlich schwarzblau undurchsichtig gewordenen Objekten abgesehen - eine mehr oder weniger intensive Bräunung des ganzen Haares, bei einzelnen auch eine feine längsgerichtete Strichelung aus kurzen einzelnen Strichen bestehend, stellenweise erscheint das 
Mark dunkler gebräunt. An manchen Haaren ist sonst nichts zu erkennen, an anderen sieht man entweder am ganzen Haar oder auf bald kleineren, bald grösseren Strecken dunkelbraune bis schwarze in ihrer Hauptrichtung quer zur Längsachse des Haares verlaufende, stellenweise bei Untersuchung mit starken Linsen aus feinen dunklen Körnchen zusarnmengesetzte, sonst kontinuierliche Linien, die sich zu einem Netz verbinden und, wie ein Vergleich mit den unbehandelten Haaren (Kontrollpräparaten) zeigt, durchaus den Uberlagerungsgrenzen der Cuticulaschüppchen entsprechen. Sie sind auch bei weiter Blende deutlich erkennbar. Diese Beobachtung widerspricht den Erwartungen, schafft weiter Schwierigkeiten für die Beurteilung sowie Mängel bezüglich der Beweiskraft. Auf diese Erscheinung bezügliche Vermútungen werden später geäussert werden, hier genüge die Schilderung des mikroskopischen Bildes. Bei den mit Serum und dann mit Silberlösung behandelten Haaren bietet sich ein ähnliches Bild, doch ist der Effekt noch unbeständiger. Die entstehenden, die Schüppchen begrenzenden Niederschläge imponieren nur stellenweise als mehr oder weniger scharf begrenzte Linien, oft reicht die Bräunung, ganz entsprechend dem Bilde bei den nach Serumbehandlung versilberten Glimmerblättchen, auf der einen Seite eine kurze Strecke zwischen das bedeckte und das deckende Schüppchen, auf der anderen Seite etwas auf die urbedeckte Schuppe, dazu kommen wahllos abgelagerte Niederschläge auf der ganzen Oberfläche, oft im Anschluss an diese an den ttberlagerungsgrenzen sitzénden Niederschlagsmassen. Diese Linien und Flecken haben stellenweise ein feinkörniges Aussehen, sie sind auch bei weiter Blende deutlich wahrnehmbar. Im Vergleich zu den Präparaten von nicht mit Serum behandelten, versilberten Haaren erscheinen hier die dunklen Niederschläge neben mehr oder weniger intensiver diffuser Bräunung, besonders bei letzterer, massiger. Dies mag hier, nicht als beweiskräftig für sich, sondern nur als unter- 
stützend $\mathrm{n}$ e be $\mathrm{n}$ den Ergebnissen der anderen Versuchsgruppen angeführt werden.

Wegen der Mängel der Versuche mit Haaren fahndete ich nach anderen mit Rinnen versehene Oberflächen bietenden, organischen Gebilden und fand als geeignetes Objekt kleine in der Lunge von Rana parasitär lebende Nematoden (Ascaris nigrovenosa). Diese Würmer zeigen nach Versilberung in der üblichen Weise bei mikroskopischer Untersuchung an der Oberfläche der Epidermis feine äusserst scharfe schwarze Linien, die quer zur Längsrichtung des Körpers verlaufen und meist bei Betrachtung mit starken Linsen fein gekörnt erscheinen. Diese sind auch bei weiter Blende deutlich erkennbar. Da nach der einen der beiden herrschenden Hauptanschauungen es sich hier vermutlich um Niederschläge handelt, die oberflächlich der Epidermis aufgelagert in Furchen der Cuticula als Ausdruck eines dort befindlichen eiweiss- und kochsalzhaltigen Inhaltes erscheinen, wurde mit der von $\mathrm{Sch}$ weigger-Seidel empfohlenen Technik durch Abspülen mit Zuckerlösung versucht, diese oberflächliche Schicht, zu entfernen mit dem den Ergebnissen früherer derartiger Vĕrsuche bei Epithelien entsprechenden Erfolge, dass bei nachfolgender Behandlung mit Argentum nitricum-Lösung diese Linien nicht mehr erschienen. Da dies Resultat wiederum die Richtigkeit der vorausgesetzten Annahme wahrscheinlich machte, so liess sich auch in Rücksicht auf das Ergebnis der Versuche mit Glimmerblättchen die Möglichkeit vermuten, eine der entfernten Schicht entsprechende durch Einbringen der Würmer in eine ähnliche eiweiss- heziehungsweise kochsalzhaltige Flüssigkeit erneut zu schaffen, die dann bei Versilberung auch die erwähnten Bilder zustande kommen lassen müsste. Die angestellten Versuche wurden in folgender Weise ausgeführt: Es wurde eine Anzahl der dem Froschkörper entnommenen Würmer für einige Zeit in $4 \%$ ige Zuckerlösung gebracht. Ein Teil derselben wurde dann in Blutserum von 
Rana gelegt, bald darauf nach kurzem Abspülen in destilliertem W'asser mit Silbernitratlösung wenige Minuten behandelt, in destilliertem Wasser wieder abgespült und in diesem dem Lichte (möglichst Sonnenlichte) ausgesetzt, wobei sich die Objekte bräunten. Schliesslich erfolgte die Eindeckung in Canadabalsam. Auch hier wurden, um Täuschungen etwa durch optische Effekte auszuschliessen, Kontrollpräparate angefertigt; indem der andere Teil der in Zuckerlösung eingebrachten 'Tiere nicht mit Serum behandelt, aber sonst in genau gleicher Weise versilbert und eingedeckt wurde. Bei letzteren ist nun neben einer leichten diffusen Bräunung nichts von irgendwelchen Niederschlägen $\mathrm{zu}$ bemerken, die mit Serum behandelten Würmer aber zeigen deutlich schwarze scharfe körnige Linien, die genau denen gleichen, welche bei der Versilberung nicht mit Zuckerlösung behandelter Tiere zu beobachten sind (Fig. 2).

Das Ergebnis der Versuche mit diesen Nematoden gah Anlass zu entsprechenden Experimenten an Epithelgeweben. Verwandt wurde Mesenterium und Darmserosa von Rana und Bufo, die Technik entsprach genau der bei den Würmern angewandten. Als Eiweiss- beziehungsweise Kochsalzlösung wurde das Blutserum des Tieres verwandt, dem das Material entnommen war. Nach zahlreichen ergebnislosen Versuchen wurden schliesslich Präparate (Flächenansichten) gewonnen, die Erwähnenswertes zeigen. Mit Zuckerlösung abgespültes und ohne Serumbehandlung versilbertes Peritonealepithel (Mesenterien und Darmserosa von Bufo) zeigt stellenweise keine, stellenweise nur äusserst zarte Silbernetze an den Grenzen der Epithelzellen, das gleiche mit Zuckerlösung abgespülte, mit Serum behandelte und dann versilberte Epithel weist wenigstens an den meisten Stellen der Präparate deutliche kräftige Silberlinien auf (Fig. 3), die genau denen entsprechen und gleichen, welche an nicht mit Zuckerlösung bespülten, sondern physiologisch serumdurchfeuchteten gleichen Epithelien zu beobachten 
Historische Darstellung zur Deutung des Wesens der Silbermethode etc. 175

sind. Diesem durchaus entsprechend sind die Befunde bei der Magenmucosa von Rana (Flächenansichten), hier sind bei dem mit Serum behandelten Material die Silberlinien besonders deutlich in den Schleimhautfalten (Magengrübchen), in denen vermutlich das Serum besonders reichlich haften geblieben war.

Bei dem Ergebnis der angestellten Versuche lassen sich einige Vermutungen äussern und Schlüsse ziehen: Die verwandten Objekte bieten Oberflächen dar, welche mit sehr feinen Furchen versehen sind. Diese Oberflächen mit Furchen waren frei von anhaftenden Flüssigkeitsschichten (Glimmerblättchen, Haare) oder wurden von solchen durch die angewandte Technik befreit (Würmer, Peritoneal- und Magenmucosa-Epithel). Durch Einbringen der Objekte in Blutserum wurden die Oberflächen von einer eiweiss- beziehungsweise kochsalzhaltigen Flüssigkeitsschicht überzogen, die durch kurzes Abspülen in destilliertem Wasser auf eine sehr geringe Mächtigkeit gebracht oder auf die erwähnten feinen Furchen beschränkt wurde. Diese Serumschicht wurde durch Einwirkung der Silbernitratlösung koaguliert, falls sie die ganze Oberflä.che gleichmässig überzog, vermutlich so, dass sich die Eiweissmassen bei der Verdichtung (Koagulation) in den erwähnten Furchen oder ihrer nächsten Umgebung absetzten, falls sie nur noch auf diese Furchen beschränkt war, so, dass die Koagulate ohne weiteres in diese $\mathrm{zu}$, liegen kamen. Durch chemische Einwirkung der zueinander gebrachten Stoffe und bei Einwirkung des Lichtes kam es zu einer Bräunung oder Schwärzung dieser koagulierten Eiweissmassen beziehungsweise der Produkte der chemischen Umsetzungen, die die dunklen Silberlinien der Präparate bedingt.

Diese Utberlegungen stellten eine Arbeitshypothese dar. Waren sie richtig, dann musste auch eine im folgenden skizzierte Methode entsprechende Bilder liefern. Es konnte erhofft werden durch Aufbringen von Tusche auf Gewebe in physiologisch 
serumdurchfeuchtetem Zustande Tuscheteilchen in die oberflächlich anhaftende Serumschichte zu verteilen und durch Hinzufügen von absolutem Alkohol diese zur Koagulation zu bringen; es wurde erwartet, dass dann bei der Verdichtung die Tuscheteilchen mitgerissen und in den Koagulaten einander mehr genähert als in der nicht koagulierten Serumschichte als dunkle Linien oder Streifen sichtbar werden würden. Diese Erwartungen wurden auf ihre Berechtigung duŕch den Versuch geprüft.

Froschblutserum, mit verdünnter schwarzer chinesischer Tusche auf einem Objektträger vermischt und mit einem Tropfen absoluten Alkohols beschickt, ergab tief dunkle Koagulationsgerinnsel. Darauf wurde für den Versuch am Gewebe das Peritonealepithel ausgewählt. Eine Darmschlinge mit Mesenterium einer frisch getöteten Rana wurde nach kurzem Abspülen in Aqua destillata vorsichtig auf einer Glasplatte ausgebreitet und mit verdünnter schwarzer chinesischer Tusche betropft; nachdem die Tusche einige Zeit auf dem Objekt belassen war, wurden vorsichtig einige Tropfen absoluten Alkohols zugesetzt, schliesslich kam das so behandelte Objekt in absoluten Alkohol. Das herausgeschnittene Mesenterium wurde dann nach Aufhellen in Xylol in Canadabalsam eingedeckt. Bẹi der mikroskopischen Betrachtung zeigen sich an vielen Stellen Zeichnungen, die durchaus denjenigen nach Behandlung mit Höllensteinlösung entsprechen (Fig. 4). Die Zeichnungen sind nicht überall ganz so scharf und deutlich wie bei der Versilberung, letztere arbeitet entschieden viel feiner, aber es unterliegt keinem Zweifel, dass es sich hier um ganz entsprechende Gebilde handelt. Beispielsweise zeigen sich auch feine Auflagerungen auf den durch die dunklen Linien begrenzten Zellfeldern, die oft einen kleinen etwa central gelegenen Hof frei lassen (Fig. 4), der wohl einer durch den Kern bedingten Erhebung der Zelloberfläche entspricht; dies ist auch bei Versilberungen oft $\mathrm{zu}$ beobachten, wie die Schilderungen von A uerbach (1864, Lit. 9) und Schweig- 
ger-Seidel (1866, Lit. 104) ja auch zeigen. Bei reichlich vorhandenem Serum kommen auch unregelmässig dicke auf die Fläche der Zellen übergreifende Grenzstreifen zustande, Bilder ähnlich denen, die A ue rbach (1864, Lit. 9) für Silberpräparate beschrieben hat. Durch den Nachweis des Kernes durch Färbung für jedes Areal konnte die Natur der entstandenen Zeichnungen als Zellgrenzen sichergestellt werden. Durchaus entsprechende Präparate ergaben bei gleichem Verfahren z. B. die Serosa des Rectum beim Frosch (Fig. 5) und das Venenendothel beim Rind (Kernnachweis).

Die direkte Beobachtung des der Erscheinung zugrunde liegenden Vorgangs unter dem Mikroskop verbessert nun die in einer Hinsicht noch nicht ganz klaren Vorstellungen. Ich brachte eine Darmschlinge mit Mesenterium eines frisch getöteten Frosches nach kurzem Abspülen in destilliertem Wasser vorsichtig auf eine Glasplatte und setzte auf die obere Fläche des schonend ausgebreiteten Häutchens einen Tropfen verdünnter schwarzer chinesischer Tusche. Bei Betrachtung unter dem Mikroskop zeigte sich bereits bei dem so behandelten Objekt, also ohne Zusatz von Alkohol, eine Zeichnung schwarzer feiner Linien, die genau den vorher beschriebenen Bildern entsprach. Der mit Delafields Hämatoxylin am frischen, nicht fixierten Präparat vorgenommene Kernnachweis stellte die ZellgrenzenNatur der Linien ausser jeden Zweifel. Danach kann gesagt werden, dass bei der Behandlung nicht fixierter Epithelien mit Argentum nitricum wohl die Koagulation wegen der auf Eiweisslösungen eben immer wirksamen Eigenschaften dieses Reagens in Rechnung zu ziehen ist, dass die Koagulation aber von untergeordneter Bedeutung erscheint, während als das Wesentliche bei dem Vorgang die Füllung der capillaren Spalten (Furchen, Rinnen) zwischen den Zellen zu erkennen ist. Auch nach Abspülen des Mesenterium in Zuckerlösung lassen sich diese Spalten in der beschriebenen Weise mit Tusche-Teilchen füllen. 
Dies Verfahren mit chinesischer Tusche bietet - dies darf hier vielleicht bemerkt werden - vor der Silbermethode einige Vorteile, wenn es auch nicht so exakt arbeitet. Die Tusche ist reichlich zu verdünnen, etwa bis sie in dünner Schicht (ausgebreiteter Tropfen auf einem Objektträger) mitteldunkel rauchfarben und durchscheinend bis durchsichtig erscheint. Einige Zeit nach Zusatz der Tusche kann das Objekt schonend mit destilliertem Wasser abgespült wérden. Man kann nun die Kerne entweder am nicht fixierten Gewebe darstellen oder erst das Objekt mit guten Fixationsmitteln behandeln und dann die Kerne färben. Vermutlich werden alle in Frage kommenden Fixations- und Färbemethoden Anwendung finden können, doch wurde dies noch nicht genauer geprüft. Jedenfalls bietet das 'T'usche-Verfahren den Vorteil, dass nicht eine das Gewebe stark verändernde Wirkung gleichzeitig mit der Erzeugung der Zellgrenzlinien ausgeübt wird, wie bei der Silbermethode, so dass eine wesentlich schonendere Fixation vor der Färbung möglich wird und die Färbung dann vor allem besser angreift. Dieser Unistand berechtigt vielleicht zu gewissen Erwartungen bezüglich einer praktischen Verwendung des Tusche-Verfahrens nach dessen weiterer Erprobung. Nach einigen Versuchen wurden wenigstens beim Peritonealepithel immer hinreichend deutliche Zellgrenzen erhalten, die Präparate demonstrieren meist sehr schön die Verhältnisse. Es sei noch erinnernd bemerkt, dass bereits Severin (1871, Lit. 106) versucht hat, in den vermuteten Räumen zwischen den Epithelzellen durch Fällen von Carmin aus schwacher Carminlösung eine Markierung der Zellgrenzen hervorzurufen, jedoch ohne Erfolg. Ferner sei auch an seine Eisenchlorid-Ferrocyankalium-Versuche sowie an die Verfahren von A chard und A y a u d (1906/07, Lit. 1, 2, 3, 4) erinnert; bei allen diesen Verfahren erscheint eine Möglichkeit der gröberen Gewebsveränderung durch die angewandten Chemikalien nicht ausgeschlossen, bei dem Tusche-Verfahren wäre eine entsprechende Vermutung gegenstandslos. 
Hiatorische Darstellung zur Deutung des Wesens der Silbermethode etc. 179

Ob die Adhäsion für das Zustandekommen der Silber- oder Tuschelinien von Bedeutung ist, wie B overi (1886, Lit. 14) für die Silbemiederschläge vermutet, ist schwer $\mathrm{zu}$ erkennen. Boveri prüfte, wie vorher geschildert, die Versilberurigsmöglichkeit an Froschmesenterien, die er auf eine Uniterlage fixiert oder nicht fixiert mehr oder weniger austrucknen liess. Ich habe ganz entsprechende Versuche mit Mesenterien und Lymphsackwandungen vom Frosch angestellt teilweise mit entsprechenden Ergebnissen, teilweise aber auch mit anderen, so dass kein eindeutiges Gesamtresultat zur Verlügung steht. Vielleicht kann man die von Boveri zur Begründung seiner Vermutung, dass der Kontakt eine so wichtige Rolle spiele, angeführten Versuchsergebnisse auch anders erklären, nämlich durch die Annahme, dass bei der Trocknung fixicrter Objekte durch das Auseinanderweichen der Zellen die erst steilwandigen Spalten zwischen ihnen allmählich in schrägwandige Furchen umgewandelt werden, in denen dann wegen der damit verbundenen Vèrgrösserung der SerumschichtOberfläche die Austrocknung schneller erfolgt als bei nicht fixierten Endothelien, bei denen die Rinnen steilwandig bleiben. Übrigens entsteht der bei Belichtung braun werdende Niederschlag auch im Reagenzglas bei Zusatz von Argentum nitricumLösung zu Blutserum. Es sei daher an die Bedenken Rabls (1893, Lit. 84) erinnert und, wie von diesem, die Anwesenheit von Gewebsflüssigkeit (oberflächliche Serumschicht) in den Spalter als das wichtigste Moment angesprochen. Die Erzeugung von Silberlinien zwischen einander berührenden Blutkörperchen, wie sie Legros (1868, Lit. 75) beschreibt, gelang nicht, auch liessen sich derartige Bilder in Gefässen versilherter Mesenterien, wo sie Boveri (1886, Lit. 14) gesehen hat, nicht finden.

Da bei den vorher beschriebenen Tuscheversuchen die Leistungsfähigkeit des geplanten Vorgehens den Erwartungen 
entsprach, so war an der Richtigkeit der Voraussetzungen nicht mehr zu zweifeln. Deshalb kann wohl auch allgemëin die eingangs gestellte Frage nunmehr beantwortet und folgendes mittels „hypothetischen Urteils" als erwiesen angesehen werden:

Bei der Versilberung nicht fixierter Epithelien ist der Niederschlag der Silberliniennetze oberflächlich dem Gewebe a u gelagert, nicht innerhalb des Gewebes gelegen; durch den Niederschlag werden in den Furehen (Rinnen, Spalten) der Epitheloberfläche an den Zellgrenzen Reste der Serum-. schicht, welche physiologisch die Gewebsoberfläche befeuchtet, beziehungsweise deren Umwandlungsprodukte sichtbar.

$\mathrm{Zu} \mathrm{Punkt} \mathrm{2:} \mathrm{Welcher} \mathrm{Gewebszustand} \mathrm{ist} \mathrm{beim} \mathrm{Epithel}$ Voraussetzung für die der Erscheinung zugrunde liegende Reaktion?

Die Ansicht von Le g r os (1868, Lit. 75), dass die Silbermethode nur. an lebenden Tieren beziehungsweise beim Menschen nur an amputierten Gliedern anwendbar sei, ist bereits als falsch durch Sobor off (1872, Lit. 110) erkannt. Auch erschien ihm und anderen Autoren, so $\mathrm{H}$ ueter (1866, Lit. 57), Reich (1873, Lit. 93) und Eberth (1894, Lit. 35) die Wirkung des Versilberungsverfahrens mehr oder weniger gesichert, wenn sie über die von v. Recklinghausen (1862, Lit. 88) gegebene Vorschrift, ganz frisches oder höchstens 24 Stunden nach dem Tode entnommenes Material zu verwenden, hinausgingen. Mir scheint in allen diesbezüglichen Äusserungen wohl der "supravitale" Gewebszustand gemeint zu sein, der als Voraussetzung für das Angreifen der Methode angesehen wird. Doch gilt wohl der Satz: Je frischer das Gewebe, desto schöner die Silberliniennetze. Merkel (1908, Lit. 76 und 1913, Lit. 77) bringt den Säftestrom mit dem Zustandekommen der Ablagerurgen in Beziehung. Wo dieser am lebhaftesten ist, sollen „die in der eiweisshaltigen Ernährungsflüssigkeit entstehenden Niederschläge" abgesetzt werden. So begründet sich die in 
obiger Frage enthaltene Forderung nach einer Prüfung der Beziehungen zwischen dem Zustandekommen der Niederschläge und Lebensvorgängen in dem behandelten Gewebe. Bei der Beantwortung der Frage ist möglichst Präzisierung anzustreben unter Benutzung unserer modernen Begriffe von den Gewebszuständen in der Zeit lückenloser tubergänge von dem Eintritt der tödlichen Schädigung bis zum definitiven Gewebstod und darüber hinaus.

Es wurde angestrebt, der Lösung der Frage durch einige Versuche näher zu kommen.

Dis mehrfache Erprobung der Versilberung der Zellgrenzen an Stücken physiologisch in Wasser abgelöster Froschepidermis zeitigte durchweg negative Ergebnisse.

Dann erschienen die bereits im vorigen Abschnitt geschilderten Versilberungsversuche an Haaren beachtenswert, auf dio hier deshalb zurückgekommen werden mag. Es interessiert jetzt nur der dort bereits geschilderte Effekt der Versilberung am entfetteten, sonst unbehandelten Haar, vor allem der Umstand, dass überhaupt an diesen Objekten, deren oberflächliche Cuticula zweifellos totes Zellenmaterial darstellt, nach Behandlung mit Silbernitrat wenigstens stellenweise oberflächliche dunkle Zeichnungen auftreten, die offenbar den Uberlagerungsgrenzen der Cuticulaschüppchen entsprechen und durchaus den Silbernetzen z. B. beim versilberten Endothel des Peritoneums des Froschmesenteriums gleichen. Aber die grosse Unbeständigkeit des Effektes ișt auffallend. Es erscheint bedenklich, diese Erscheinung ohne Einschränkung als einen positiven Ausfall der Versilberungsversuche zu deuten. Zunächst scheint die Möglichkeit nicht ausgeschlossen, dass durch das Einbringen der organischen Substanz in die Argentum nitricum-Lösung Reaktionen ausgelöst und deren Produkte abgeschieden werden, die dann in den durch die Überlagerung der Cuticulaschüppchen entstehenden Furchen liegen bleiben, während sie sonst ab- 
gespült werden. In diesen Produkten kommt es bei Belichtung zur Abscheidung dunkler Körnchen, vor der Belichtung sind diese nicht wahrzunehmen. Diese Vermutung findet eine Stütze in dem Ergebnis einiger Versuche, bei denen entfettete Haare mit verdünnter schwarzer chinesischer Tusche behandelt wurden. Nachdem diese einige Minuten in solchen gelegen haben, zeigen sie deutlich, entweder auf grössere oder auf kleinere Strecken, ein Netz schwarzer scharfer Linien und im Anschluss an diese einige schwarze Flecken. Dieses Netz, das auch bei weiter Blende deutlich erkennbar ist, entspricht genau den Uberlagerungsgrenzen der Cuticulaschüppchen, wie der Vergleich mit Kontrollpräparaten, erkennen lässt. Ferner ist zu denken an die weitere Möglichkeit, dass die Entfettung der Haare nur unvollkommen sein und kleinste Spuren von Fett gerade in den erwähnten Furchen haften bleiben können, die dann gerade hier Silberlinien zustande kommen lassen, etwa durch Umsetzungen zwischen Fett und Argentum nitricumLösung und Abscheidung von dunklen Kömchen in den Produkten. Diese Vermutung suchte ich auf ihre Berechtigung zu prüfen durch Einbringen von Haaren, die in gleicher Weise mit Schwefeläther zwecks Entfettung behandelt waren, in Osmiumsäure und Sudan. Die Osmiumpräparate zeigen jedoch nur ganz vereinzelt kleine Stellen, an denen eine schwarze Zeichnung, den Uberlagerungsgrenzen der Cuticulaschüppchen entsprechend, sichtbar ist, dic Sudanpräparate lassen nichts Erwähnenswertes erkennen. Die Ergebnisse aller dieser Versuche sprechen somit mehr für die erste Annahme (mechanische Festhaltung von Reaktionsprodukten an gewissen Stellen, in denen bei Belichtung dunkle Körnchen abgeschieden werden). Höchstwahrscheinlich handelt es sich eben hier um Sonderverhältnisse, die nicht in Parallele gestellt werden können mit den Vorgängen bei der Versilberung frischer Epithelien.

Weiterhin wurden zahlreiche Versilberungsversuche an ab- 
sterbendem Epithelgewebe unternommen. Besonders geeignet erschien das Flimmerepithel der Trachea, da die Flimmerbewegung ein gutes Kriterium des Gewebszustandes abgibt. Verwendet wurde Material von Warmblütern, besonders Katzen. In gewissen Zeitabständen wurden den Kadavern der Katzen kleine Stückchen der Trachea entnommen. Der grösste Teil jedes dieser Stückchen wurde in üblicher immer gleicher Weise versilbert (Arg. nitric. 0,5\%, 2-3 Min.), nachdem vom kleineren Teile das dem zu versilbernden also unmittelbar benachbarte Epithelhäutchen mit der Pinzette vorsichtig abgezogen und in physiologischer Kochsalzlösung bezüglich Flimmerbewegung untersucht war. Diese Untersuchungen in physiologischer Koch salzlösung wurden mehrere Male wiederholt, wenn überhaupt nicht oder nicht deutlich oder nur stellenweise Flimmerbewegung wahrnehmbar war, an ebenfalls den zu versilbernden unmittelbar benachbarten Epithelbezirken. Die Schilderung des Effektes der Versilberung an den Epithelschichten der einzelnen Präparate bleibt hier zweckmässig unterlassen; es sei nur im allgemeinen folgendes gesagt: Die Methode griff noch deutlich an, als auch bei sorgfältigster Untersuchung in physiologischer Kochsłlzlösung Flimmerbewegung nicht mehr erkennbar: war, allerdings waren die Bilder verschieden. In der ersten Zeit nach der Tötung des Tieres erzeugte die Behandlung mit Argentum nitricum nebien diffuser Bräunung scharf begrenzte, winklig polygonale Felder, die durch kräftige Linien voneinander getrennt waren, später wurden die Linien stellenweise zarter, die Begrenzung der Felder wurde abgerundeter, es erschienen mehr oder weniger zahlreich wesentlich grössere rundliche Felder, das Bild machte den Eindruck, als ob das Gewebe gequollen wäre, noch längere Zeit nach der Tötung (rund $100 \mathrm{Std}$.) machte das versilberte Epithel deutlich einen glasig gequollenen Eindruck, die Methode hatte nur stellenweise, aber deutlich angegriffen. Von sonstigen Unterschieden darf hier wohl ab- 
gesehen werden. Diese Verschiedenheit der Bilder ist meines Erachtens im wesentlichen bedingt durch Veränderungen im morphologischen, physikalischen und chemischen Aufbau der behandelten Gewebe infolge nekrobiotischer Vorgänge. Als solche sind zu nennen Dissoziationen durch Uberdehnungen und Erweichungen der fibrillären Stützgerüste und durch Lockerung der Intercellularsubstanzen, Konturyeränderungen durch Aufquellung, Vakuolenbildung oder Schrumpfung sowie durch Kolliquationen und Koagulationen, letztere besonders infolge der Fixation durch das Reagens. Zu diesen Veränderungen, allmählich mehr und mehr hervorgerufen durch diese histolytischen Prozesse, kommen noch die Unterschiede, die bedingt werden durch die metamorphotischen Prozesse der Nekrobiose. Die entsprechenden Untersuchungen benachbarter Epithelbezirke bezüglich der Flimmerbewegung in physiologischer Kochsalzlösung liess in der ersten Zeit nach dem Tode überall deutliche Bewegung der Flimmerhaare erkennen, später wurde dieselbe träge und war nur vereinzelt wahrnehmbar, während ein Teil der Zellen die Flimmerhaare in Ruhe zeigte. Die Versilberung hatte bei den Nachbarbezirken stets deutlich angegriffen und ein meist kontinuierliches Netz dunkler Silberlinien erzeugt. Noch längere Zeit nach der Tötung (rund $100 \mathrm{Std}$.) war die Flimmerbewegung nur noch vereinzelt an kleinen Bezirken wahrnehmbar und nur durch Untersuchung mehrerer Epithelstreifchen festzustellen, der grösste Teil der Flimmerepithelzellen wies die Härchen in Ruhe auf. Schliesslich liess das Epithel auch bei sorgfältigster Prüfung überhaupt keine Flimmerbewegung mehr erkennen, am. Saum der Epithelzellen waren Zellkörper und Haare oft nicht mehr deutlich unterscheidbar und, weit in grösserem Umfange als vordem, waren Flimmerepithelzellen von ihrer Unterlage abgehoben und isoliert. Die entsprechenden mit Argentum nitricum behandelten Nachbarteile zeigten stets deutlich das Angreifen der Methode, wenn 
auch das Liniennetz stellenweise unterbrochen war, scheinbar an Stellen, wo das Epithel eben vorher abgehoben wurde: So wies beispielsweise ein Stück Tracheaschleimhaut 127 Stunden nach Tötung der Katze (Chloroformtod, Carotideneröffnung und Ausblutung) bei mehrfacher sorgfältiger Prüfung keine Spur von Flimmerbewegung mehr auf, die Epithelzellen waren sämtlich, scheinbar erst durch die Strömungen infolge Auflegen des Deckglases, isoliert, das entsprechende versilberte Präparat zeigte aber sehr deutlich in einem relativ grossen Bezirk ein kontinuierliches Netz von Silberlinien. Auch bei Epithelien von Fröschen (Munddachflimmer-, Magen- und Lungen-Epithel) wurden zahlreiche ähnliche Versuche gemacht, die vielfach entsprechende Verhältnisse zeigten. Gewebe von Kaltblütern erschienen aber aus verschiedenen Gründen weniger geeignet. Es ist wohl statthaft, in dem Aufhören der Flimmerbewegung, oder doch in der Abhebung der Flimmerepithelzellen von ihrer Unterlage und in ihrer Isolierung den Abschluss des Prozesses des Zelltodes zu erblicken. Nach den Wahrnehmungen an diesem unter allmählichen Absterbeerscheinungen zugrunde gehenden Gewebe beziehungsweise ihren Zellen darf daher wohl gesagt werden: Während der ganzen Dauer der Nekrobiose (im Sinne Verw orn s) beziehungsweise über deren Abschluss hinaus (ganze Dauer des supravitalen Gewebszustandes und Beginn des postmortalen) greift die Methode an. Diese Beobachtung und die bereits im vorigen Abschnitt behandelten Untersuchungsergebnisse machen es schliesslich wahrscheinlich, dass der Zustand der Gewebe selbst beziehungsweise der diese zusammensetzenden Zellen allein überhaupt nicht von Bedeutung ist, es kommt vielmehr der Zustánd der die Gewebe oberflächlich bedeckenden Serumschichte in erster Linie in Betracht; solange diese die für die Methode notwendigen reaktionsfähigen Substanzen enthält, wird die Methode angreifen. Es ist zu vermuten, dass diese Substanzen noch sehr lange nach dem defini- 
tiven Tode der von der Serumschicht bedeckten Gewebe in dieser reaktionsfähig verbleiben, denn wenn man aufgekochtes Frosch- oder Rinderblutserum beziehungsweise rund 4 Minuten lang gekochtes Hühnereiweiss, also Eiweiss, in dem alle labilen Substanzen beseitigt sind, mit Argentum nitricum-Lösung behandelt (geschehen im Reagenzglas für 2 Minuten mit 0,3- bis $0,5 \%$ iger Silbernitratlösung), mit destilliertem Wasser abspült und belichtet; so zeigen die Koagulate deutliche Bräunung und auch (sichtbar bei den Koagulaten dés Rinderblutserum) $\mathrm{Ab}$ scheidung dunkler Körnchen. Bis das Serum der benetzenden Schicht bei der Zersetzung so weit kommt, dauert vermutlich relativ lange Zeit. Die Prüfung der Vermutungen am Gewebe ist unmöglich, weil das Gewebe, welches die für den Effekt. der Methode massgebende Oberflächengestaltung bietet, bezüglich seiner Strukturveränderungen bereits während der Nekrobiose (supravitaler .Gewebszustand) grösstenteils bis an das Ende der Möglichkeiten, d. h. zum Zerfall in seine Elemente gelangt ist. Die Annahme einer Aktivität der Gewebe beziehungsweise der Ernährungslymphe bezüglich der Reduktion der entstehenden Silberverbindungen erscheint auch nicht nötig, denn in der Dunkelkammer behandelte Epithelien lassen bei rotem Licht keine dunklen Silberlinien erkennen, sondern erst nach Belichtung im Tageslicht und durch Kochen koaguliertes Hühnereiweiss, von dem das oben Ciesagte gilt, das später mit Höllensteinlösung behandelt wird, bräunt sich im Dunkeln nicht, sondern erst bei Belichtung. Die entstehenden Silberverbindungen sind eben nicht lichtbeständig, und auch bei der Behandlung der. Gewebe mit Höllensteinlösungen scheint, wie später noch näher zu erörtern sein wird, nur das Licht. die Ausscheidung der dunklen Körnchen aus den Verbindungen zustande zu bringen. Dass das Erzeugen dunkler Linien auch ohne eine Aktivität der Gewebe möglich' ist, allein durch Behandlung frischen Serums mit. Argentum nitricum, beweist. 
ferner der vorher geschilderte Versilberungsversuch an Glimmerblättchen, die in Serum getaucht waren; hier ist ja das die notwendige Oberflächengestaltung bietende Gebilde anorganisch. Ferner ist hier auf das Ergebnis der Versilberungen bei Ascaris nigrovenosa hinzuweisen. Hier entstehen die Niederschläge oberflächlich in Furchen der Cuticula, die bei den Nematoden kontinuierlich die Epidermis oberflächlich bedeckt, es kommt hier also eine Beteiligung der Ernährungslymphe usw. nicht in Frage.

Nach alle diesem lässt sich wohl die eingangs gestellte Frage mit folgendem beantworten:

Voraussetzung für die der Erscheinung zugrunde liegende Reaktion am Epithelgewebe ist der supravitale Gewebszustand, der postmortale nur so weit, als in ihm der Zusammenhang der einzelnen Zellen zum Gewebe gewahrt bleibt. Ebenso wesentlich aber als dies ist der Zustand der das Gewebe oberflächlich bedeckenden Serumschichte. Bezüglich dieser" scheint Voraussetzung für die Reaktion der unzersetzte Zustand derselben zu sein, wenigstens darf eine Zersetzung nur in dem Masse erfolgt sein, dass die für die Methode notwendigen reaktionsfähigen Substanzen ungespalten bleiben.

$\mathrm{Zu} \mathrm{Punkt} \mathrm{3:} \mathrm{Was} \mathrm{lässt} \mathrm{sich} \mathrm{bezüglich} \mathrm{der} \mathrm{chemischen}$ Vorgänge für das Epithelgewebe sagen?

Die Frage nach den chemischen Vorgängen ist in der Literatur bereits vielfach diskutiert. Es stehen sich vor allem zwei Anschauungen gegenüber, nach den einen Autoren, so Krause (1844, Lit. 66), Boveri (1886, Lit. 14), Kultschitzky (1887, Lit. 71), A chard und A y a ud (1906/07, Lit. 1, 2, 3, 4) entsteht zunächst Chlorsilber, nach anderen wird kein Chlorsilber gebildet (A d le r, 1864, Lit. 6), sondern Silberalbuminat (Adamkiewicz, 1874, Lit. 5; Gierke, 1885, Lit. 41, und M uscatello, 1895, Lit. 81). Rabl (1893, Lit. 84) 
denkt neben der Möglichkeit der Bildung von Silberalbuminat an die einer Zusammenlagerung der Moleküle zu einem .Silbernitrat-Eiweiss, analog dem Vorgang bei der Fällung des Harnstoffs aus seiner Lösung durch Quecksilbersalze. Auch über die Natur der dunklen Körnchen beim Epithel oder allgemein ist die Anschauung nicht einheitlich, sie werden von manchen Forschern als reduziertes, metallisches Silber angesehen (Krause, 1844, Lit. 66; Schwalbe, 1869, Lit. 103; G i erke, 1885, Lit. 41; B overi 1886, Lit. 14). Ra bl hingegen (1893, Lit. 84) hält die Körnchen nicht für metallisches Silber, sondern für eine Verbindung desselben, wahrscheinlich ein Oxydationsprodukt. Bezüglich der Bedeutung der oft verwendeten Lichtwirkung sind die Ansichten verschieden. Nach Adler (1864, Lit. 6) entstehen die Silberniederschläge im Dunkeln ebenso wie im Licht, nach anderen wird die Reduktion durch Sonnenlicht „wesentlich gefördert" (Gi i rke, 1885, Lit. 41), beziehungsweise es bleibt die Wirkung ohne Lichteinfluss aus (Chrzonszczewsky, 1865, Lit. 18; Boveri, 1886, Lit. 14). Flemming (1895, Lit. 32) vermutet die Möglichkeit einer Verschiedenartigkeit der chemischen Reaktion bei Einwirkung von. Argentum nitricum auf Epithellymphe und Lymphe im Bereiche der Bindesubstanzen. Genauere Hypothesen als für die Versilberung des Epithels sind für die der Hornhautgrundsubstanz ausgesprochen, so von $\mathrm{H}$ is (1861, Lit. 50, 1862, Lit. 52, primär extracellulär Chlorsilber, erneute Lösung nach Zersetzung des Chlorsilbers durch phosphorsaure Alkalien, sekundärer Niederschlag von reduziertem Silber intracellulär, Lichteinfluss bleibt rätselhaft), L e b e r (1868, Lit. 73, im wesentlichen Anschluss an $\mathrm{His}$ ) und $\mathrm{Schweigger-}$ S e idel (1869, Lit. 105, primär Silberalbuminat, sekundäre Umwandlung in Chlorsilber). Besonders in Anbetracht der soeben angeführten Äusserung Flemming s erscheint es aber nicht angängig, ohne eingehende Prüfung für die Hornhaut- 
Historische Darstellung zur Deutung des Wesens der Silbermethode etc. $\quad 189$

grundsubstanz ausgesprochene Vermutungen auch für das Epithelgewebe für anwendbar zu erachten.

Es darf wohl als sicher gelten, dass bei der Einwirkung von Metallsalzen, also auch von Silbersalzen, auf organische Substanzen sich Verbindunge in bilden, dass also die Metallsalze chemisch gebunden werden.

Bezüglich der Frage, welche Verbindungen bei der Behandlung der Gewebe mit Argentum nitricum zunächst entstehen, möchte ich erwähnen, dass $\mathrm{Buchheim}$ in seiner Arzneimittellehre (S. 242, zitiert nach $\mathrm{His}$, 1861, Lit. 50) ausführt, trotz der Verwandtschaft des Chlors zum Silber verbinde sich letzteres bei Gegenwart eiweissartiger Körper zunächst mit diesen. Deshalb hat die Annahme, dass sich ein Albuminat bildet, viel für sich, gegen diese sprechen aber vor allem die Ergebnisse der neueren Untersuchungen von A chard und Aynaud (1906/07, Lit. 1, 2, 3, 4). Wie von diesen wurden auch hier Gewebe (Lymphsackwandung vom Frosch) mit Zuckerlösung dechloriert, z. B. mit Calciumchloridlösung rechloriert und dann versilbert. Die Silberbilder der rechlorierten Objekte waren deutlich; aber die Linien waren in der Farbtönung und ihrem ganzen Aussehen anders, mehr grau gekörnt gegenüber den bräunlichen bis schwarzen meist kontinuierlichen Silberlinien am frischen Gewebe. Dass die Chloride eine Rolle spielen, ist somit wahrscheinlich, hingegen scheinen sie $n$ icht allein, von Bedeutung zu sein. Die Verschiedenheit der Bilder versilberter frischer und versilberter de- und dann rechlorierter Epithelien erklärt sich vielleicht durch das Fehlen der oberflächlichen Serumschicht bei letzteren, welche durch die Behandlung entfernt wird ${ }^{1}$ ). Offenbar scheinen

1) Neben der von Achard und A y naud beschriebenen und benatzten Dechlorierung der Gewebe durch Linbringen derselben in Zuckerlosung, kommt os moines Erachtens bei dieser Behandlung fraglos auch zu einem $\mathrm{A}$ bspulen der oberflachlichen Serumschicht. Diesen Umstand hat schon Schweigger:Seidel (1866, Lit. 104) angenommen und verwandt, auch bei den geschilderten 
hier kompliziertere chemische Vorgänge abzulaufen, deren $\mathrm{Er}$ kenntnis noch eingehender, spezieller Untersuchung überlassen werden muss. A $\mathrm{ch}$ ard und A y $\mathrm{n}$ a $\mathrm{ud}$ ziehen aus ihren Untersuchungsergebnissen den Schluss, dass die Intercellularflüssigkeit reich an Chloriden, aber arm an Eiweiss ist. Die hier genauer untersuchten oberflächlichen Silberlinien lassen sich aber, wie vorher geschildert, auch auf freien Oberflächen, welche Rinnen aufweisen, nach Aufbringen von Blutserum erzeugen. Letzteres enthält bekanntlich relativ viel Eiweissstoffe, aber relativ wenig Chloride. Deshalb bestehen Bedenken gegen die Richtigkeil der Uberlegungen von A chard und A ynaud in dieser Richtung.

Was die Natur der Körnchen in den Niederschlägen nach der Reduktion anlangt, so kann die Angabe Rabls (1893, Lit. 84) bestätigt werden. Sie lösen sich in thioschwefelsaurem Natrium, stellen also kein metallisches Silber dar.

Die Bedeutung der Lichtwirkung wurde ebenfalls geprüft.

Studien wurde er vielfach benutzt. Für die Richtigkeit dieser Ubberlegung sprechen unter anderem drei Tatsachen: Erstens werden bei die Behandlung der Epithelien mit Zuckerlösung und nachfolgender Versilberung die Linien abgestuft schmaler, bis sie überhaupt nicht mehr hervorgerufen werden, sind aber, wenn sie noch auftreten, stets scharf, ja scharfer als ohne Behandlung in Zuckerlobung, und gleich dunkel, was ohne Annahme eines Fortspulens der oberflächlichen Serumschicht allein durch die Dechlorierung kaum erklarbar erscheint. Zweitens spricht hierfür, dass durch Kinbringen der Objekte in Zuckeriðsung oder andere Flüssigkeiten das Zustandekommen von Niederschlagsauflagerungen erfahrungsgemäss vermieden wird. Drittens würde, wenn keine Abspulung erfolgen whirde, bei der hier oft angewandten nachträglichen Eisbringung in Blutserum die Eiweissschicht verstarkt werden und es mussten dann nach den Erfahrungen von Achard und Aynaud bei anschliessender Versilberung nur mangelhafte Bilder erzengt werden. Hierbei musste dảs von mir benutzte Silbernitrat wegen seiner koagulierenden Wirkung n o ch schlechtere Bilder liefern als das nicht koagulierende von den beiden französisehen Autoren verwandte Acetat. Dies ist jedoch nicht der Fall (s. Fig. 3). 'Die Ergebnisse von $A \mathrm{cb}$ ard und $\mathrm{Ayna}$ u bezüglich der störenden Wirkung des Eiweisses geben auch die Moglichkeit für Erk]ärungen des öfteren Misslingens der Versilberungsversuche nach Abspalen in Zuckerlösung und erneuter Serumdurchfenchtung (s. S. 174). 
Historische Darstellung zur Deutung des Wesens der Silbermethode etc. 181

Hierzu wurde die Versilberung an frischen Epithelien in der Dunkelkammer ausgeführt und bei rotem Licht nach verschieden langer Zeit (Stunden und Tagen) mit dem Mikroskop nach den Linien gesucht, jedoch wurden niemals solche gefunden. Es erschienen die Silberlinien aber an den Objekten, sobald dieselben in das Tageslicht gebracht wurden. Auch gekochtes Hühnereiweiss, das nach Behandlung mit Argentum nitricum gut mit destilliertem Wasser bespült worden war, bräynte sich im Dunkeln auch nach Tagen nicht, jedoch sehr bald bei Belichtung, Es erscheint daher, wie schon von Chrzonszczewsky (1865, Lit. 18) und Boveri (1886, Lit. 14) angegeben wurde, der Lichteinfluss für das Zustandekommen der Silberlinien nötig. Auf die Möglichkeit der Reduktion durch chemische Agentien soll hier nicht weiter eingegangen werden.

Somit mag die eingangs gestellte Frage mit folgendem beantwortet werden:

Die chemischen Vorgänge bei der Behandlung frischer Epithelien mit Silbernitrat scheinen recht kompliziert zu sein, sie bedürfen weiterer "eingehender Untersuchung, vermutlich spielen neben den Chloriden die Eiweissstoffe der Gewebe heziehungsweise der sie durchtränkenden oder sie benetzenden Serumschichten auch eine Rolle. Die nach der Reduktion entstehenden dunklen Körnchen sind kein metallisches Silber, für ihre Entstehung ist der Lichteinfluss notwendig.

Z u Punkt 4: Berechtigt die Art des Zustandekommens der Silberliniennetze zu Schlüssen auf die Intercellularstruktur des Epithels, gestattet das Wesen der Versilberung frischer Epithelien überhaupt, sie als beweiskräftig für die Richtigkeit gewisser Anschauungen bezüglich der Intercellularstruktur (Kittsubstanz-Hypothese) anzusehen?

Die Äusserungen in der Literatur, welche beim Eingehen auf diese Fragen beachtenswert scheinen, sind bereits bei dem kurzen Rückblick auf die Literatur zu Punkt 1 zusammen- 
gestellt, es kann daher auf alles dort Ausgeführte Bezug genommen werden. Besonders betont Kultschitzky (1887, Lit. 71), dass die Silberreaktion für die Kittsubstanz nicht beweisend sei. Boveri (1886, Lit. 14) sagt, dass man den gegen die Auffassung der Darstellung einer Kittsubstanz durch die Silbermethode geäusserten Bedenken wenig Beachtung schenkte, weil letztere auch nicht einwandfrei waren, und dass man zu seiner Zeit von der Kittsubstanz ,als von etwas vollständig Erwiesenem, ja Selbstverständlichem" spräche, diesem kann man heute hinzufügen, dass sich hierin nichts wesentlich geändert hat trotz der weiteren Bekämpfung dieser Anschaiuung durch viele Autoren. Die Vorstellung der Kittsubstanz ist in neueste Lehr- und Handbücher übernommen (z. B. S o b otta, 1902, Lit. 111; Böhm-David off, 1903, Lit. 11; Kopsch, 1908, Lit. 65 u. a.), wie auch Merkel (1908, Lit. 76) ausführt, wohl hauptsächlich infolge der verbreiteten Anerkennung der Sicherheit ihres Nachweises durch Argentum nitricum.

Da es sich nach den bisherigen Ausführungen bei dem Niederschlag der Silberliniennetze um dem Gewebe oberflächlich in Furchen (Rinnen, Spalten) a u f gelagerte Gebilde handelt, so könnten diese Zeichnungen zu Schlüssen auf das Gefüge $\mathrm{z}$ w is chen den Zellen, also innerhalb des Zellverbandes, des Gewebes, nur herangezogen werden, wenn mindestens eine gewisse gleich zu besprechende Voraussetzung zuträfe. Es wäre denkbar, dass eine etwa vorhandene spezifische intercelluläre Masse in ihren oberflächlichsten Bezirken mit dem Silbersalz in Berührung kommt, wenn dieses in der zu Punkt 1 näher besprochenen Weise auf die Epithelien einwirkt. Bei dieser Berührung dürfte ein erkennbarer und verwertbarer (für Schlüsse auf die Struktur), allerdings vielleicht von den rein oberflä.chlichen Niederschlägen der Liniennetze mehr oder weniger verdeckter Effekt erwartet werden, wenn überhaupt das Argentum nitricum beim Zusammentritt mit dieser Masse oder Bestand. 
Historische Darstellung zur Deutung des Wesens der Silbermethode etc. 193

teilen derselben eine spezifische Reaktion auslösen würde, wenn also die Versilberung frischer Epithelien ihrem Wesen nach überhaupt gestattet, sie als beweiskräftig für die Existenz einer etwa vorhandenen spezifischen intercellulären Substanz oder gewisser Bestandteile derselben und damit für die Richtigkeit gewisser Anschauungen über die Intercellularstruktur (Kittsubstanz-Hypothese) anzusehen. Mit der Prüfung dieser g e nerellen Frage wird zugleich die Beweiskraft der Niederschläge in der Tiefe, von denen hier sonst abgesehen ist, beurteilt. Trifft diese Voraussetzung nicht zu, so dürfen also auch die Silberliniennetze nicht $\mathrm{zu}$ Schlüssen auf die Interecllularstruktur verwendet. werden, $d$. h. es sind dann b eid e eingangs gestellte Fragen zu verneinen.

Wir wissen nach den bisherigen Betrachtungen auf Grund eingehender experimenteller Prüfungen, dass die Versilberungsmethode am Epithel durch Niederschläge lediglich einen eiweissund kochsalzhaltigen Stoff (Serum) oder dessen Umwandlungsprodukte sichtbar macht. Diese Erkenntnis gibt jedoch nicht die Möglichkeit einer Entscheidung bezüglich der Konsistenz dieses Stoffes oder gewisser Bestandteile desselben beziehungsweise seiner oder deren Eigenschaften im lebenden Gewebe. Speziell für die oberflächlichen silberliniennetze gilt, dass der in ihnen sichtbar werdende Stoff am lebenden Objekt von flüssiger Konsistenz ist, dies ist aber auf andere Weise erkannt (Abspülbarkeit, Ersatzmöglichkeit durch flüssige Stoffe, Rückschluss aus Tuscheversuch), das Silberbild bietet hierfür kein Kriterium. Nach diesem kann also auch nicht entschieden werden, ob die intercellulär etwa vorhandene Masse oder Bestandteile derselben dünner, zäh-flüssig, ẃeich oder fest, cementartig sind und ob sie verkittende Eigenschaften besitzen, oder auch mit anderen. Worten, ob sie flüssige Lymphe, eine Zwischen $\mathrm{s} u \mathrm{bstan} \mathrm{z}$ oder $\mathrm{K}$ it t substanz ist.

Würde die Schwärzung nach Behandlung mit Argentum 
nitricum die Existenz einer Kittsubstanz beweisen, so müssten wir nach den Ergebnissen der Versilberungen von Ascaris nigrovenosa auch hier auf eine Kittsubstanz schliessen. Es ist aber bekannt, dass bei den Nematoden die Cuticula kontinuierlich die Epidermis oberflächlich überdeckt, und es ist vorher bereits gesagt, dass die Niederschläge in oberflächlichen Furchen der Cuticula erzeugt werden. Auch noch an die Glimmerblättchen, die in Blutserum getaucht, dann versilbert wurden und dunkle Linien erkennen liessen, sei hier erinnert.

Es ist hier noch zu zwei Angaben der Literatur Stellung zu nehmen:

Severin (1871, Lit. 106) behandelt, wie bereits vorher erwähnt, Epithelien mit Eisenchlorid und Ferrocyankalium. Die Ergebnisse seiner Versuche machen ihm die Existenz einer Kittsubstanz wahrscheinlich, wenn sie ihm auch nicht eindeutig erscheinen. Scheinbar nimmt Severin für das Eisenchlorid eine Verwandtschaft zur Kittsubstanz an, für das Ferrocyankalium nicht, aus welchen Gründen ist nicht zu erkennen. Die nach dem von mir geübten, vorher beschriebenen Verfahren mit schwarzer chinesischer Tusche erhaltenen Bilder und die auf diese bezüglichen Uberlegungen (gleicher optischer Effekt, keine chemische Einwirkung der Tusche) nehmen der S everin schen Beweisführung das Uberzeugende.

Flemming (1895, Lit. 32) sagt, dass er, was den Ausdruck „Kittsubstanz" betreffe, möglichst vermieden habe, ihn in dem meist gebräuchlichen Sinne zu benützen, denn durch ihn werde $u$. a bei den Epithelien die falsche Vorstellung begünstigt, dass es sich immer um eine Masse von erheblicher Fèstigkeit handele, was doch u. a. für den Inhalt der tiefen Epithellücken nicht gelten könne. Dieser Äusserung kann man sich wohl insoferm anschliessen, als die Wahl der Bezeichnung „Kittsubstanz" unzweckmässig erscheint, da die von den An- 
Historische Darstellung zur Deutung des Wesens der Silbermethode etc. 195

hängern der Kittsubstanz-Hypothese oft zitierte Schwärzung durch Argentum nitricum, wie vorher schon ausgeführt, eine feste oder zähe, verkittende Konsistenz der intercellulären Masse nicht beweist, und sogar viele andere Umstände es wahrscheinlich machen (Flemming, 1895, Lit. 32), dass der Inhalt der Intercellularräume flüssige Lymphe ist. Die Lymphnatur dieser intercellularen Massen wird natürlich durch die Silbermethode auch nicht bewiesen.

Nach alle diesem lässt sich sagen, dass die Versilberung nicht fixierter Epithelien wohl auf die stoffliche Beschaffenheit des Inhaltes der Intercellularräume gewisse Schlüsse gestattet, nicht aber auf sein Gefüge und seine Eigenschaften und dementsprechend:

Die beiden eingangs gestellten Fragen sind zu verneinen.

$\mathrm{Zu}$ Punkt 5: Sind die Silberliniennetze mit den durch $\mathrm{H}$ e i d e $\mathrm{nh}$ a in $\mathrm{s}$ Eisenhämatoxylin darstellbaren Schlussleisten (Bonnet) oder Kittstreifen ( $\mathrm{Th}$. Cohn) identisch ?

Mit Heidenhains Eisenhämatoxylin lassen sich bekanntlich an den meisten Epithelien die Schlussleisten (Bonn e t) in sehr klarer Weise darstellen. M. Heide $\mathrm{n} h \mathrm{~h}$ in selbst (vber Kern und Protoplasma, Separatabdruck aus der Festschrift zum 50 jährigen Doktorjubiläum des Herrn Geheimrat. Prof. Dr. v. Koellike r, Leipzig 1892 , zitiert nach K. W. Z i m merm a n n, 1898, Lit. 122, auch zitiert von B o n n e t, 1895, Lit. 13) sagt sehr mit Recht von diesem Schlussleistennetz: „.. . man hat durchaus den Eindruck, als ob eine gut gelungene Versilberung der Kittsubstanz vorläge." Die Frage, ob vielleicht diese Schlussleisten (B onnet) oder (wie sie Th. Cohn nennt) Kittstreifen und die Silberlinien identisch sind, liegt also sehr nahe. Sie ist wohl zuerst aufgeworfen von $\mathrm{Th}$. Cohn (1895, Lit. 20). Dieser hält Silberlinien und Kittstreifen für nicht identisch. Nach Solger (1896, Lit. 113) handelt es sich hingegen „um gleichwertige Einrichtungen". In einer zweiten 
Arbeit vertritt $\mathrm{Th} . \mathrm{Cohn}$ (1897, Lit. 21) seine früher geäusserte Ansicht entschiedener, er hält Solgers Annahme der Identität für nicht berechtigt. In einigen neueren Lehrbüchern (v. E bne r, 1902, Lit. 25; Kop s h, 1908, Lit. 65) werden die Schlussleisten als eine ,besondere Art der Kittsubstanz" oder als eine „verkittende Substanz", aber als etwas „von der übrigen Kittsubstanz Verschiedenes“ angeführt.

Da nach den früheren Ausführungen die Silberliniennetze als oberflächlich dem Gewebe aufgelagerte Niederschläge erkannt sind, die Schlussleistennetze aber im Gewebe beim Dünndarmepithel beispielsweise unter der Cuticula liegen, scheint die Ansicht $\mathrm{Th}$. Cohns die richtige zu sein.

Um zu einem Urteil zu gelangen, überzeugte ich mich durch Versilberung dieses Materials zunächst von der oberflächlichen Lagerung der Silberlinien. Am optischen Querschnitt derselben bei dem Flächenbild versilberter Dünndarmzotten ist dies leicht möglich, schwieriger ist es an Schnitten des Dünndarmepithels. Es wurde nun versucht, versilberte Dünndarmschleimhaut mit $\mathrm{Heidenhains} \mathrm{Eisenhämatoxylin} \mathrm{zu} \mathrm{färben,} \mathrm{um}$ auf diese Weise neben den Silberlinien auf der Cuticula die Schlussleisten unter derselben unterscheiden zu können. Das Gewebe nahm aber besonders gerade in seinen oherflächlichen Bezirken die Färbung so schwor an, dass ich zu keinen befriedigenden Präparaten kam.

Ich suchte daher nach einer von diesem Nachteil freien Methode, die dasselbe wie die Silbermethode leisten und möglichst auch einen anders als schwarz gefärbten Niederschlag zustande bringen sollte (Kontrast gegen die dunklen Schlussleisten).

Ohne die letzte Forderung zu erfüllen, schien in diesem Sinne verwendbar das vorher beschriebene Verfahren mit verdünnter schwarzer chinesischer Tusche. Diese Methode, welche bei manchen Vorteilen doch nicht so exakt arbeitet 
wie das Argentum nitricum, führte auch $\mathrm{zu}$ keinen befriedigenden Ergebnissen. Scheinbar stört vor allem der auf der Darmschleimhaut reichlich vorhandene Schleim die Vor. gänge; die Verhältnisse scheinen eine gewisse Ähnlichkeit mit denen bei Versilberung der Gelenkkapselepithelien zu haben, wie sie Schweigger-Seidel (1866, Lit. 104) andeutet; es crscheint daher die Entfernung dieses. Schleimes in schonender Weise vorher notwendig, besonders zwischen den Dünndarmzotten.

Um gleichzeitig auch der letzten Forderung (Kontrastfärbung) zu genügen, wurde noch versucht, mit Suspensionen ganz feinen Zinnobers zum Ziele zu kommen. Um feinste Zinnoberteilchen zu erhalten, benutzte ich die fraktionierte Sedimentierung besten Malerzinnobers (Günther Wagners Zinnober II). Die Versuche hatten jedoch noch weniger Erfolg. Die Teilchen schienen trotz allem zu gross. Andere Versuche blieben ähnlich erfolglos.

Es ist also bisher nicht geglückt, eine Methode, welche obige Forderungen mehr oder weniger erfüllt, zu finden. Weitere Versuche in dieser oder anderer Richtung (z. B. entsprechend den Versuchen von Müller [1867, Lit. 80], L e ber [1868, Lit. 73], Severin [1871, Lit. 106] und denen von A c h a r d und A y n a d [1906/07, Lit. 1, 2, 3, 4]) müssen aber wohl schliesslich zum Ziele führen.

Wenn nun auch solche Präparate, welche zugleich, aber in leicht voneinander unterscheidbarer Farbe, den Silberlinien gleichwertige Zeichnungen und die Schlussleisten zeigen müssten, besonders wünschenswert erscheinen, vor allem weil sie auch bei Epithelien ohne Cuticularsaum brauchbare Bilder liefern müssten, so kann man doch schon an Schnitten von versilbertem Dünndarmepithel erkennen, dass die Silberniederschläge auf der Cuticula liegen. Besonders deutlich wahmehmbar war dies mit starker Vergrösserung an Schnitten vom Dünn- 
darmepithel des Rindes nach Versilberung und Färbung mit Böhmers Hämatoxylin. Aus diesem Befund und der Tatsache, dass die Schlussleisten unter der Cuticula liegen, geht schon hervor, dass von einer Identität beider Netze wenigstens am Darm nicht die Rede sein kann.

Es darf wohl daher wenigstens für das Darmepithel die obige Frage mit folgendem beantwortet werden:

Die Silberliniennetze und die durch- $\mathrm{H}$ eid e $\mathrm{n} h$ a in s Eisenhämatoxylin darstellbaren Schlussleisten (Bonnet) oder Kittstreifen (Th. Cohn) sind nicht identisch.

\section{Entsprechende Untersuchungen und Überlegungen an markhaltigen Nervenfasern bezïglich der „Ranvierschen Kreuze“.}

Auch über einige den am Epithelgewebe unternommenen Versuchen zum Teil entsprechende Untersuchungen an markhaltigen Nervenfasern mag kurz berichtet werden.

ther die Behandlung des Nervengewebes mit. Silbersalzen ist in der Literatur vielfach gesprochen, es sei erinnert an die Arbeiten von Frommann (1864, Lit. 36), Grandry (1869, Lit. 42), Ranvier (1875, Lit. 86), K och (1878, Lit. 61, bzw. Gerlach, 1878, Lit. 39), R u mpf (1878, Lit. 99), Engel. mann (1880, Lit. 28), Solger (1883, Lit. 112), Boveri (1886, Lit. 14), Schiefferdecker (1887, Lit. 101), Joseph (1888, Lit. 59), Jakimovitsch (1888, Lit. 58), Fischel (1893, Lit. 31), R a bl (1893, Lit. 84), S i ma r ro (1900, Lit. 107), Mosse (vor 1903, Lit. 26, II, S. 501 Anm.), Achard und Aynaud (1906/07, Lit. 1, 2, 3, 4) und Retzius (1910, Lit. 95).

Meine am Nervengewebe angestellten Versuche beschränken sich auf die sog. „Ranvierschen Kreuze" markhaltiger Nervenfasern. 
Die Frage nach dem Sitz der Niederschläge und der Natur der dargestellten Masse hat ja bereits B overi (1886, Lit. 14) sehr eingehend beantwortet. Es wurden hier zunächst entsprechend den Versuchen am Epithel frische markhaltige Nerven vom Frosch zerzupft, in etwa $4 \%$ iger Zuckerlösung einige Zeit abgespült, in Blutserum des Tieres, dem das Material entnommen war, gebracht, dort einige Zeit (mehrere Stunden) belassen, dann nach kurzem Abspülen in destilliertem Wasser in üblicher Weise versilbert und in Canadabalsam eingedeckt. Wie beim Epithelgewebe wurden die nötigen Kontrollpräparate angefertigt. Es zeigt sich folgendes: Die nur mit Zuckerlösung abgespülten und dann versilberten Nervenfasern zeigen deutlich Einschnürungen, an diesen aber keine so deutlichen Niederschläge, dass dieselben als „Ranviersche Kreuze“ angesehen werden können. Die mit Zuckerlösung und Blutserum behandelten Nervenfasern lassen, wenigstens zuweilen, an den Einschnürungen Niederschläge erkennen, die deutlich den Querschenkel des Ranvierschen Kreuzes darstellen, der Längsschenkel ist nur eben angedeutet (Fig. 6). Das vorher (beim Epithel) besprochene Tuscheverfahren lieferte bis jetzt nicht. voll befriedigende Resultate. Nach den Feststellungen am Epithel und nach dem eben geschilderten Befund kann unter Anschluss an B o v e ri gesagt werden: In dem Spaltraum zwischen den beiden aneinander stossenden Scheidenzellen ergibt sich aus den Niederschlägen ein Ring, der optisch als Querschenkel des Ranvierschen Kreuzes imponiert. Er ist vollkommen mit den zwischen anderen Zellen auftretenden Silberlinien zu homologisieren, ist also der Nervenfaser oberflächlich a ufgelagert. Er macht Reste einer physiologisch in diesem Spaltraum befindlichen Gewebsflüssigkeit (Serum) beziehungsweise deren Umwandlungsprodukte sichtbar. Bezüglich der Bedeutung der Adhäsion bei dem Zustandekommen des Ringes gilt dem für das Epithel Gesagten Entsprechendes. 
Die Frage nach dem Gewebszustand, welcher bei den Fasern Voraussetzung für die der Erscheinung der Ranvierschen Kreuze zugrunde liegende Reaktion ist, haben Grandry, Jakimovitsch und Rabl (s. o.) behandelt. Versilberungsversuche an absterbenden Nervenfasern vom Rind liessen ein Urteil gewinnen. In gewissen Zeitabständen wurden kleine Faserstückchen peripheren markhaltigen Nerven entnommen und in üblicher, immer gleicher Weise versilbert. Die Präparate wiesen mehr oder weniger Zeichen nekrobiotischer Vorgänge auf. Noch 72 Stunden nach dem Tode des Tieres wurden deutliche Ranviersche Kreuze erhalten, vor allem war der Querschenkel deutlich. Unter Anschluss an Rabl (s. o.), der zum Gelingen der Darstellung die Intaktheit der Funktionsfähigkeit nicht für nötig, aber die Anwesenheit „noch gelösten unveränderten Eiweisses" für notwendig hält, lässt sich äussern : Bezüglich des Gewebszustandes, welcher bei markhaltigen! Nervenfasern Vorausselzung für das Zustandekommen des den Silberlinien am Epithelgewebe homologen Ringes (Querschenkel des. $R$ anvier schen Kreuzes) ist, gilt dem für die Silberlinien bei Epithelien Gesagten Entsprechendes.

Was die chemischen Vorgänge belrifft, so sei hier speziell an die Arbeiten von Boveri und Rabl (s. o.) erinnert. Es ist wohl ohne weiteres anzunehmen, dass die vorher bei den Epithelien gewonnenen Anschauungen auch bei der Beurteilung der Vorgänge an den markhaltigen Nervenlasern in wesentlichen angewandt werden dürfen.

Auch bei den markhaltigen Nervenfasem wird zuweilen von einer Kittsubstanz und ähnlichem in den sog. Einschnürungen gesprochen, so von v. Mor o ch ow etz (1878, Lil. 79), solge r (1883, Lit. 112) und in einigen neueren Lehrbüchern (z. B. S töhr, 1909, Lit. 114, Krause, 1911, Lit. 67). Nach den Ergebnissen der Untersuchung, ob das Wesen der Versilberung überhaupt gestattet, sie als beweiskräftig für die 
Richtigkeit gewissè Anschauungen bezüglich der Intercellularstruktur (Kittsubstanz-Hypothese) anzusehen, darf wohl folgendes gesagt werden: Die Art des Zustaudekommens des den Silberlinien ain Epithelgewebe homologen Ringes (Querschenkel des $R$ anvierschen Kreuzes) an markhaltigen Nervenfasern berechtigt nicht zu Schlüssen auf die Struktur der zwischen zwei aneinander stossenden Scheidenzellen (im Sinne B o ver i s) befindlichen Masse. Für diese erscheint daher die Bezeichnung „Kittsubstanz“ (u. ähnl.) verwerflich aus Gründen, welche den bei Besprechung der Verhältnisse beim Epithelgewebe geäusserten entsprechen.

\section{Kurze Zusammenfassung der Ergebnisse.}

1. Gewinn einer Orientierung über die Entwickelung der Anschauungen bezüglich des Wesens der Versilberung am nicht fixierten Objekt (Epithel-, Binde-, Muskel- und Nervengewebe).

2. Positive beziehungsweise negative Ergebriisse der Nachprüfungen mehrerer Versuche und Beolachtungen ialterer Autoren am Epithelgewebe.

3. Indirekter Beweis, dass bei der Versilberung nicht fixierter Epithelien der Niederschlag oberflächlich gelegen, an den Zellgrenzen in Furchen Reste einer Serumschicht, welche physiologisch die Gewebsoberfläche benetzt, beziehungsweise deren Umwandlungsprodukte darstellt (Anschluss an die Anschauungen älterer Autoren).

4. Auffindung eines Verfahrens zur. Darstellung der Epithelzellgrenzen mittels Füllung der Furchen an diesen durch Tusche-Teilchen, welches vielleicht wegen einiger Vorteile vor der Silbermethode, die allerdings exakter arbeitet, zu gewissen Erwartungen berechtigt, zunächst aber noch eingehenderer Erprobung bedarf.

5. Erkenntnis des Gewebszustandes, welcher beim Epithel 
Voraussetzung für die der Versilberung zugrunde liegende Reaktion ist (Präzisierung).

6. Stellungnahme zu den Auffassungen bezüglich der chemischen Vorgänge bei der Versilberung der Epithelien, die noch eingehenderer Untersuchung bedürfen.

7. Verwerfung der Versilberung als Beweismittel für gewisse Vorstellungen bezüglich Gefüge, Konsistenz oder Eigenschaft der intercellulären Massen („Kittsubstanz") (Anschluss an ältere Autoren).

8. Erkenntnis, dass die Schlussleisten (B onn et) und die Silberlinien - wenigstens am Darmepithel - nicht identisch sein können (Anschluss an. Th. Cohn).

9. $\mathrm{Zu} \mathrm{2,} \mathrm{3,} \mathrm{5,} 6$ und 7 entsprechende Erkenntnisse an markhaltigen Nervenfasern (Ranviers Kreuze).

Göttingen, den 15. Januar 1919. 


\section{Literaturverzeichnis.}

1. Achard und Aynaud, Sur le rôle du chlorure de sodium dans l'imprégnation histologique des tissus par l'argent. Compt. Rend. de l'Acad. d. Sciences, Paris 1906.

2. Dieselben, Sur les conditions histo-chimiques de l'imprégnation par l'argent. Compt. Rend. d. séances et mém. de la Soc. Biol. T. 61. Paris 1906.

3. Dieselben, Sur l'imprégnation histologique par les précipités colorés. Compt. Rend. d. séances et mém. de la Soc. Biol. T. 61. Paris 1906.

4. Dieselben, Recherches sur l'imprégnation histologique de l'endothélium. Arch. de médecine Expérim. 1907.

5. Adamkiewiez, Über die Behandlung von Geftssen mit Silbernitratlösnngen. Berl. klin. Wochensohr. Nr. 29. 1874 (d. Verf. nach d. Citat bei Gierke, Lit. 41, nicht zu ermitteln, nach diesem angefthrt).

6. Adler, Vorldufige Mitteilung uber eine mit Silberimbibition gemachte Beobachtung. Zeitschr. f. rat. Med. 3. Reihe. Bd. 21. 1864.

7. A eby, Utber den feineren Bau der Blatkapillaren. Zentralbl. f. d. med. Wiss. Nr. 14. 1865.

8. Alf erow, Serge, Nouveaux procédés pour les imprégnations à l'argent. Arch, de physiol. 1874.

9. Áuerbach, Tageblatt der 40. Versamml. deutsch. Naturf. u. Ãrzte, Nr. 6, Untersuchungen über Blut- und Lymphgefüsse. Arch. f. path. Anat. u. Phys. Bd. 33. 1864.

10. Bergh, Beiträge zur vergleichenden Histologie. II. Über den Bau der Gefasse bei den Anneliden. Anat. Hefte, 45. Heft (Bd. 14, Heft 2). 1900.

11. B $a \mathrm{hm}, A$. A. und M. v. David off, Lehrbuch der Histologie des Menschen einachliesslích der mikroskopischen Technik. Verlag von J. F. Bergmann, Wiesbaden. 3. Aufl. 1903.

12. B $0 \mathrm{hm}, A$. und A. $0 \mathrm{ppel}$, Taschenbuch der mikroskopischen Technik. Verlag von R. Oldenbourg, Munchen-Berlin. 5. Aufl. 1904 (enthalt viele Literatur-Hinweise).

13. B o n n $\operatorname{\theta t}$, Über die "Schlussleisten " der Epithelien. Vereinsbeilage Nr. 9 der Deutsch. med. Wochenschr. Jahrg. 21. 1895.

14. Boveri, Th., Beiträge zur Kenntnis der Nervenfasern. Abhandlungen d. math.-physik. Klasse d. kgl bayer. Akad. d. Wiss., Munchen, Bd. 15. 1886 (Original). Zeitschr. f. wiss. Mikrosk. Bd. 4. 1887. (Referat.) 
15. Broueff und Eberth, Zar Kenntnis der Epithelien. Warzb. naturwiss. Zeitsehr. 1864. 1. u. 2. Heft. Bd. 5.

16. Chrzonszczewsy, Uber das Epithel der Lungenbläschen der Säuget.ere. Wurzb. med. Zeitschr. IV. 1863.

17. Derselbe, Uber die feinere Struktur der Blutkapillaren. Virch. Arch. 3. Folge. Bd. 5. 1866.

18. Derselbe, ther die feinere Struktur der Blutkapillaren. Virch. Arch. XXXV. 1866.

19. Coh n, E., Die v. Ku p f er schen Sternzellen der Säugetierleber und ihre Darstellung. Beitr. zur pathol. Anat. 1904.

20. Cohn, Th., Über Interzellulurlücken und Kittsubstanz. Anat. Hefte 5. Bd. (Heft 2). 15. Heft. 1895.

21. Derselbe, Über epitheliale Schlussleisten an embryonalen und aus. gebildeten Geweben. Verh. d. physik.-med. Ges. zu Wurzburg. N. F. Bd. 31. Nr. 4. 1897.

22. Cohnheim, Über Entzundung und Eiterung. Arch. f. pathol. Anat. u. Physiol. (Virchow). 40. 1867.

23. Cornél, Sur quelques procédés de préparations microscopiques, et en particulier sur l'emploi du nitrate d'argent. Arch. gén. de méd. 1863.

24. Dekhuyzen, Über das Imprägnieren lebender Gewebe mit Silbernitrat. Anat. Anz. 1889.

25. v. Ebner in A. Kölliker, Handbuch der Gewebelehre des Menschen. Bd. 3. Verlag von Wilh. Engelmann, Leipzig. 6. Aufl. 1902.

26. Ehrlich, P., R. Krause, M. Mosse, H. Rosin und C. Weigert, Enzyklopädie der mikroskopischen 'Technik. Verlag von Urban und Schwarzenberg, Berlin.Wien. 2. Aufl. 1910 (and 1. Aufl. 1908). (Enthalt viele Literatur-Hinweise.)

27. Elenz, E., Über das Lungenepithel. Würzb. natarwiss. Zeitachr. Bd. 5. 1864.

28. Engelmann, Uther die Diskontinuitat des Achsenzylinders und den fibrillären Bau der Nervenfasern. Pflügers Arch. Bd. 22. 1880.

29. Federn, S., Untersuchungen tuber die Bedeutung der Silberzeichnungen an den Kapillaren der Blutgeflsse. Wien. Sitzungaber. d. Akad. Bd. 53. 1866.

30. Feltz, Recherches expérimentales sur le passage des leucocythes à truvers les parvis vasculaires. Journ. de l'snat. 1870.

31. Fischel, A., Zur Lehre von der Wirkung des Silbernitrat auf die Elomente des Nervensystems. Areh. f. mikrosk. Anat. 1893. Bd. 42 (Original). Zeitschr. f. wiss. Mikrosk. 1894. Bd. 11 (Referat). (Enthalt viele Literatur-Hinweise.)

32. Flemming, W., Uber Interzellularlücken des Epithejs und ihren Inhalt. Anat. Hefte 1896. 1. Abt. 17. Heft (Bd. 6. Heft 1). 1895. (Enthalt viele Literatur-Hinweise.)

33. Flinzer, M. C. A., De argenti nitrici usu et effectu praesertim in oculorum morbis sanandis. Lipsiae. 1854 (Nov.). Dias.

34. Frey, Das Mikroskop. 2. Aufl. 1865. 
35. Friedlaender, C., Mikroskopische Technik. 5. Aufl, bearbeitet von Eberth. 1894.

36. Fromman n, C., Zur Silberfärbung der Achsenzylinder. Virchors Arch. 1864. Bd. 31. Heft 2.

37. Gaupp, E., A. Eckers und R. Wiedersheims Anatomie des Frosches, 1.-3. Abt. Verlag von Friedr. Vieweg u. Sohn, Braunschweig 1904.

38. Genersich, Zur Lehre von den Saftkanalchen in der Kornea. Wien. med. Jahrb. 1871. Heft 1.

39. Gerlach, L., Zur Kenntnis der markhaltigen Nervenfaser. Tageblatt der 51. Versammlung deutsch. Naturf. u. Ärzte in Cassel, 1878. (Soweit bier von Interesse: nur Bericht äber die Untersuchungen Kochs, Lit. 61, und günstige Beurteilung seiner Schlüsse.)

40. Gerota, Ober die Anatomie und Physiologie der Harnblase. Arch. f. Anat. u. Pbysiol. 1897.

41. Gierke, H., Färberei zu mikroskopischen Zwecken. Zeitschr. f. wiss. Mikrosk. Bd. 1, 1884 und Bd. 2, 1885. (Enthalt viele Literatur-Hinweise.)

42. Grandry, De la structure intime du cylindre de l'axe et des cellules nervenses. Journ. de l'anat. et de la physiol. 1869.

43. Hansen, Untersuchungen uber die entzundlichen Veränderungen der Hornhautkorper. Wien. med. Jahrb. 1871. Heft 2.

44. Harpeck, Über die Bedeutung der nach Silberimpragnation auftretenden weissen lücken- und spaltähnlichen Figuren in der Kornea. Arch, f. Anat. (Reichert und Du Bois.Reymond). 1864. Heft 2.

45. Harmer, On a method for the silver staining of marine objects. Mitt. Zool. Stat. Neapel 1884.

46. Hartman n, Über die durch den Gebrauch der Höllensteinlossung künstlich dargestellten Lymphgefässanbänge, Saftkanalichen und epithelähnlichen Bildungen. Arch. f. Anat. (Reichert und Da Bois-Reymond). 1864. Heft 2.

47. Henle, J., Bericht über die Fortschritte der Anatomie im Jahre 1864. Zeitschr. f. rat. Med. 3. Reihe. Bd. 25. 1865.

48. Derselbe, Bericht tiber die Fortschritte der Anatomie im Jahre 1866. Zeitschr. f. rat. Med. 3. Reihe. Bd. 30. Heft 1. 186 ?.

49. His, W., Beiträge zur normalen und pathologischen Histologio der Kornea. Basel 1856.

50. Derselbe, Uther das Verhalten des salpetersauren Silberoxyds zu tierigchen Gewebsbestandieilen. Virchows Arch. Bd. 20. 1861.

51. Derselbe, Über das Epithel der Lymphgefässwurzeln und uber die v. Recklinghausenschen Saftkanälchen. Zeitschr. f. wiss. Zool. 1863. Bd. 13.

52. Derselbe, Uber die Einwirkung des salpetersauren Silberoxyds auf die Hornhaut. Schweiz: Zeitschr. f. Heilk. Bd. 2. Heft 1. 1863.

53. Derselbe, Utber ein perivaskulares Kanalsystem in dea nervosen Zentralorganen und aber dessen Bexiehungen zu dem Lymphsystem. Zeitsehr. f. wiss. Zool. Bd. 15. 1864 . 
54. Hoggan, G. und Frs. Hizab., Etude sar les lymphatiques de la peau. Journ. de l'anat. et de la physiol. 1879. XV. Nr. 1.

55. Hoyer, Ein Beitrag zur Histologie bindegewebiger Gebilde. Mallers Arch. f. Anat. u. Physiol, 1865.

56. De rsel be, Beiträge zur anatomischen und histologischen Technik. Arch. f. mikrosk. Anat. 1877. Bd. 13.

57. Hueter, Zur Pathologie der Gelenkflăchen und Gelenkkapseln mit einem kritischen Vorwort uber die Versilberungsmethode. Arch. f, pathol. Anat. u. Physiol. Bd. 36. 1866.

58. Jakimovits ch, J., Sur la structure du cylindreaxe et des cellules nerveuses. Journ. de l'anat. et de la physiol. XXIV. 2. 1888. (Original.) Zeitschr. f. wiss. Mikrosk. Bd. 5. 1888. (Rëferat.)

59. Joseph, M., Uber einige Bestandteile der peripheren, markhaltigen Nervenfasern. Sitzungsher. d. kgl. preuss, Akad. d. Wiss. Berlin 1888. (Enthalt viele Literatur.Hinweise.)

60. Klebs, Das Epithel der hinteren Hornhautfläche. Zentralbl, f. med. Wiss. 1864.

61. Koch, Uber die Marksegmente der doppelkonturierten Nervenfasern und deren Kittsubstanz. Inaug.-Diss, Erlangen 1879.

62. Kolliker, Handbuch der Gewebelehre, die für das Ende des Jahres 1863 neueste Auflage. (Zitiert nach $\nabla$. Recklinghausen, Lit. 90, gerade diese Aufluge war dom Verf. nicht zuganglich.)

63. Kulossow, A., Über eine neue Methode der Bearbeitung der Gewebe mit Osmiumsäure, Zeitschr. f. wiss. Mikrosk. Bd. 9. Heft 1. 1892,

64. Derselbe, Utber die Struktur des Pleuroperitonesl- und Gefassepithels (Endothels). Arch. f, mikrosk. Anat. 1893. Bd. 42. (Enthalt viele Literatur Hinweise.)

65. Kopsch, Fr., Rankos Lehrbuch der Anatomie des Menschen. Abt. 1 . Verlag von Georg Thieme, Leipzig. 8. Aufl. 1908.

66. Krause, C., Artikel "Haut" in R. Wagners Handworterbuch der Physiologie. Bd. 2. 1844. Verlag von Friedr. Vieweg u. Sohn, Braunschweig.

67. Krause, R., Kursas der normalen Histologie. Verlag von Urban u. Schwarzenberg. Berlin-Wien 1911.

68. Krause, W., Handbuch der menschlichen Anatomie. 3. Aufl. 1876. Bd. 1.

69. Ku hne, Lehrbuch der physiologischen Chemie. 1870.

70. Kuster, K., Die Entwicklung der Karzinome und Sarkome. Würzburg, Abschn. 1. (Dem Verf. nicht zuganglich, zitiert nach Sobor off, Lit. 110.)

71. Kultschitzky, Utber die Art der Verbindung der glatten Muskelfasern untereinander. Biol. Zentralbl. Bd. 7. 1887. (Dem Verf. nicht zugänglich, zitiert nack $W$ erner, Lit. 121.)

72. Landois, L., Zur Geschichte der Metallimprägnationen usw. Arch. f. mikrosk. Anat. 1902. Bd. 61. 
73. Leber, Zur Kenntnis der Imprägnationsmethoden der Hornhaut und ahnlicher Gewebe, Arch, f. Ophthalmol. Bd. 14. 3. Abt. 1868.

74. Lee, A. B. und P. Mayer, Grundztige der mikroskopischen Technik fur Zoologen und Anatomen. Verlag von R. Friedlander u. Sohn, Berlin. 2. Aufl. 1901. (Enthalt viele Literatur-Hinweise.)

75. Legros, Note sur l'épithélium des raisseaux sanguins. Journ. de l'anat. et de la physiol, 1868. V.

76. Morkel, Fr., Epithelium, Ergebnisge d. Anat. u. Entw.Gesch. (MerkelB onnet). Bd. 18. 1908.

77. Derselbe, Anatomie des Menschen. Verlag von J. F. Bergmann, Wiesbaden. 1913. 1. Abt.

78. Mitrophanow, P., Uber Interzellularlücken and Interzellularbrícken im Epithel. Zeitschr, f. wiss. Zool. 41.1884 (Bd. 1885).

79. v. Morochowetz, Notiz aber die Wirkung des Silbernitrats auf die Nervenfaser. Unters, aus d. physiol. Inst. d. Univ. Heidelberg. II. 2. 1878.

80. Mäller, C. F., Histologische Untersuchungen uber die Kornea. Virchows Arch. 1867. Bd. 41 .

81. Muskatello, Utber den Bau und das Aufsaugungsvermogen des Peritoneum. Virchows Arch. Bd. 142. 14. Folge. Bd. 2. 1895.

82. Ödmansson, Beitrag zur Lehre vom Epithel. Virchows Arch. 1863.

83. v. Pfungen, Studien uber Entzïndung der Froschkornea. Wien. med. Jahrb. 1873.

84. Rabl, Über geschichtete Niederschluge bei Behandlung der Gewebe mit A rgentum nitricum. Sitzungsber. d. Akad. Wien. Bd. 102. 3. Abt. 1893. (Original); Zeitschr. f, wiss. Mikrosk. Bd. 11. 1894 (Referat).

85. Ranvier, L, betr. Silberimpränation. Sitzungsber. d. Sociétè Micrographique de Paris. Sitzung vom 4. Nov. 1867. Journ. de l'anat. et de la physiol. 1868. Nr. 2.

86. Derselbe, Technisches Lehrbuch der Histologie, Paris 1875, ubersetzt von Nikati and v. Wyss, Leipzig. Verlag von F. C. W. Vogel, 1877.

87. v. Recklinghausen, Eine Methode, mikroskopische hohle und solide Gebilde voneinander zu unterscheiden. Virehows Arch. 1860. Bd. 19.

88. Derselbe, Die Lymphgefasse und ihre Beziehungen zum Bindegewebe. Berlin 1862.

89. Derselbe, Zur Fettresorption. Virchows Arch. 1863. Bd. 26.

90. Derselbo, Zur Geschichte der Versilberungsmethode. Virchows Arch. 1863. Bd. 27.

91. Regaud, Arch. d'anat. micr. Bd. 4. 1901. (Dem Verf. nicht zuganglich, zitiert nach Lit. 26.)

92. Regaud and Dubreuil, Compt. rend. assoc. des anat. V. 1903. (Dem Verf. nicht zugänglich, zitiert nach Lit. 26.)

98. Reich, Einige mikroskopische Studien mit Silbersalpeterlbsung, besonders an Geflussen des Auges und anderer Organe. Sitzangaber. d. Wien Akad,, math.-naturw. Klasse. III, Abt. Aprilheft 1873. 
94. Renaut, Applications des propriétés électives de l'éosine soluble dans l'eau à l'étude du tissu conjonctiv. Arch. de physiol. 1877. 2. série. T. IV.

95. Retzius, G, Uber die sog. Frommannzchen Querlinien der Achsenzylinder der Nervenfasern. Die Fraentzelsche Silberzeichnung an den Spinalganglienzellen. Die Versilberungsbilder an der Körperoberfläche der Myzostomiden. Biol. Unters. N. K'olge. Bd. 15. 1910. (Enthalt viele Literatur-Hinweise.)

96. R obin ski, Recherohes microscopiques sur l'épithèle et sur les raisseaux lymphatiques capillaires. Arch. de physiol. 1869.

97. Derselbe, Die Kittaubstanz auf Reaktion des Argentum nitricum. Mullers Arch. f. Anat. u. Physiol. 1871. (Enthalt viele Literatur-Hinweise.)

98. Rougot, Mémoire sur le développement, la structure et les propriétés physiologiques des capillaires sanguins et lymphatiques. Arch. de physiol. 1873.

99. Rumpf, Zur Histologie der Nervenfaser und des Achsenzylinders. Unters, aus d. physiol. Inst. d. Univ. Heidelberg. II. 2. 1878.

100. Sattler, Die Verwendung des Lapisstiftes zur Untersuchung der Epithelien. Arch. f. mikrosk. Anat. Bd. 21. 1882.

101. Schiefferdecker, P., Beiträge zur Kenntnis des Baus der Nervenfasern. Arch. f. mikrosk. Anat. Bd. 30. 1887.

102. Schwalbe, G., Beiträge zur Kenntnis der glatten Muskelfasern. Arch. f. mikrosk. Anat. Bd. 4. 1868 .

103. Derselbo, Untersuchungen uber die Lymphbahnen des Auges und ihre Begrenzungen. Arch. f. mikrosk. Anat. Bd. 6. 1870.

104. Schweigger-Seidel, F., Die Behandlung der tierischen Gewebe mit Argentum nitricum usw. Ber. uber d. Verh. d. kgl. atichs. Ges. d. Wiss. Leipzig, math.-phys. Kl. 1866/7. IV, V.

105. Derselbe, Uber die Grundsubstanz und die Zellen der Hornhaut des Auges. Ber. Wber d. Verh. d. kgl. shchs. Ges, d. Wiss. Leipzig, math.phys. Kl. 1869. Leipzig 1870.

106. Severin, Beiträge zu der Lehre von den Entzundungen. Dorpat 1871. Diss.

107. Simarro, L., Nuero método bistológico de impregnución por les sales fotográficas de plata (Revista trimestr. microgr. T. V. fasc. 2. 3. 1900), zitiert wach dem Referat in d. Zeitschr. f. wiss. Mikrosk. Bd. 18. 1901.

108. Skw orzow, Zur Histologio des Herzens und seiner Hullen. Pflügers Arch. Bd. 8. 1874. (Bericht über die physiol. und histol. Mitteilungen, die auf der 4. Versammlung russischer Naturforscher zu Kasan gemacht wurden, tabersetzt und redigiert von N. Kowalewsky und C. A rnstein.)

109. Slawjansky, Der medizinisohe Westrik, 1867, Nr. 7. (Dem Verf. nicht zuganglich, zitiert nach S o bor of f, Lit. 110.)

110. Soboroff, Untersuchungen ther den Ban normaler und ektatischer Venen. Arch. pathol. Anat. u. Physiol. Bd. 54. 1872. 
111. Sobotta, J., Atlas und Grundriss der Histologie und mikroskopischen Anatomie des Menschen. Verlag von J. F. Lehmann, München 1902.

112. Solger, B, Utber die kombinierte Anwendung von Osminmsäure und Argentum nitricum. Zentralbl. f. d. med. Wissensch. Bd. 21. 1883. Nr. 19.

112a. Derselbe, Studien zur Entwicklungsgeschichte des Cöloms und des Cblomepithels der Amphibien. Morph. Jahrb. Bd. 10. 1884.

113. Derselbe, Über den feineren Bau der Glandala submaxillaris des Menschen mit besonderer Bericksichtigung der Drïsengranula. Festschrift zum 70. Geburtstage von $\mathrm{Caxl}$ Gegenbaur. Bd. 2. Leipzig 1896.

114. St $8 \mathrm{hr}, \mathrm{Ph}$., Lehrbuch der Histologie und der mikroskopischen Anatomie des Menschen mit Einschluss der mikroskopischen Technik. Verlag von Gustav Fischer, Jena. 13. Aufl, 1909.

115. Strickẹr, Untersuchungen uber den Eiterungsprozess. Wien. mod. Jahrb. 1874 .

116. Szymonowicz, L, Lehrbuch der Histologie und der mikroskopischen Anatomie mit besonderer Berucksicbtigung des menschlichen Körpers einschliesslich der mikroskopischen Technik. Verlag von Ourt Kabitzsch (A. Stubers Verlag), Wurzburg. 2. Aufl. 1909.

117. v. Thanh offor, Das Mikroskop und soine Anwendung. Stuttgart 1880. (Dem Verf. nicht zugänglich, zitiert nach Lit. 26, 41 and 74.)

118. To m m as i, Uber den Ursprung der Lymphgefusse im Hoden."Virchows Arch. 1863.

119. Tourneux und Herrmann, Recherches sur quelques épithéliums plats duns la série animal. Joarn. de l'anat. et de la physiol. 1876.

120. Traube, M., Experimente zur Theorie der Zellenbildung und Endosmose. Arch. f. Anat. u. Physiol. (keichert and Du Bois-Reym ond), 1867.

121. W e r e r, G., Zur Histologie der glatten Muskulatur. Inaug.-Diss. Jurgew (Dorpat) 1894.

122. Zimmermann, H. W., Beitrëge zar Kenntnis einiger Drusen und Epithelien. Arch. f. mikrosk. Anat. Bd. 52. 1898.

123. Zoerner, E, Bau und Entwickelung des Peritoneum nebst Beschreibung des Banchfelles einiger Edentaten. Inaug.-Diss. Halle 1881. 


\section{Abbildungen.}

\section{Mikrophotogramme:}

Fig. 1. Teil eines Glimmerblattchens, mit Blntserum behandelt und versilbert.

Fig. 2. Teil der Körperoberfläche von Ascaris nigrovenosa, mit Zuckerlösung ahgesptult, mit Blutserum behandelt und versilbert.

Fig. 3. Teil vom Mesenterium von Bufo, Pleuroperitoneal-Epithel, nit Zuckerlosang abgespult, mit Blutserum behandelt und versilbert. Die Epi. thellage der anderen Fläche der Pleuroperitonealduplikatur ist nicht zugleich eingestellt, sie bietet ein ganz entsprechendes Bild, an manchen Stellen schimmert sie durch.

Fig. 4. Teil vom Mesenterium von Rana, Pleuroperitoneal-Epithel, Tuscheverfahren, Fixation mit absolutem Alkohol.

Fig. 5. Teil von der Serusa des Rektum von Rana, Pleuroperitoneal-Epithel, Tuscheverfuhren, Fixation mit absolutem Alkohol.

Fig. 6. Ranviersche Einschnürung an einer peripheren markhaltigen Nervenfaser von Rana, mit Zuckerlösung abgespult, mit Blatserum behandelt und versilbett.

Fig. 1-5. Winkel, Gobttingen, Complanat Okular 1, Apochromat $4 \mathrm{~mm}$. Vergr. $1: 170$.

Fig. 6. Winkel, Göttingen, Complanat Okular 1, 1/20 homog. Immers. (Cedernholz.Oel.). Vergr. 1:510. 
Anatomische Hefte. 177. Heft (59. Bd.).

Tafel 3.

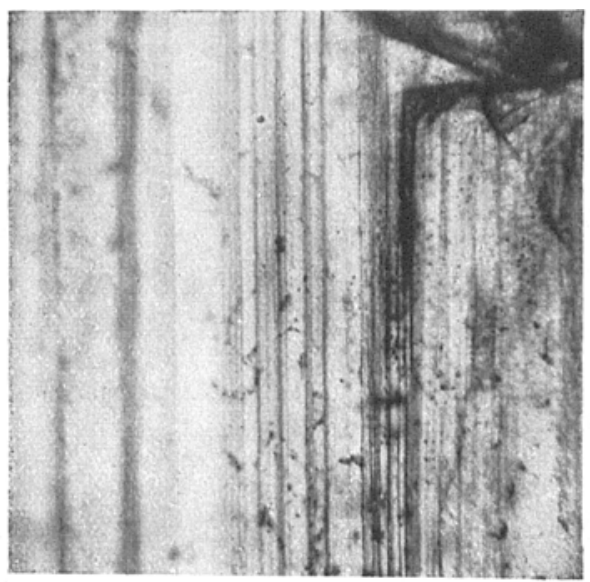

Fig. 1.

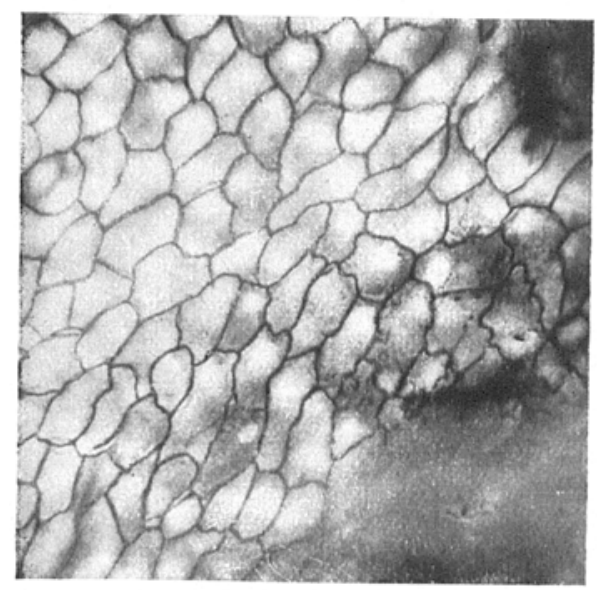

Fig. 3.

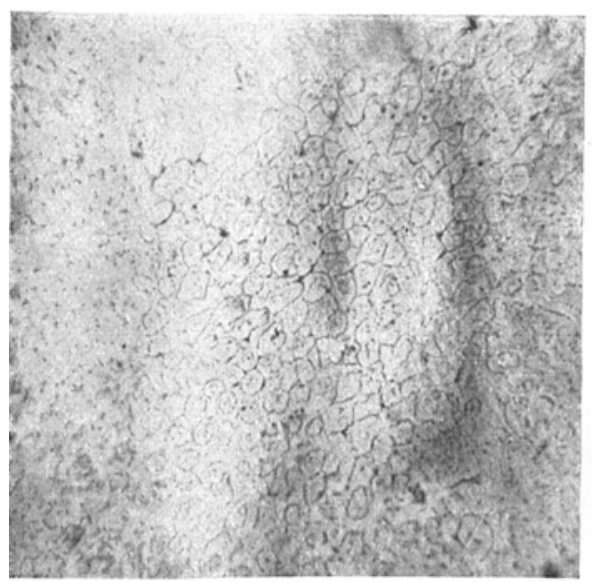

Fig. 5.

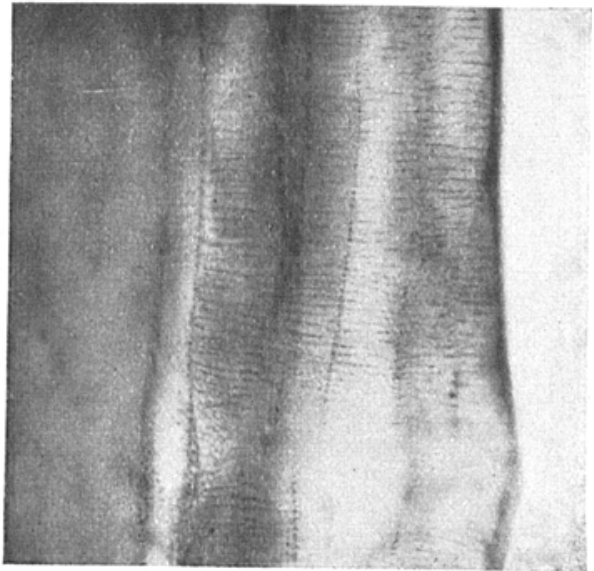

Fig. 2.

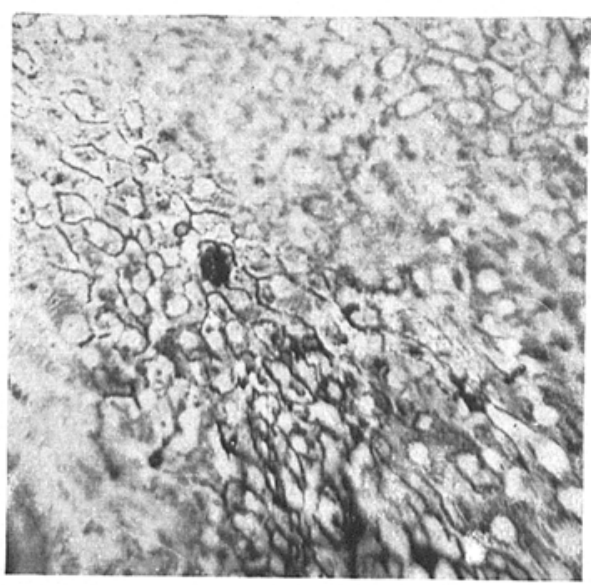

Fig. 4.

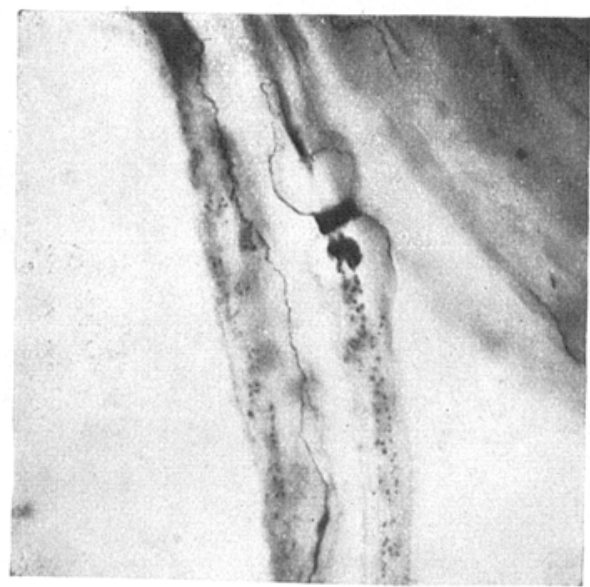

Fig. 6 . 